\title{
Earnings properties
}

Citation for published version (APA):

Smeets, B. (2020). Earnings properties: The role of industry and life cycle fundamentals. [Doctoral Thesis, Maastricht University]. ProefschriftMaken Maastricht. https://doi.org/10.26481/dis.20200313bs

Document status and date:

Published: 01/01/2020

DOI:

10.26481/dis.20200313bs

Document Version:

Publisher's PDF, also known as Version of record

\section{Please check the document version of this publication:}

- A submitted manuscript is the version of the article upon submission and before peer-review. There can be important differences between the submitted version and the official published version of record.

People interested in the research are advised to contact the author for the final version of the publication, or visit the DOI to the publisher's website.

- The final author version and the galley proof are versions of the publication after peer review.

- The final published version features the final layout of the paper including the volume, issue and page numbers.

Link to publication

\footnotetext{
General rights rights.

- You may freely distribute the URL identifying the publication in the public portal. please follow below link for the End User Agreement:

www.umlib.nl/taverne-license

Take down policy

If you believe that this document breaches copyright please contact us at:

repository@maastrichtuniversity.nl

providing details and we will investigate your claim.
}

Copyright and moral rights for the publications made accessible in the public portal are retained by the authors and/or other copyright owners and it is a condition of accessing publications that users recognise and abide by the legal requirements associated with these

- Users may download and print one copy of any publication from the public portal for the purpose of private study or research.

- You may not further distribute the material or use it for any profit-making activity or commercial gain

If the publication is distributed under the terms of Article $25 \mathrm{fa}$ of the Dutch Copyright Act, indicated by the "Taverne" license above, 
Earnings Properties:

The Role of Industry and Life Cycle Fundamentals

Britt Smeets 
ISBN: 9789463807371

Cover: Britt Smeets \& ProefschriftMaken

Print: ProefschriftMaken || www.proefschriftmaken.nl 


\title{
Earnings Properties: \\ The Role of Industry and Life Cycle Fundamentals
}

\author{
DISSERTATION \\ to obtain the degree of Doctor at Maastricht University, \\ on the authority of the Rector Magnificus, Prof.dr. Rianne M. Letschert, \\ in accordance with the decision of the Board of Deans, \\ to be defended in public \\ on Friday March 13, 2020, at 14.00 hours \\ by
}

Britt Smeets 


\section{Supervisor:}

Prof. Dr. Ann Vanstraelen

\section{Co-Supervisors:}

Dr. Annelies Renders

Dr. Patrick Vorst

\section{Assessment Committee:}

Prof. Dr. Frank Moers (Chair)

Dr. Stefan T.M. Straetmans

Prof. Dr. David Veenman, University of Amsterdam, the Netherlands

Prof. Dr. Teri L. Yohn, Indiana University, United States \& Northwestern University, United States 


\title{
ACKNOWLEDGEMENTS
}

\author{
One step at a time, crossing silent valleys, \\ tackling steep climbs, sometimes technical, sometimes easy, \\ mastering the descents, enjoying peaks along the way, \\ at times running, on marked trails or only vaguely defined paths; \\ 'spuren'.
}

A reflection on beloved days in the mountains as much as it resembles the process of writing this dissertation. A long expedition with alternating periods of progress and setbacks, where perseverance is essential, where the correct path is often not given, where you learn to celebrate even the smallest of achievements, and where you develop an appreciation for the journey, rather than the mere end result or final summit. Throughout my $\mathrm{PhD}$, I was fortunate to enjoy the company and support of great people, some to whom I would like to express a couple of words of gratitude.

First of all, I would like to thank my supervisory team, Ann Vanstraelen, Annelies Renders and Patrick Vorst. While my trajectory was far from nominal, your continuous understanding, patience, and support was invaluable. Ann, I have always been impressed by your level of care and your professionalism, towards everything and everyone, irrespective of how busy you are. As much as I had the opportunity to benefit from your expertise, I learnt from your work attitude. Annelies, your enthusiasm and easy-going approach is contagious, and has helped me countless times when I was making things unnecessarily complicated for myself. Also, the way you combine work, life, and sports serves as an example that I have much respect for. Patrick, from $\mathrm{PhD}$ colleagues in my first year to being my supervisor. Yes, that set a different tone for our supervisor-supervisee relationship. Some say 'must be weird', I say 'no problem'. While this surely has resulted in many less professional conversations, we still have had at least as many high-level, 'sophisticated' talks about research. I have deepest respect for your intellect - you are one of the smartest persons I know - and am grateful for the opportunity to work together. Together, the three of you provide a great mix of expertise in auditing and financial accounting, and this dissertation has greatly benefited from all your guidance and insights. Thank you, or as Patrick would say: 'Mahola'! I also would like to thank Frank Moers, Stefan Straetmans, David Veenman, and Teri Yohn for evaluating my dissertation and their approval of it, and for providing helpful comments and suggestions. Furthermore, thank you Willem Buijink, Harold Hassink, Roger Meuwissen, and Peter Sampers for your willingness to take part in my defense committee.

Next, I would like to thank my two paranymphs for providing this little extra support in the final stage of my PhD. Lars, my (way) younger academic brother - remember you called me your (way) older sister in your dissertation - and the other half of 'Sacha's dreamteam'. Your contribution to my $\mathrm{PhD}$ time has been invaluable, from mutually supporting each other no matter what, to sharing many enjoyable moments in- and outside the office. I am thankful for our friendship, and proud that it also lasts beyond university walls. Of course, I knew from early on that you should be one of my 
paranymphs; I am happy that you excitedly accepted this role. Olga, once a student in my financial statement analysis and valuation class, and now a dear colleague and friend. With your warm personality, you have certainly enriched my $\mathrm{PhD}$ journey. Our coffees, good laughs, and chats about all kinds of things are always a welcoming break at work. I am honored to have you as one of my paranymphs - I count on you as much as your 'Boomshakalaka' skills.

Even though the process of writing a dissertation may be tedious at times, I hardly ever experienced dull moments in the office thanks to great former and current colleagues from the Accounting and Information Management (AIM) department. The 'early' PhD clan, Anant, Christoph, Jonas, Judith, Lars R., Nadine, Patrick, and Thomas. Thanks for setting the right example and providing helpful comments and tips on my research early on. Our later 'girls-only' PhD office in B2.23 brought different vibes. Olga, Lei, Lu, Ulrike and frequent visitor Raginee, thank you for the 'work hard, play hard' mentality, providing a good environment to work in, while still having our crazy moments with lots of laughter. Throughout my PhD, I also got to enjoy spending time with numerous other colleagues and research visitors of the B2- and D2-wings: Alexander, Banu, Caren, Erwin, Frank, Isabella, Katlijn, Leon, Maarten, Marie-Laure, Mark, Mathijs, Oscar, Rick, Robert, Sanne, as well as the 'newest' PhD cohort: thanks for the good times! A special thank you goes to the lovely ladies of the secretariat, who are always available for a nice (non-academic) chat and always make sure to keep the department afloat. Throughout my PhD time, I was also lucky to meet many great individuals from other departments. A particular word of gratitude goes to Annemarie, Benedikt, Corrie, Deniz, Dinah, Eva, Jasper, Sofya, Therese, and Yuliya. I have always enjoyed our coffee moments, lunches, drinks, activities and trips outside. Thanks for your friendship, and for getting me out of the accounting bubble.

Actually, a little reflection on the social activities that we shared is warranted. I believe a strong department with a good atmosphere does not come about when one only stays in the office. Social activities create a bond between people and as such also affect the working atmosphere in the department. With the risk of being highly incomplete, and due to a lack of printing space, rather than listing all the fun activities individually, I would like to thank each and every one of you for all those many enjoyable moments. Among (many) others, these include department trips; conference trips; PhD activities; weekend getaways to Champagne, Düsseldorf, the Eifel, the Oktoberfest in München, and to Rome; wedding parties of Christoph \& Birgit, Banu \& Deniz, Lars \& Dinah, and Nadine \& Thomas; birthday celebrations; tennis matches on the B2-corridor; running and cycling events; go-karting; and finally, many dinners (either home-cooked or in restaurants; and yes, I promise to cook an Indonesian rice table for you again sometime after the $\mathrm{PhD}$ defense). Thanks for the good fun!

Lastly, I am very lucky to have great friends and family outside of the academic world. While I could not enjoy your company as often as I would have wanted to throughout the PhD, your understanding and support is unconditional, and your company always makes sure that from time to time, I take a healthy distance from work. A special thanks goes to two of my best friends. Frederique, thanks for always being there for me on this journey, no matter the destination. 
Boy, irrespective of how busy our schedules are, I am happy that we always take the effort and manage to squeeze in 'wines and dines'. Your genuine interest in my work - which is why you are one of my favorite non-academic sparring partners - is something I have always particularly valued. A special thanks also goes to my uncle Bruno, who has since early on been my go-to person for insightful discussions about real-world and business problems. You are my leading example of how to combine a great, challenging job with a healthy lifestyle and an equally healthy mind. As a little girl, my answer to questions about my ambitions always included that I wanted to become "better than Bruno" - so far, I am only about to manage to surpass you in education...I will have to keep working on the practical side of the job ;-). Finally, I would like to express my eternal gratitude to my closest family. Mama and papa, thank you for your lifelong support and love. Mama, thanks for being my strong role model. Papa, you would always ask me how things were going - and (!) when I would be finally done with my $\mathrm{PhD}$ - I know you would have been very, very proud today. Last but not least, I would like to thank Robbert and Tyas. Robbert, big brother, a solid thanks for always being there for me and sharing many valuable memories. Tyas, while you patiently witnessed that my biggest challenge in the past years was not completing my $\mathrm{PhD}$, but actually obtaining and keeping a stronger physical health, your flexibility and unconditional support ensured that I would have to worry a little less about 'the rest' and could spend more energy on writing this dissertation. Your contribution has been beyond invaluable, thank you.

Britt Smeets

Maastricht, February 2020 



\section{TABLE OF CONTENTS}

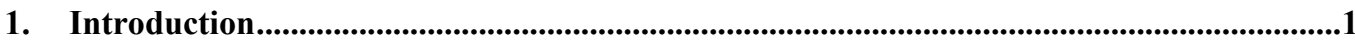

1.1. The Role and Relevance of Accounting Information .........................................................1

1.2. The Earnings Generating Process ..........................................................................2

1.3. Auditor Industry Specialists and Accrual Informativeness .........................................3

1.4. Relevance of Differential Persistence of Earnings Components in the Pricing of Mergers and Acquisitions ..................................................................................................4

1.5. The Role of Life Cycle-Wide Earnings in Forecasting and Valuation .........................6

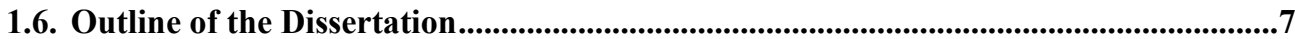

2. Auditor Industry Specialists and Accrual Informativeness..............................................9

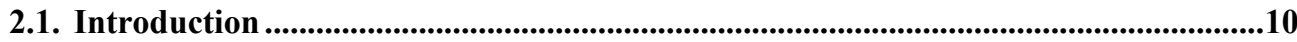

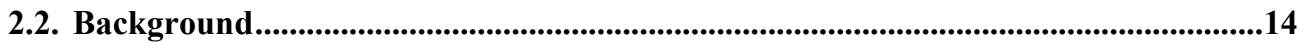

2.2.1. Audit Quality and Accrual Informativeness....................................................... 14

2.2.2. Industry Specialist Auditors and Accrual Informativeness ......................................15

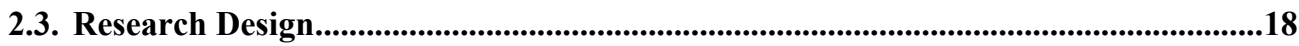

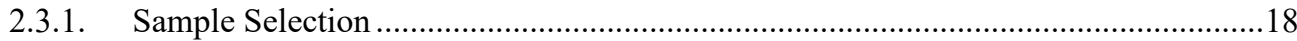

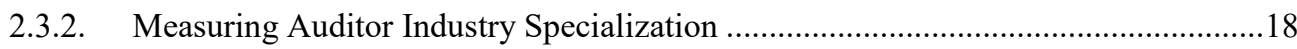

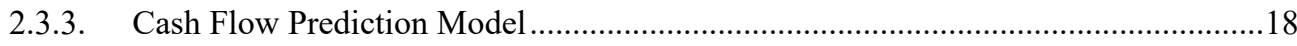

2.3.4. Propensity Score Matching and Entropy Balancing..............................................19

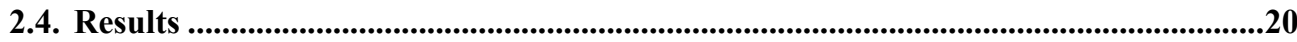

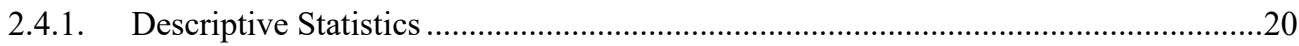

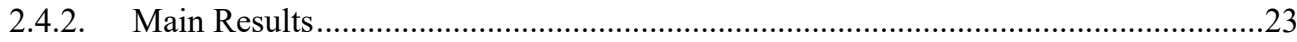

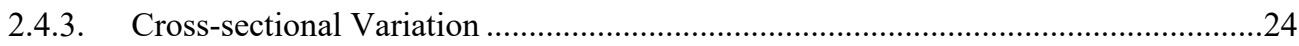

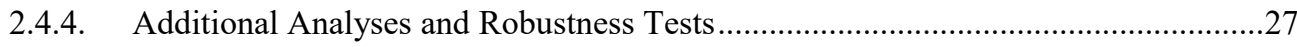

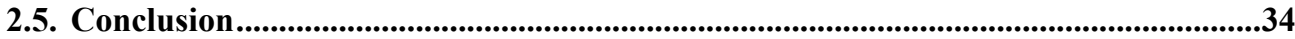

Appendix 2A - Variable Definitions .................................................................................................36

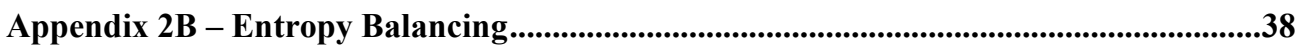

3. Relevance of Differential Persistence of Earnings Components in the Pricing of Mergers and Acquisitions.................................................................................................................................41

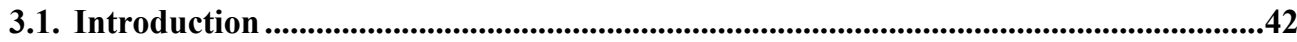

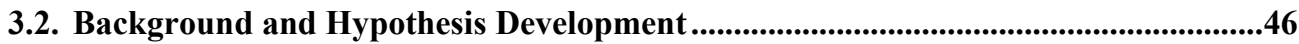

3.2.1. Equity Valuation and the Persistence of Accounting Information..............................46

3.2.2. Role of Accounting Information and its Persistence in M\&A Pricing........................47

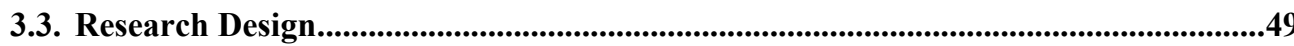




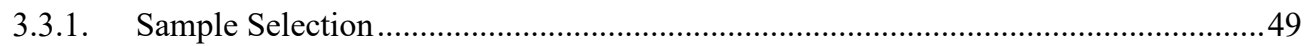

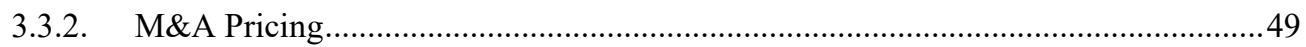

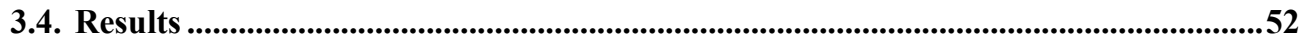

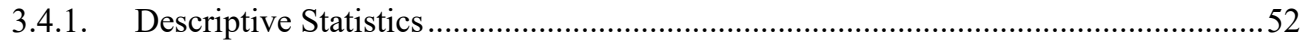

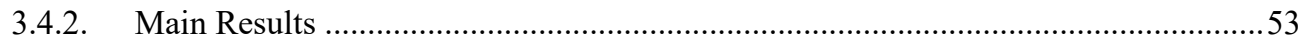

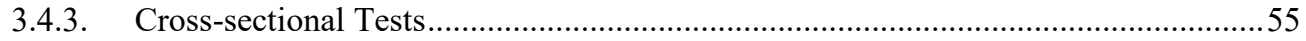

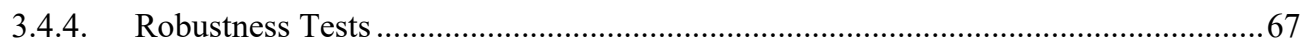

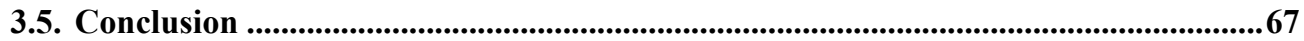

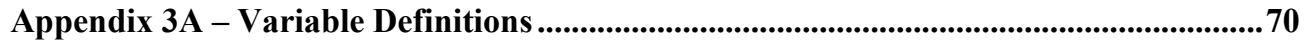

4. The Role of Life Cycle-Wide Earnings in Forecasting And Valuation .............................73

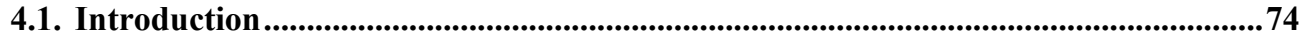

4.2. Life Cycle and Earnings Persistence .......................................................................................78

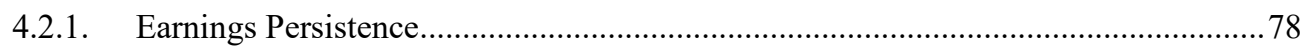

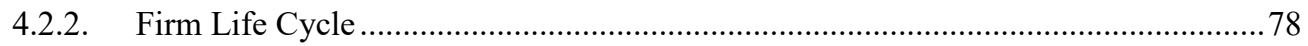

4.2.3. Firm Life Cycle and Earnings Persistence ..............................................................79

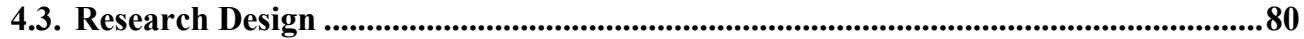

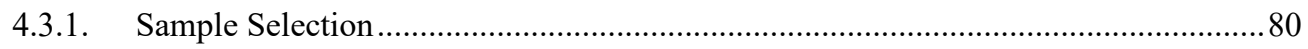

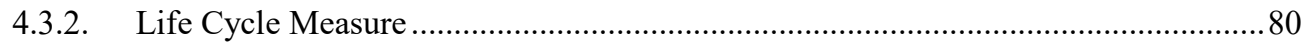

4.3.3. Earnings Disaggregation: Life Cycle-Wide and Firm-Specific Earnings ..................81

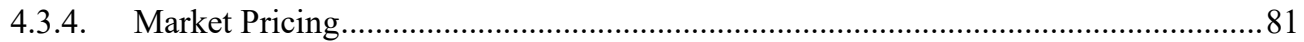

4.3.5. Life Cycle-Wide Earnings and Future Abnormal Returns........................................ 82

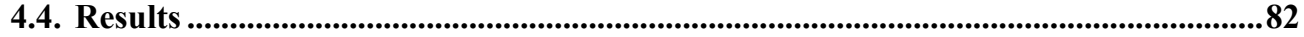

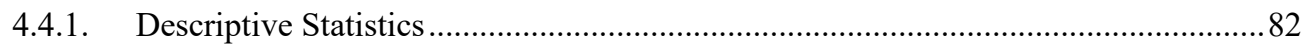

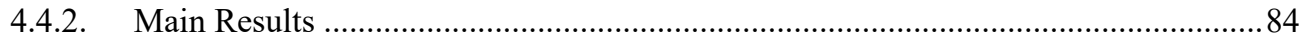

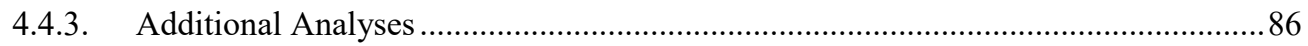

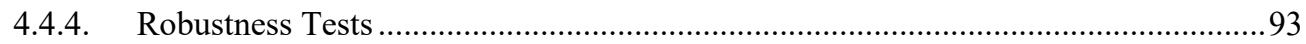

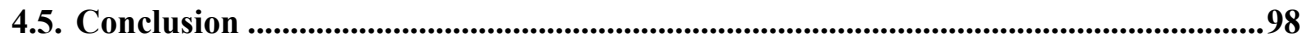

Appendix 4A - Variable Definitions .............................................................................100

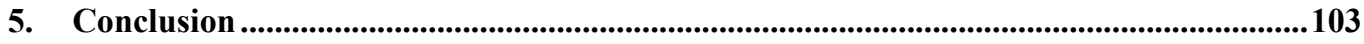

5.1. Summary ................................................................................................................................. 103

5.2. Contributions and Future Research....................................................................105

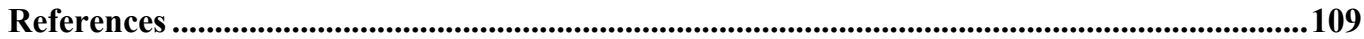

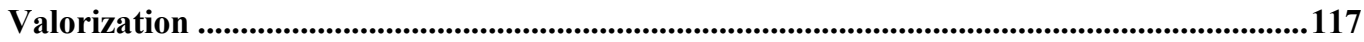

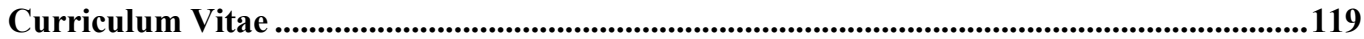




\section{INTRODUCTION}

\subsection{The Role and Relevance of Accounting Information}

Since long there has been a great interest in the importance and role of accounting information (Ball and Brown 1968; Kothari and Wasley 2019). Accounting information, and especially earnings information, is relevant for a wide variety of stakeholders. Capital market participants such as equity investors and analysts, and acquirers, use earnings information to form expectations about future firm performance. These forecasts are key in determining appropriate (stock) prices and in motivating subsequent investment advice or investment decisions. Next to its valuation role, accounting information has a stewardship or 'efficient contracting' role (Zimmerman 2015). In this role accounting information is used to manage conflicts of interest in firms by serving as relevant input in for example compensation contracts and debt covenants (e.g., Armstrong et al. 2010; Lambert 2001; Shivakumar 2013). Although accounting was originally designed for stewardship, its role shifted towards valuation as public capital markets developed (Zimmerman 2015). While both roles remain important, accounting for valuation is currently still a primary focus for accounting standard-setters. This also becomes evident from the objective of general purpose financial reporting in the Conceptual Framework of the International Accounting Standards Board (IASB) (2018, A17A18):

"The objective of general purpose financial reporting is to provide financial information about the reporting entity that is useful to existing and potential investors, lenders and other creditors in making decisions relating to providing resources to the entity. [...] [Users'] expectations about returns depend on their assessment of the amount, timing and uncertainty of (the prospects for) future net cash inflows to the entity and on their assessment of management's stewardship of the entity's economic resources. [...] [Note that] general purpose financial reports are not designed to show the value of a reporting entity; but they provide information to help existing and potential investors, lenders and other creditors to estimate the value of the reporting entity."

A fundamental quality attribute for earnings information to be useful is relevance, which is the ability to make a difference in users' decisions (IASB 2018). Early capital market research on the value relevance of earnings, i.e., the extent to which earnings explain variation in share prices, demonstrates that earnings have informational value (e.g., Ball and Brown 1968; Easton et al. 1992; Kothari 2001). More recent studies, however, often document a decline in value relevance of accounting information and earnings in particular, and provide two main explanations. The first includes the transition from an industrial economy to one with more knowledge-intensive firms (e.g., Srivastava 2014; Zimmerman 2015). The value of these firms largely depends on expected future benefits of investments in intangible assets (Barth et al. 2018), something that is not well-captured by current earnings due to the timing mismatch of expenses and revenues associated with intangibles (Lev and Zarowin 1999). The second explanation is an increase in the number of loss firms over time (Barth et al. 2018), for which current earnings are less informative about future performance (e.g., Collins et al. 1999; Hayn 1995). At the same time, however, Barth et al. (2018) provide a more 
nuanced view on the relation between accounting information and share prices and find no decline in its combined value relevance. Specifically, accounting figures related to intangible assets, growth opportunities, and alternative performance measures have become more relevant to investors over time, which offsets the declining relevance of aggregate earnings. Together, these studies shed light on the ongoing debate about the value relevance of accounting information, and earnings information in particular, for capital market participants.

\subsection{The Earnings Generating Process}

Given the purpose of reported earnings information as defined by accounting standard-setters and the limitations of aggregate earnings as single performance input for valuation, there is need for a more detailed understanding of the (quality of the) earnings generating process of firms. This motivates, for example, financial statement analysis research, which aims to identify how accounting information, including disaggregations of earnings, can be used to improve profitability forecasts and firm value estimates, as well as to identify potential market inefficiencies (Dichev and Tang 2009; Yohn 2018). ${ }^{1}$ Until recently, these research streams have received limited attention (Yohn 2018). Hence, more research is needed on what drives and affects the earnings generating process and how these earnings are subsequently used in forecasting and valuation.

Earnings are jointly determined by the accounting measurement system and the firm's fundamental performance (Dechow et al. 2010). To assess its properties and usefulness, multiple studies have focused on the accounting measurement system to identify decomposed earnings components that carry variation in their informational value. For example, Sloan (1996) examines the persistence and pricing of cash flows and accruals, and Fairfield et al. (1996) shed light on the optimal use of the income statement and examine which earnings disaggregations improve forecasts of return on equity. Yet, we know relatively little about the effect that (knowledge of) fundamental firm characteristics have on the earnings generating process. Given certain fundamentals such as the industry a firm is operating in or a firm's life cycle stage, firms undertake different strategic activities in order to maximize firm value. These activities, including investment and financing decisions, result in specific asset and liability structures that generate a certain operating cycle and accrualgenerating process (Owens et al. 2017), thus affecting the earnings generating process. As a result, fundamental firm performance "is likely to vary in cross-section and has its own inherent properties, such as persistence" (Dechow et al. 2010, 349). ${ }^{2}$ This suggests that earnings components that are driven by firm fundamentals or are affected by parties who possess superior knowledge of such fundamentals may contain additional information that can be useful in forecasting and valuation.

\footnotetext{
${ }^{1}$ In this dissertation, 'aggregate' earnings refer to total earnings, whereas 'disaggregated' or 'decomposed' earnings refer to total earnings that are split into two or more components.

${ }^{2}$ In the accounting literature, as well as in this dissertation, persistence of earnings information refers to the extent that current year's earnings or components of earnings recycle into next year's earnings. The level of persistence is indicated by regressing next year's earnings on current year's earnings, where a higher coefficient for current year's earnings implies a higher level of persistence.
} 
This creates an interest to further explore the effect of fundamental firm characteristics on the earnings generating process, its potential value for forecasting and valuation, and its use by market participants such as investors, analysts, and acquirers. In this dissertation, I investigate the relation between industry and life cycle fundamentals and earnings properties. The first study analyzes the relation between auditor industry specialists and accrual informativeness. Auditors who specialize in a certain industry benefit from superior knowledge of industry fundamentals and are therefore assumed to deliver higher quality audits. While their expertise should thus be related to higher accrual informativeness, this relation is not evident ex ante and is an empirical question that I investigate in this study. The second study examines the valuation role of differential persistence in earnings in the pricing of mergers and acquisitions (M\&As). Prior literature shows differences in persistence of disaggregate earnings components and documents investor mispricing of these components (e.g., Hui et al. 2016; Sloan 1996). It is not clear whether and how findings on the capital market transfer to the merger market. Compared to the average capital market investor, acquirers are generally more knowledgeable, sophisticated investors. Hence, I explore whether within-earnings variation in persistence is relevant during the target valuation process and is priced accordingly. Finally, the third study investigates the existence and informational value of life cyclewide and firm-specific earnings components, and examines their use in forecasting and valuation. Additionally, this study sheds light on the incremental effect of firm life cycle over industry as a fundamental driver of firm profitability, as well as on analysts' use of life cycle information. In the next sections, I discuss each study in more detail.

\subsection{Auditor Industry Specialists and Accrual Informativeness}

Auditor industry specialists are often associated with higher audit quality. An important part of the audit quality literature focuses on the reliability of clients' financial statements as one potential benefit associated with industry specialization. The first study, which can be found in chapter two of this dissertation, focuses on a different quality dimension of accounting information by examining the relation between auditor industry specialization and accrual informativeness. Investigating this relationship is salient for at least three reasons. First, the ability of accruals to inform users about future net cash inflows is defined as one of the main objectives of financial reporting (FASB 2010). Second, high-quality auditors are expected to provide greater assurance that the financial statements faithfully reflect firms' underlying economics (DeFond and Zhang 2014). Hence, auditors have an implicit responsibility towards informative accounting numbers to the extent that it better reflects the firm's underlying economics. Third, from an empirical perspective, examining the ability of accruals to predict future cash flows is a relatively clean and less subjective way to measure the impact of industry specialist auditors compared to the widely used discretionary accruals.

Whether clients of industry specialist auditors show higher accrual informativeness is not clear ex ante. Audit firms have their own "audit style", resulting in more comparable earnings and accruals for clients that are audited by the same audit firm (Francis et al. 2014). As audit firms are frequently organized along industry lines (Minutti-Meza 2013), their audit practices tend to be 
relatively standardized within industries. This potentially leads to an "industry style", especially for audit firms with many engagements in the same industry (i.e., industry specialists). Furthermore, industry specialists can increase knowledge and expertise by for example building an internal database with industry-specific best practices (Krishnan 2003; Reichelt and Wang 2010), making use of decision aids and training sessions (Bédard 1989; Power 1996), and receiving guidance from a centralized national office (Danos et al. 1989). Such industry expertise and standardization may increase the informativeness of accruals to the extent that specialists can form better judgements of firms' asset values and accruals. However, if managers' ability to signal relevant private information is constrained due to industry specialists requiring greater comparability and standardization across clients in the same industry, accruals of clients audited by an industry specialist may be less informative.

Using a sample of U.S. public firms including 44,928 firm-year observations over the period 2000 to 2017 , I estimate a cash flow prediction model to examine the extent to which current operating cash flows and accruals map into next year's operating cash flows. I find that, on average, there is a weaker relation between accruals and future cash flows for firms audited by an industry specialist. This suggests that accruals of clients audited by an industry specialist are less predictive of future cash flows. This finding holds under various specifications, including a firm-fixed effects analysis and analyses using entropy balancing and propensity score matching. Additionally, results of cross-sectional tests show that my findings are concentrated in industries that are less homogeneous, in industries that experience a shock, in firms that are less comparable to industry peers and in firms that operate in environments that are more uncertain and are therefore also characterized by higher information asymmetry. In more similar industries, superior knowledge of industry fundamentals is especially useful and relevant, which also justifies the application of standardized industry procedures. In less similar industries, however, it is more difficult to transfer knowledge about audit risks and audit processes across clients (Bills et al. 2015). To the extent that auditors try to minimize costs and apply standardized industry procedures in such industries, I show that this can come at a cost in the form of a loss of accrual relevance. Overall, my results provide evidence that auditor industry specialists are not always associated with higher earnings quality.

This study contributes to the literature on auditor industry specialization by providing novel evidence on its effects. Specifically, on average, auditor industry specialization comes at the expense of accrual informativeness. I further provide insights into the role of industry fundamentals in the earnings generating process by documenting the relation between an auditor's industry knowledge and standardization and the informativeness of accounting constructs, as well as the importance of industry homogeneity in this relation.

\subsection{Relevance of Differential Persistence of Earnings Components in the Pricing of Mergers and Acquisitions}

Significant corporate investments such as mergers and acquisitions (M\&As) come with a large investment risk. There is a long-standing view that M\&A transactions often destroy value for the 
acquiring firms, as these are prone to overpay for the target (The Economist 2019). While this may not hold true for all deals, the risk of overpaying provides a strong incentive for acquiring firms to properly value and price targets. As such, it is key for acquirers to incorporate all decision-useful information into bid prices. Prior literature has shown that financial reporting information from a range of other firms is important for a firm's investment decisions: from peer firms - those in the same industry or life cycle stage - as well as from customers and suppliers, all of which may be considered potential target firms. What has received less attention so far, however, is which specific financial reporting characteristics are important in the investment decision-making process (Ferracuti and Stubben 2019). For example, it is less clear whether overall profitability measures or disaggregated earnings components are more useful in investment decisions, as is the extent to which uncertainty - for example in the variability or persistence of earnings measures - influences investment decisions.

The second study, which can be found in chapter three of this dissertation, explores whether within-earnings variation in persistence - a property of earnings that is often perceived to be positively associated with relevance and thus earnings quality - is relevant to acquirers during the target valuation process. Variation in persistence is observable at various levels of earnings disaggregations. Besides variation in the persistence of aggregate earnings and book value of equity stemming from acquirer intent or market expectations, respectively (Burgstahler and Dichev 1997; Rabier 2018), Sloan (1996) documents differential persistence levels for cash flows and accruals, while Hui et al. (2016) show that industry fundamentals further drive differences in the persistence of earnings components. Yet, whereas both capital market investors and acquirers seem to recognize when aggregate earnings are relatively more (or relatively less) important than book value of equity and price firms accordingly (Burgstahler and Dichev 1997; Rabier 2018), prior literature documents that capital market investors fixate on aggregate earnings and fail to incorporate differential persistence levels of disaggregate earnings into stock prices (Hui et al. 2016; Sloan 1996).

It is ex ante unclear whether and how these last findings regarding capital market investors transfer to the merger market setting, and thus, whether acquirers also fail to price earnings components according to their persistence levels. I provide three potential scenarios. First, like capital market investors, it may be that acquirers do not recognize the persistence differences of disaggregated earnings and value firms similar to the market. Second, more detailed and in-depth analyses as part of the due diligence should result in more precise forecasts, enabling acquirers to better incorporate information contained in disaggregate earnings components. To the extent that acquirers perceive more persistent components as more informative about future firm value and incorporate this in their valuation, bid prices, relative to stock prices, may better reflect the persistence differences in earnings components. Third, however, even in the case that acquirers are aware of within-earnings persistence differences, they may rationally make alternative valuation choices and attach greater weights to components that they perceive as more informative about future firm value, regardless their (potentially lower) persistence. 
I explore the weighting of disaggregate earnings in M\&A deal values using a sample of 2,313 completed transactions involving U.S. public acquirers and targets over a period from 1992 to 2014. I benchmark the analyses to capital market pricing to see how acquirers price earnings differently compared to 'the majority' (as reflected by the market price). Results for the pooled sample suggest that acquirers perceive (less persistent) accruals as relatively more informative than (more persistent) cash flows in estimating future firm performance. Additionally, they do not exploit the informational value of common earnings driven by industry fundamentals, as they 'underreact' to industry-wide cash flows - the most persistent component - and 'overreact' to firm-specific accruals - the least persistent component. Cross-sectional tests show that the relatively greater weights on accruals are concentrated in subsets of deals with non-common auditors, high accounting quality targets, targets benefiting from highly persistent industry earnings, and with diversifying transactions. Furthermore, I observe a higher overall importance of earnings for the same subsets of deals, except for diversifying deals. Overall, results of the cross-sectional tests suggest that the valuation role of earnings components varies with information asymmetry. For example, acquirers attach greater weights to earnings components when the historical industry earnings are more persistent and the information asymmetry therefore lower. Yet, the significantly greater weights placed on accruals in comparison to cash flows suggest that the components' perceived informativeness about future firm value is not always in line with their general persistence levels. As acquirers perceive (both industry-wide and firm-specific) accruals as relatively more informative, I conclude that differences in the persistence of disaggregate earnings do not play a relevant role in target pricing.

This study contributes to a growing body of literature on the role of publicly available accounting information in target valuation. While prior studies consider the role of aggregate earnings in M\&A prices and outcomes, this study exploits variation in persistence within accounting fundamentals and shows to what extent this is considered in M\&A pricing. Specifically, this study sheds light on the relevance of differential persistence of earnings components in the pricing of mergers and acquisitions.

\subsection{The Role of Life Cycle-Wide Earnings in Forecasting and Valuation}

The third study, which can be found in chapter four of this dissertation, investigates the existence and persistence of life cycle-wide and firm-specific earnings, and examines the extent to which these components are reflected in stock prices. Prior literature on the relation between fundamental firm characteristics and firm performance has primarily focused on industry as a valuable determinant of a firm's earnings generating process (e.g., Dechow et al. 1995; Fairfield et al. 2009; Hui et al. 2016). As a result, industry models are now extensively used in forecasting and valuation. This study departs from this major focus on industry and examines organizational life cycle as a driver of a firm's fundamental performance.

Recent studies show that life cycle stage commonalities affect earnings dynamics (Dickinson 2011; Vorst and Yohn 2018). While these findings suggest that a life cycle-wide earnings component 
exists, the studies do not identify this component nor are they informative about its persistence. Based on the relatively sticky nature of fundamentals underlying firm life cycle, I expect the common earnings component to be more persistent than firm-specific deviations from the life cyclewide average. Furthermore, given prior findings that capital market investors fail to fully incorporate persistence differences of industry fundamentals-based earnings components (Hui et al. 2016), I expect investors to underreact to life cycle-wide earnings and overreact to firm-specific earnings.

The sample period in this study runs from 1987 to 2016 and the main sample includes 70,386 firm-year observations. Firm life cycle is measured by the cash flow based life cycle measure of Dickinson (2011) and profitability is defined as return on net operating assets. I use the Mishkin (1983) test, in which I regress next year's profitability on current profitability, to identify the persistence of both earnings components, and obtain the implicit weights impounded in stock prices by regressing next year's abnormal returns on current profitability. Results show that life cycle-wide earnings are significantly more persistent than firm-specific earnings and thus enjoy a higher informational value. Investors misprice these earnings by underreacting to the life cycle-wide component and overreacting to the firm-specific component. Consistent with these results reflecting investor mispricing, I show that life cycle-wide earnings significantly predict future abnormal stock returns. Given the possibility that industry and firm life cycle share underlying fundamentals such as a firm's competitive environment, I test whether life cycle-wide earnings add incremental value over industry earnings. I find that my results are not affected by industry dynamics, as the adjusted life cycle earnings are incrementally relevant and thus complementary to industry earnings. This further illustrates the added value of firm life cycle as a fundamental driver of a firm's earnings generating process. Finally, I examine the use of life cycle information by more sophisticated market participants such as analysts. Results show that analysts, at least partially, incorporate life cycle information in their earnings forecasts and as such perform better than the average capital market participant.

This study contributes to the literature by documenting the importance of firm life cycle as a driver of a firm's fundamental performance. Specifically, the results show that commonalities shared by firms in the same life cycle stage are captured by a common earnings component that impacts earnings persistence in a predictable way. While investors misprice these earnings, analysts appear more efficient and do consider life cycle fundamentals in their forecasts. Overall, this study adds to the understanding of a firm's earnings generating process and provides additional evidence on the relevance of life cycle information in forecasting and valuation.

\subsection{Outline of the Dissertation}

The remainder of my dissertation is organized as follows. Chapter two presents the first study on auditor industry specialists and accrual informativeness. Chapter three covers the second study, which examines the relevance of differential persistence of earnings components in the pricing of mergers and acquisitions. In chapter four, I present results on the third study investigating the role of life cycle-wide earnings in forecasting and valuation. Finally, chapter five concludes. 



\title{
2. AUDITOR INDUSTRY SPECIALISTS AND ACCRUAL INFORMATIVENESS
}

\begin{abstract}
$^{3,4}$
We examine the relation between the degree of auditor industry specialization and the mapping of accruals into future cash flows, a key attribute of informative accounting. We find that on average, there is a weaker relation between accruals and future cash flows for firms audited by an industry specialist, suggesting that industry specialists are associated with less informative accruals. However, we also find considerable sample-wide variation in this relation. Specifically, our crosssectional tests show that these results are concentrated in industries in which firms are less homogeneous, industries that experience a shock, for firms that differ more from their industry peers, and for firms with greater information asymmetry. Overall, our results shed new light on the effects of industry specialist auditors.
\end{abstract}

\footnotetext{
${ }^{3}$ This chapter is based on a working paper co-authored with Annelies Renders, Ann Vanstraelen, and Patrick Vorst.

4 Acknowledgements: We would like to thank Jean Bedard, Andrew Jackson, Jere Francis, Sarah Stein, David Veenman, Lasse Niemi (discussant), Erik Peek, Peter Pope, Nicole Ratzinger-Sakel (discussant), Kenneth Reichelt, Ulrike Thürheimer, and Roger Simnett, as well as participants at the 2016 EIASM Audit Quality Workshop in Florence, the 2016 EAA Doctoral Colloquium in Maastricht, the 2017 Auditing Midyear Meeting in Orlando, the 2017 EAA Annual Congress in Valencia, the 2018 Tilburg Winter Camp, and seminar participants at KU Leuven, Maastricht University, University of Bristol, Exeter University, Stockholm School of Economics, and University of New South Wales for their helpful comments and suggestions.
} 


\subsection{Introduction}

This paper examines the relation between auditor industry specialization and accrual informativeness. Over the past years, auditor industry specialization has received considerable attention in the literature, with many studies investigating the costs and benefits of industry specialist auditors. An important part of the audit quality literature focuses on the impact of auditor industry specialization on the reliability of clients' financial statements as one potential benefit associated with auditor industry specialization. Several studies find evidence supporting the view that industry specialization is associated with greater reliability. For example, Balsam et al. (2003) find that firms audited by an industry specialist have smaller absolute discretionary accruals, while Reichelt and Wang (2010) also document lower abnormal accruals and further show that benchmark-beating behavior is less likely for firms audited by an industry specialist. However, other studies challenge these findings. For example, Minutti-Meza (2013) finds that, after using propensity score matching to control for differences in audit engagements between specialist and non-specialist auditors, there is no evidence that clients of industry specialist auditors have lower levels of discretionary accruals. In contrast, Gaver and Utke (2019) do find evidence of lower earnings management for clients of industry specialist auditors, even after using propensity score matching.

In this paper, we take a different perspective and investigate the relation between industry specialist auditors and the mapping of accruals into future cash flows, a key attribute of informative accounting numbers. Investigating the relation between auditor industry specialization and accrual informativeness, which to the best of our knowledge has not been examined yet, is salient for at least three reasons.

First, referring to the objective of financial reporting as defined by the Financial Accounting Standards Board (FASB), Dechow et al. (2010, p. 344) define higher quality earnings as "earnings that provide more information about the features of a firm's financial performance that are relevant to a specific decision made by a specific decision-maker." The cash-generating ability of an entity is one important feature that is of interest to a wide range of users including investors, creditors, suppliers, and employees. Concept Statement 8 of the FASB indeed recognizes that "existing and potential investors, lenders, and other creditors need information to help them assess the prospects for future net cash inflows to an entity" (FASB 2010, p. 2), and defines the ability of accruals to inform users about the future net cash inflows of an entity as one of the main objectives of financial reporting. ${ }^{5}$

Second, professional auditing standards require auditors to consider "the quality, not just the acceptability" of the client's financial reporting (see DeFond and Zhang 2014). Hence, high-quality auditors are expected to consider not only whether the client's accounting choices merely comply with GAAP, but also whether the financial statements reflect the firm's underlying economics. Such

\footnotetext{
${ }^{5}$ Note that FASB Concept Statements are non-authorative and do not establish generally accepted accounting standards. However, still they are relevant as they specify the objectives, goals and purposes of financial accounting and they "guide the Board in developing sound accounting principles and provide the Board and its constituents with an understanding of the appropriate content and inherent limitations of financial reporting." As such they form the "foundation in establishing new standards and amending existing standards." (FASB 2010).
} 
a view is also consistent with the FASB's conceptual framework that defines relevance and faithful representation as the two fundamental qualitative characteristics of useful information. In line with this view, DeFond and Zhang (2014) define audit quality as "greater assurance that the financial statements faithfully reflect the firm's underlying economics." To the extent that a better reflection of underlying economics is associated with greater informativeness, this suggests that auditors have a responsibility towards reporting accounting numbers that are not only reliable but also informative. $^{6}$

Third, from an empirical perspective, investigating the ability of accruals to predict future cash flows provides a relatively clean setting to measure the impact of industry specialist auditors. Discretionary accruals are well-known to provide noisy estimates of accounting discretion and most studies that rely on discretionary accruals assume that any discretion is used opportunistically, ignoring that managers can use discretionary accruals to inform investors (see also Badertscher et al. 2012). In contrast, investigating the mapping of accruals into future cash flows involves less subjectivity, while speaking to informativeness as an earnings quality attribute that is of direct importance to investors. ${ }^{7}$

A large literature investigates the relation between auditor industry specialization and measures and/or attributes of audit quality. For example, next to the previously discussed studies that focus on discretionary accruals, other studies that investigate the benefits of industry specialist auditors document that they are associated with better disclosure quality (Dunn and Mayhew 2004) and higher earnings response coefficients (Balsam et al. 2003). Furthermore, other studies find evidence of lower crash risk (Robin and Zhang 2015), a higher valuation of firm cash holdings (Kim et al. 2015), lower SEO underpricing (Kwon, Park, and Yu 2018), and a lower cost of equity (Krishnan, Li, and Wang 2013), for firms audited by an industry specialist auditor, consistent with less information risk for these firms. Collectively, these studies are suggestive of a positive relation between industry specialist auditors and (perceived) audit quality. As such, it seems natural to assume that clients of industry specialist auditors show higher accrual informativeness as well. However, there are reasons to believe that industry specialist auditors are not associated with greater accrual informativeness and may, in fact, reduce the informativeness of accruals.

Specifically, Francis et al. (2014) present evidence that auditors impose an "audit style" on the financial statements of their clients. The authors argue and find that Big 4 audit firms have their own working rules that affect what is ultimately reported in the financial statements, such that firms audited by the same audit firm have earnings and accruals that are more comparable. As audit firms are also frequently organized along industry lines (Minutti-Meza 2013), audit practices of audit

\footnotetext{
${ }^{6}$ In the auditing literature, there is some discussion about the role of the auditor. Whereas DeFond et al. (2018) argue that auditors should assure that financial statements faithfully reflect the firm's underlying economics, Palmrose and Kinney (2018) argue that this view is impracticable and that auditors should solely opine on financial statement compliance with GAAP. To the extent that auditors merely focus on compliance with GAAP, we should find no effects of industry specialist (or non-specialist) auditors on accrual informativeness.

${ }^{7}$ Other studies have investigated whether earnings response coefficients are higher for firms audited by an industry specialist to combine both relevance and reliability aspects of accounting information. However, a disadvantage of using ERCs is that they measure investor perceptions of quality, which may not always coincide with actual quality.
} 
firms tend to be relatively standardized within industries, potentially leading to an "industry style", especially for audit firms that have many audit engagements in an industry (i.e., industry specialists).

Furthermore, by building an internal database with industry-specific best practices (Krishnan 2003; Reichelt and Wang 2010), investing in various decision aids (such as checklists), training sessions (Bédard 1989; Power 1996), and guidance from a centralized national office (Danos et al. 1989), industry specialist auditors can build their knowledge and expertise. One the one hand, such industry expertise and standardization may increase accrual informativeness if industry specialist auditors can form a better judgment of a firm's asset values and accruals. On the other hand, to the extent that such standardization constrains managers' ability to signal relevant private information to investors, accrual informativeness may be lower for firms audited by an industry specialist.

The notion that discretionary accounting choices are not necessarily opportunistic but in fact may reflect the release of relevant (private) information to investors is also apparent in Badertscher et al. (2012). They investigate the informativeness of accruals for a sample of firms that have restated their earnings. They find that for the sample of opportunistic (i.e., benchmark-beating) firms, restated earnings are more informative than the originally reported earnings. In contrast, for the group of non-opportunistic firms, originally reported earnings are more informative than the restated earnings. To the extent that industry specialist auditors require greater comparability and standardization across clients in the same industry and thereby restrict managers' ability to signal private information, accruals of clients audited by an industry specialist may be less informative. Overall, given these two opposing arguments, the impact of industry specialist auditors on the informativeness of accruals is an empirical question that we address in this study.

To investigate whether industry specialist auditors affect the informativeness of accruals, we use a cash flow prediction model to investigate the extent to which this year's operating cash flows and accruals map into next year's operating cash flows. We begin our analyses on a pooled sample of all U.S. public companies over the period 2000-2017. We find that, on average, the accruals of clients audited by an industry specialist auditor are less predictive of future cash flows. These results hold under various specifications, including a firm-fixed effects analysis that controls for unobservable time-invariant differences across clients as well as an entropy balanced and propensity score-matched specification that controls for inherent differences in audit engagements with or without the involvement of an industry specialist auditor.

In a next step, we investigate cross-sectional variation in the relation between industry specialist auditors and accrual informativeness. The on average negative relation between industry specialization and accrual informativeness is consistent with industry specialization leading to excess levels of standardization across clients, which restricts managers' ability to disclose relevant (private) information to the capital market. We would expect this effect to be particularly strong for firms that are less comparable to other firms in the industry or in industries that are less homogeneous. Whereas industry knowledge is likely useful and relevant in more similar industries in which auditors can easily apply standardized industry procedures, it is more difficult to transfer knowledge about audit risks and audit processes across clients in industries that are less similar (Bills 
et al. 2015). Similarly, standardization likely works best for firms that are representative of and comparable to the average firm in the industry. However, if auditors still apply standardized industry procedures even in audit engagements that involve firms and/or industries that are less homogeneous, for example in an attempt to minimize costs, accrual informativeness is likely lower.

We find that the lower informativeness of accruals for firms audited by an industry specialist auditor is concentrated in industries with a more heterogeneous accrual-generating process (Dopuch et al. 2012; Hui et al. 2016). We find similar results in industries with greater within-industry variation in (operating) performance. These results are consistent with the argument that greater variation in accrual and performance dynamics makes it more difficult for auditors to apply standardized audit procedures, which leads to a loss of accrual informativeness in financial statements audited by an industry specialist. Similarly, we find lower accrual informativeness in industries with more variation in the life cycle stages of its constituents. As previous literature has found that the role of accruals (e.g., capturing investments in future growth versus adjusting for the timing of cash flows) varies across the stages (Anthony and Ramesh 1992; Hribar and Yehuda 2015), this result indicates that standardization comes at a cost of lower informativeness in industries in which accruals fulfill various roles.

In addition to documenting the importance of industry homogeneity, we also find that the similarity of the firm to the other firms in the industry has a significant impact on the relation between industry specialist auditors and accrual informativeness. Specifically, we find that the negative relation between industry specialist auditors and accrual informativeness is more pronounced for firms whose returns exhibit weaker co-movement with market and industry returns and firms whose life cycle stage differs from that of the industry.

Finally, we investigate the role of information asymmetry. The usefulness of standardized industry knowledge and procedures is likely lower for firms that operate in environments that are more uncertain. We find results that are consistent with this argumentation as the relation between industry specialist auditors and accrual informativeness is more negative for firms with high idiosyncratic risk.

Overall, these results provide novel evidence on the relation between industry specialist auditors and earnings quality. Specifically, our results indicate that industry specialism is not always associated with higher quality, defined as the ability of accruals to inform about future cash flows, especially for less comparable firms and/or industries. We perform a battery of tests to demonstrate the robustness of our findings. Specifically, we find that our results hold using alternative measures of industry specialization, alternative industry definitions, extended cash flow prediction models, and tests involving longer horizon cash flow predictions. Moreover, we find that industry knowledge is less useful in industries that experience a shock and in which, as a result, the accrual-generating process has likely changed.

Our paper contributes to the literature on auditor industry specialization by providing novel evidence on its effects. We show that, on average, auditor industry specialization comes at the expense of accrual informativeness. Our investigation of the predictive ability of accruals for future 
cash flows is consistent with relevance and faithful representation as fundamental quality attributes in the FASB's conceptual framework, requiring that information accurately reflect firms underlying economics. ${ }^{8}$ As such, these insights should also be of interest to standard-setters as well as audit firms, especially given that audit firms often are organized along industry lines (Minutti-Meza 2013).

Our results also provide insight into the role of fundamentals in the earnings generating process. Previous literature has investigated the role of industry in explaining accounting variables such as accruals. We contribute to this literature by documenting the relation between an auditor's industry knowledge and standardization and the informativeness of accounting constructs as well the importance of industry homogeneity in this relation. As such, these findings are of interest to investors who wish to rely on accounting numbers to infer the future cash-generating ability of firms.

The remainder of this paper is organized as follows: Section 2.2 provides background on auditor industry specialization and discusses how industry specialist auditors can influence accrual informativeness. Section 2.3 discusses the research design and the sample. The results are reported and discussed in section 2.4 , and finally, section 2.5 concludes.

\subsection{Background}

\subsubsection{Audit Quality and Accrual Informativeness}

It is well documented that audit quality differs across auditors (e.g., Francis and Michas 2013; $\mathrm{Knechel}$ et al. 2015). One aspect of audit quality differentiation relates to the industry specialization of the auditor. If auditors embrace industry specialization to improve their knowledge and understanding to provide high-quality audits, this is expected to be beneficial to both the client, in the form of a higher level of assurance, and the auditor, who benefits from higher fees, a greater market share, and a lower probability of audit failure (Jeter 2014).

Most studies find evidence of lower discretionary accruals for firms that are audited by an industry specialist (e.g., Chi and Chin 2011; Gaver and Utke 2019; Reichelt and Wang 2010), suggesting that industry specialist auditors deliver higher audit quality. The maintained assumption of those studies is that discretionary accruals are reflective of managements' opportunistic accounting choices. However, previous literature has shown that (discretionary) accruals can also convey relevant private information to the capital market (Badertscher et al. 2012). As such, restricting managers' ability to convey such information can come at a cost. Hence, in this study, we investigate the extent to which industry specialist auditors also improve the informativeness of accounting numbers. This is consistent with the FASB's conceptual framework which lists relevance and faithful representation as the two fundamental qualitative characteristics of (high-quality)

\footnotetext{
${ }^{8}$ To the extent that a better reflection of underlying economics translates into greater predictive ability (a reasonable assumption given that predictive ability is one key aspect of relevance), there is a role for the auditor in improving the predictive ability of financial statements.
} 
accounting numbers. The latter requires accounting constructs to accurately reflect the firm's underlying economics, which, coupled with relevance, arguably creates accountability on the part of auditors to not only care about the pure reliability of accounting numbers, but to also incorporate whether those numbers are informative about the firm's true underlying economics.

In this study, we focus on the mapping of accruals into future cash flows as a measure of accrual informativeness for two reasons. First, accruals that better reflect the firm's underlying economics (i.e., information that is more faithfully represented), are likely more informative about the firm's future cash flows. For example, inventory valuation policies that better reflect the firm's underlying economics should be more informative about the future cash inflows that a firm can generate from selling the inventory. Similar arguments can be made for other (current) accruals, such as receivables and payables, and non-current accruals, such as depreciation, for which a better reflection of underlying economics should also be associated with a stronger link with future cash flows. Second, it is consistent with relevance as the second fundamental quality attribute that determines whether accounting information is useful to investors. Accounting information is relevant if it possesses predictive and confirmatory value. For investors, predictive value is a key characteristic of useful accounting information as they use information on a firm's earnings and cash flows to predict future cash flows, value the firm, and make investment decisions. Similarly, creditors use accounting information to determine the likelihood that firms will be able to pay interest and repay debts. Consequently, it is important that current earnings (accruals) map into future cash flows (Dechow et al. 2010).

In line with this discussion professional auditing standards require auditors to consider "the quality, not just the acceptability" of the client's financial reporting and consequently, DeFond and Zhang (2014) define audit quality as "greater assurance that the financial statements faithfully reflect the firm's underlying economics." 9 Hence, both accounting and auditing standards suggest that auditors should consider the informativeness of accounting constructs when determining which (discretionary) accounting choices are acceptable.

\subsubsection{Industry Specialist Auditors and Accrual Informativeness}

In this paper, we specifically focus on the role of industry specialist auditors in improving the informativeness of accounting constructs. Since long, the literature on the role of economic fundamentals has documented the importance of industry as an inherent driver of a firm's accounting numbers (Dye and Sridhar 1995; Foster 1981; Hui et al. 2016; Lev 1969; Magee 1974). As such, one can expect industry knowledge to be important when judging whether a firm's accruals are in line with and reflect the underlying economics of the firm and the industry in which it operates.

Previous literature presents arguments that support the view that auditors can benefit from industry specialization and provide evidence that industry specialists deliver higher audit quality.

\footnotetext{
${ }^{9}$ Although Defond and Zhang (2014) refer to the currently superseded SAS 90 standard, Defond et al. (2018) further state that the new AS 1301 standard goes beyond SAS 90 by including a separate section that covers the auditors responsibility with respect to the firm's financial reporting quality (PCAOB 2015).
} 
For example, Reichelt and Wang (2010) argue that industry specialists benefit from knowledgesharing and building internal databases with industry-specific best practices as well as the use of audit programs that are tailored to the industry. Similarly, Krishnan (2003) argues that industry experts develop databases with industry-specific risks and red flags. In line with industry specialization leading to higher audit quality, Reichelt and Wang (2010) find evidence of lower discretionary accruals for firms audited by an industry specialist. As the reliable estimation of accruals is in many cases directly related to their informativeness, building on this literature, one would expect industry specialist auditors to be associated with a better mapping of accruals into future cash flows.

To further illustrate, consider the fair value estimation of an asset. Such an estimation requires the auditor to evaluate the appropriateness of the assumptions of the model that discounts the expected future cash flows associated with the (use of the) asset. Importantly, in many cases, such an analysis relies heavily on knowledge of the client's industry. For example, in deciding whether a client's goodwill needs to be impaired, the auditor needs to evaluate the future cashgenerating ability of the cash-generating unit, which requires a detailed understanding of the industry environment in which the firm is operating. Similarly, the valuation of inventory requires an auditor to judge whether, in light of firm and industry prospects, the valuation of a firm's inventory is not higher than its net realizable value.

Using their knowledge and expertise, industry specialist auditors can be expected to form a better judgment of a firm's asset values and accruals. Indeed, Krishnan (2003) argues that industry specialist auditors may be better at detecting earnings management as typical accounting errors and the methods to detect them likely vary across industries (Maletta and Wright 1996). He argues that compared to a non-specialist auditor, an expert in the manufacturing industry is, for example, better able to evaluate whether a client's provisions for warranties are in line with industry standards. Collectively, given that specialists are better informed about industry benchmarks, they are arguably better at judging whether deviations from the industry norm are justified or not. As such, an industry specialist auditor can increase the informativeness of accruals.

Whereas the previous discussion suggests that industry specialism should lead to improved accrual informativeness, there are also reasons to expect industry specialization to in fact harm the informativeness of accruals. For example, although industry specialists may benefit from standardized industry-wide audit procedures, too much standardization can also come at a cost of lower informativeness. Similarly, the widespread use of industry-specific databases of risks and red flags by industry specialist auditors (see Krishnan 2003) may make them less willing to accept deviations from what is normal in the industry despite the fact that such deviations could be justified and informative.

To illustrate, again consider that managers can reveal private information to the capital market via their accrual choices. As this signal likely relates to the release of firm-specific information, the accruals of the firm may very well be different from those that are "normal" in the industry. To the extent that the standardized procedures employed by the industry-specialist auditor 
constrain the ability of management to alter their accrual choices, a loss of information can occur. This intuition is consistent with Badertscher et al. (2012) who show that the non-restated accruals of non-opportunistic restating firms are in fact more informative than their restated counterparts, consistent with the release of relevant information via discretionary accrual choices. Similarly, Subramanyam (1996) shows that managerial discretion may improve the ability of earnings to reflect economic value. Evidence in the tax literature is also consistent with a cost arising from standardization. For example, Hanlon et al. (2008) find that book-tax conformity is associated with lower earnings informativeness as tax rules are less focused on informativeness and leave less room for signaling private information. In this sense, the findings of prior studies that industry specialist auditors are associated with lower levels of discretionary accruals could come at a cost in the form of lower informativeness.

Previous literature provides evidence that such standardization indeed occurs. For example, Francis et al. (2014) provide evidence that clients audited by the same audit firm have earnings and accruals that are more comparable. Similarly, Johnston and Zhang (2018) find that clients with the same auditor exhibit more financial reporting similarity. In addition, Drake et al. (2019) show that auditors use disclosure benchmarking across industry peers to ensure that clients' disclosures are consistent with industry reporting conventions. Although these studies apply to auditors in general, the use of industry-wide audit programs, best-practices and red flags by industry specialists make that industry specialization is likely a major driver of the comparability in accounting choices. ${ }^{10}$

Collectively, it remains an empirical question how industry specialists influence the mapping of accruals into future cash flows, which is what we examine in this study. While we do not make a prediction for the average effect of industry specialist auditors on the mapping of accruals into future cash flows, cross-sectionally we expect the effect to vary with the degree of industry homogeneity and the similarity of the audit client to the other firms in the industry.

Industry knowledge and an industry-wide standardization of audit procedures likely work best in homogeneous industries. In such industries, firms are affected by similar economic forces and have similar business models. From an auditing perspective, such similarity is important as the fundamentals that drive accounting measurements are likely also similar across firms in the industry. Relatedly, Cahan et al. (2011) report that practitioners define industry specialization as "knowledge specific to a client's industry", "an understanding of how general and specific accounting guidance applies to the client's industry", and "an understanding of operational nuances and challenges". Thus, whereas industry knowledge can be useful in homogeneous industries, in heterogeneous industries it is more difficult to transfer knowledge about audit risks, audit processes, and audit procedures across clients and economies of scale are likely limited (e.g., Bills et al. 2015). To the extent that auditors still apply industry-wide procedures there can be a loss of information as similar procedures are applied to a set of non-similar firms.

\footnotetext{
${ }^{10}$ We provide evidence that supports this claim in the section that describes our additional analyses.
} 
Whereas the previous discussion is concerned with the homogeneity of the industry, a similar argument can be made for the similarity of the focal firm with the other firms in the industry. For example, using standardized audit procedures can be costly even in homogeneous industries, if applied to firms that are not representative of and different from the other firms in the industry. Even though the industry is homogeneous on average, the economic forces that drive the accounting fundamentals of the non-representative firm are significantly different from those of the other firms in the industry such that applying standardized procedures still comes at a cost. Hence, we also expect the relation between industry specialist auditors and accrual informativeness to vary with the degree to which a client is representative of the other firms in the industry.

In summary, we aim to answer the following research questions: (1) What is the relation between auditor industry specialists and accrual informativeness, on average? (2) What is the role of within-industry homogeneity and the extent to which firms differ from industry norms?

\subsection{Research Design}

\subsubsection{Sample Selection}

Our sample consists of all U.S. listed firms with available data in Compustat and Audit Analytics from 2000 to 2017 . We estimate all models from fiscal year 2000 onwards, as this is the first year for which audit fee data, used for capturing industry specialization in our main specification, are available in Audit Analytics. After eliminating observations without the data necessary to calculate the variables included in our models, our final sample on which we estimate the cash flow prediction models includes 44,928 firm-year observations.

\subsubsection{Measuring Auditor Industry Specialization}

Since the specialist status of an auditor is unobservable, several proxies have been developed to measure industry specialization. We follow prior literature and use the auditor's market share in an industry to determine whether the auditor is an industry specialist (Bae et al. 2017; Dhaliwal et al. 2015; Lim and Tan 2010; Reichelt and Wang 2010). We use two-digit historical SIC codes to measure industry and calculate for each industry-year an auditor's market share based on the sum of audit fees in each industry. We then create an indicator variable, IndLeader_Fee, that is equal to one if the auditor has the largest audit fee-based market share in an industry, and zero otherwise. ${ }^{11}$

\subsubsection{Cash Flow Prediction Model}

For our main analysis, we follow Dechow et al. (1998), Barth et al. (2001), and Badertscher et al. (2012), and estimate a cash flow (CF) prediction model in which we estimate the predictive ability

\footnotetext{
${ }^{11}$ In recent years, there has been some criticism on the use of market share measures of auditor industry specialism and recent literature cautions against relying on a single market share measure of industry specialization (Audousset-Coulier et al. 2016). In robustness tests, we use alternative measures of auditor industry specialism. Our inferences are unaffected by using alternative measures. Please refer to section 2.4.4 for more details on these robustness tests.
} 
of current operating cash flows and accruals for future operating cash flows. As the ability to use accounting information in the prediction of future cash flows is a key aspect that determines the usefulness of accounting information to investors, this test enables us to investigate whether industry specialist auditors affect the informativeness of earnings.

Specifically, we estimate the following CF prediction model, where subscripts $i$ and $t$ denote firm and year:

$$
\begin{aligned}
& C F O_{i, t+1}=\beta_{0}+\beta_{1} C F O_{i, t}+\beta_{2} A C C_{i, t}+\beta_{3} C F O_{i, t} * I_{n d L e a d e r} F e e_{i, t}+\beta_{4} A C C_{i, t} * \\
& \text { IndLeader_Fee }_{i, t}+\beta_{5} \text { IndLeader_Fee }_{i, t}+\text { Year } F E+\text { Industry } F E+\varepsilon_{i, t}
\end{aligned}
$$

Operating cash flows $(C F O)$ are net cash flows from operating activities, scaled by average total assets. Accruals $(A C C)$ are measured as the difference between earnings (income before extraordinary items) and operating cash flows, scaled by average total assets (Sloan 1996). ${ }^{12}$ IndLeader_Fee is our proxy for auditor industry specialists as defined in the previous section. We interact IndLeader_Fee with both accruals $(A C C)$ and cash flows $(C F O)$ to examine whether auditor industry specialists affect the informativeness of accruals. We control for year and industry fixed effects. Standard errors are clustered by industry.

\subsubsection{Propensity Score Matching and Entropy Balancing}

To strengthen identification and to control for differences in client and engagement characteristics across audits conducted by industry specialists and non-industry specialist auditors, we use two different methods, namely propensity score matching and entropy balancing. Both techniques allow us to control for a variety of characteristics without having to be concerned about functional form misspecification. Propensity score matching is used to find comparable clients across specialist and non-specialist auditors. Using propensity score matching, control observations are matched to treatment observations based on a specified distance between their overall probabilities of undergoing treatment (i.e., being audited by an industry specialist). These probabilities are estimated using several covariates that predict choice, aggregating multiple dimensions into the probability of treatment, which is then used as a single matching variable.

To construct the propensity-score-matched sample, we use the indicator variable IndLeader_Fee that is equal to one if the firm has an industry specialist auditor, and zero otherwise, as the dependent variable. We include the following independent variables: Big $\mathrm{N}$ auditor, size (measured by the natural logarithm of total assets), leverage, loss, book-to-market ratio, inherent risk (measured as inventory and receivables divided by total assets), sales growth, number of business segments, auditor tenure, going-concern opinion, and performance (measured by Tobin's

\footnotetext{
${ }^{12} \mathrm{We}$ truncate these variables at the $0.5^{\text {th }}$ and $99.5^{\text {th }}$ percentile. Results are robust to winsorizing or estimating robust regressions to mitigate the influence of outliers. We find similar results if we use operating accruals, defined as operating income after depreciation less operating cash flows, divided by average total assets.
} 
Q, annual market-adjusted returns, and the natural logarithm of sales). In addition, we control for year and industry fixed effects. All these variables are defined in Appendix 2A.

Given the limitations inherent in the propensity score matching methodology (see Shipman et al. 2016), we also run our tests on a reweighted sample where we use entropy balancing to achieve covariate balance. Hainmueller (2012) introduces entropy balancing as a generalization of commonly used propensity score weighting/matching approaches. ${ }^{13}$ Appendix $2 \mathrm{~B}$ provides a more detailed explanation of entropy balancing, including its advantages compared to propensity score matching.

To construct our balanced sample, we use the same variables as those included in the propensity score matching specification, including the industry and year fixed effects. Specifically, we balance the sample means and variances of all these variables and require a maximum difference of 0.001 across the treated and untreated observations. ${ }^{14}$ The fact that the entropy-balanced specification allows us to achieve balance also on higher-order moments such as covariate variance is important as differences in variability can be associated with differences in informativeness (e.g., Lipe 1990). In the results section, we present the results with propensity score matching and entropy balancing side-by-side. In the propensity score-matched specification, the sample is reduced to 22,622 firm-year observations, which is less than half of the total sample. As discussed in more detail in Appendix 2B, the loss of observations in the propensity-score-matched sample is one of the major drawbacks of the method.

\subsection{Results}

\subsubsection{Descriptive Statistics}

Summary statistics of the variables used in the CF prediction model (Model 1) and the propensity score matching and entropy balancing specifications are reported in Table 2.1, Panel A. On average, cash flows are positive (0.056) and accruals are negative (-0.074), consistent with prior literature (Hui et al. 2016). Around 26 percent of the observations are audited by an industry specialist; about 33 percent of the observations experience a loss during the sample period and 81 percent of the observations employ a Big N auditor. Table 2.1, Panel B, presents a correlation matrix. Panel B shows that both accruals and cash flows are positively correlated with future cash flows, while contemporaneous accruals and cash flows exhibit a slightly negative correlation. In addition, industry specialists are positively correlated with the level of cash flows and accruals.

\footnotetext{
${ }^{13}$ Whereas with propensity score matching the observation weights follow from a logistic regression of a treatment indicator on a set of variables that predict treatment, entropy balancing directly uses the information that is available about the sample moments and the balance constraints imposed on them. Hence, instead of matching treated observations to untreated observations with the closest propensity score, entropy balancing starts from the base weights (which are generally equal to one) and adjusts them to achieve covariate balance. Thus, whereas with propensity score matching observations are either included or completely discarded, the weights in entropy balancing can be less than unity and are furthermore kept as close as possible to the original base weights.

14 The results are not affected by using different levels for the maximum difference.
} 
TABLE 2.1

Descriptive Statistics

\begin{tabular}{lcccccccc}
\hline \hline $\begin{array}{l}\text { Panel A: Summary Statistics } \\
\text { Variable }\end{array}$ & $\mathbf{N}$ & Mean & Median & SD & $\mathbf{1 \%}$ & $\mathbf{2 5 \%}$ & $\mathbf{7 5 \%}$ & $\mathbf{9 9 \%}$ \\
\hline CFO $_{t+1}$ & 44,928 & 0.054 & 0.081 & 0.161 & -0.623 & 0.025 & 0.134 & 0.327 \\
CFO $_{t}$ & 44,928 & 0.056 & 0.082 & 0.159 & -0.604 & 0.024 & 0.135 & 0.332 \\
ACC $t$ & 44,928 & -0.074 & -0.057 & 0.112 & -0.505 & -0.105 & -0.022 & 0.171 \\
IndLeader_Fee & 44,928 & 0.260 & 0.000 & 0.438 & 0.000 & 0.000 & 1.000 & 1.000 \\
BigN & 44,928 & 0.812 & 1.000 & 0.391 & 0.000 & 1.000 & 1.000 & 1.000 \\
Size & 44,928 & 6.252 & 6.191 & 2.073 & 2.036 & 4.755 & 7.677 & 11.035 \\
BTM & 44,928 & 0.603 & 0.464 & 0.673 & -0.530 & 0.260 & 0.759 & 3.400 \\
Leverage & 44,928 & 0.219 & 0.183 & 0.210 & 0.000 & 0.016 & 0.346 & 0.904 \\
Risk & 44,928 & 0.253 & 0.220 & 0.188 & 0.001 & 0.098 & 0.362 & 0.780 \\
Growth & 44,928 & 0.137 & 0.068 & 0.450 & -0.616 & -0.033 & 0.196 & 2.256 \\
Segments & 44,928 & 1.020 & 0.693 & 0.525 & 0.000 & 0.693 & 1.386 & 2.079 \\
LnSale & 44,928 & 6.002 & 6.107 & 2.254 & -0.007 & 4.525 & 7.541 & 10.880 \\
ROA & 44,928 & -0.018 & 0.032 & 0.192 & -0.807 & -0.034 & 0.075 & 0.253 \\
Loss & 44,928 & 0.328 & 0.000 & 0.470 & 0.000 & 0.000 & 1.000 & 1.000 \\
Opinion & 44,928 & 0.020 & 0.000 & 0.141 & 0.000 & 0.000 & 0.000 & 1.000 \\
Tenure & 44,928 & 1.413 & 1.386 & 0.823 & 0.000 & 0.693 & 2.079 & 2.773 \\
Tobins $Q$ & 44,928 & 1.663 & 1.223 & 1.343 & 0.313 & 0.845 & 1.951 & 7.912 \\
CAR t $_{t}$ & 44,928 & 0.104 & -0.013 & 0.806 & -0.799 & -0.253 & 0.256 & 2.878 \\
\hline
\end{tabular}

Panel B: Correlations (continued on next page)

This table presents the descriptive statistics of the main variables used in the cash flow prediction model (model 1) and the propensity score matching and entropy balancing specifications. Panel A provides summary statistics and panel B shows the correlations among the variables. The sample includes all firms with available data on Compustat and Audit Analytics from 2000 to 2017. $C F O_{t+1}, C F O_{t}$, and $A C C_{t}$ are truncated at the $0.5^{\text {th }}$ and $99.5^{\text {th }}$ percentile. Other continuous (non-log) variables, except $C A R_{t}$, are winsorized at the $1^{\text {st }}$ and $99^{\text {th }}$ percentile. All variables are defined in Appendix $2 \mathrm{~A}$. 


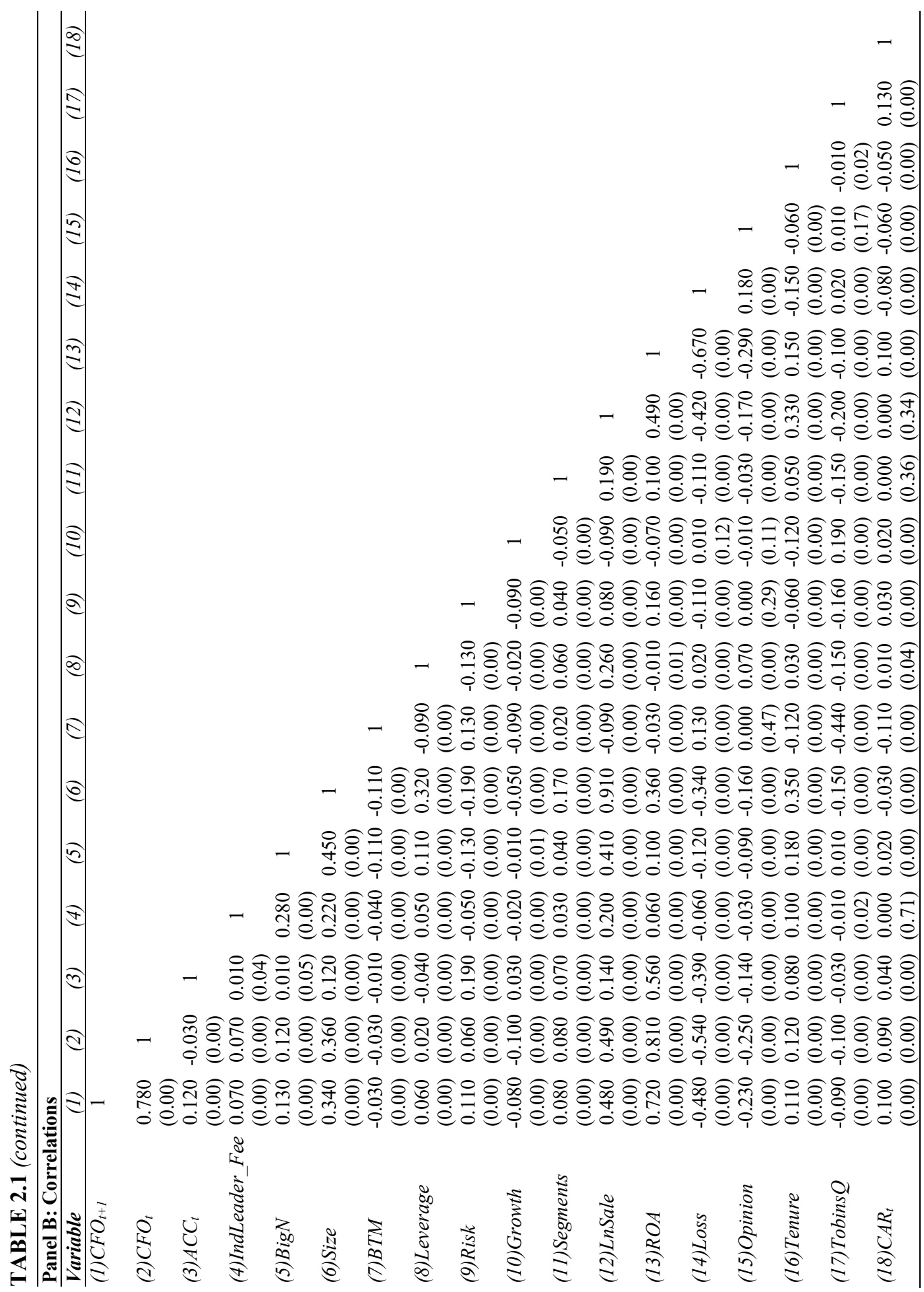




\subsubsection{Main Results}

Table 2.2 presents the results for the CF prediction model. Column (2) presents the findings of the base model including year and industry fixed effects. Column (3) presents the results with firm fixed effects, while columns (4) and (5) presents the findings after entropy balancing and propensity score matching, respectively. We observe positive and significant coefficients on the main effects of $C F O$ and $A C C$ in all four specifications, suggesting that the contemporaneous cash flows and accruals of firms audited by a non-industry specialist auditor are informative about their future cash flows. More central to our research question, however, we find that the interaction between $A C C$ and IndLeader_Fee is negative and significant in all specifications, suggesting that on average accruals are less informative about next year's operating cash flows for firms audited by an industry specialist. These results are also economically significant. For example, in the entropy-balanced specification we find that the mapping of accruals into future cash flows of firms audited by an

TABLE 2.2

Cash Flow Prediction Model

\begin{tabular}{|c|c|c|c|c|c|}
\hline & $(1)$ & $\begin{array}{c}\text { Base Model } \\
(2)\end{array}$ & $\begin{array}{l}\text { Firm Fixed } \\
\text { Effects } \\
\text { (3) }\end{array}$ & $\begin{array}{c}\text { Entropy } \\
\text { Balancing } \\
(4)\end{array}$ & $\begin{array}{c}\text { PSM } \\
(5)\end{array}$ \\
\hline Variables & $\begin{array}{l}\text { Coeff. } \\
\text { (t-stat) }\end{array}$ & $\begin{array}{l}\text { Coeff. } \\
\text { (t-stat) }\end{array}$ & $\begin{array}{l}\text { Coeff. } \\
\text { (t-stat) }\end{array}$ & $\begin{array}{l}\text { Coeff. } \\
\text { (t-stat) }\end{array}$ & $\begin{array}{l}\text { Coeff. } \\
\text { (t-stat) }\end{array}$ \\
\hline Constant & $\begin{array}{c}0.017 * * * \\
(3.93)\end{array}$ & $\begin{array}{c}0.017 * * * \\
(3.70)\end{array}$ & $\begin{array}{c}0.054 * * * \\
(4.82)\end{array}$ & $\begin{array}{c}0.017 * * * \\
(3.53)\end{array}$ & $\begin{array}{c}0.032 * * * \\
(6.23)\end{array}$ \\
\hline$C F O_{t}$ & $\begin{array}{c}0.775^{* * *} \\
(31.19)\end{array}$ & $\begin{array}{c}0.773 * * * \\
(31.14)\end{array}$ & $\begin{array}{c}0.362 * * * \\
(25.77)\end{array}$ & $\begin{array}{c}0.782 * * * \\
(27.13)\end{array}$ & $\begin{array}{c}0.778 * * * \\
(26.90)\end{array}$ \\
\hline$A C C_{t}$ & $\begin{array}{c}0.219 * * * \\
(8.39)\end{array}$ & $\begin{array}{c}0.229 * * * \\
(8.81)\end{array}$ & $\begin{array}{c}0.172 * * * \\
(18.88)\end{array}$ & $\begin{array}{c}0.215^{* * *} \\
(7.66)\end{array}$ & $\begin{array}{c}0.215^{* * * *} \\
(9.73)\end{array}$ \\
\hline IndLeader_Fee ${ }_{t}$ & & $\begin{array}{l}0.001 \\
(0.54)\end{array}$ & $\begin{array}{l}-0.002 \\
(-0.91)\end{array}$ & $\begin{array}{l}-0.002 \\
(-1.49)\end{array}$ & $\begin{array}{l}-0.002 \\
(-1.02)\end{array}$ \\
\hline $\mathrm{CFO}_{t} *$ IndLeader_Fee ${ }_{t}$ & & $\begin{array}{l}0.004 \\
(0.46)\end{array}$ & $\begin{array}{l}0.012 \\
(0.55)\end{array}$ & $\begin{array}{l}-0.002 \\
(-0.16)\end{array}$ & $\begin{array}{l}0.003 \\
(0.17)\end{array}$ \\
\hline ACC $_{t}^{*}$ IndLeader_Fee ${ }_{t}$ & & $\begin{array}{c}-0.052 * * * \\
(-4.60)\end{array}$ & $\begin{array}{c}-0.034 * * \\
(-2.09)\end{array}$ & $\begin{array}{c}-0.041 * * \\
(-2.05)\end{array}$ & $\begin{array}{c}-0.041 * * \\
(-2.07)\end{array}$ \\
\hline Year FE & YES & YES & YES & YES & YES \\
\hline Industry FE & YES & YES & YES & YES & YES \\
\hline Observations & 44,928 & 44,928 & 44,928 & 44,928 & 22,622 \\
\hline R-squared & 0.644 & 0.644 & 0.143 & 0.640 & 0.641 \\
\hline
\end{tabular}

This table presents results of the cash flow prediction model (model 1) analyzing the implications of an industry specialist auditor on the informativeness of accruals. The sample includes all firms with available data on Compustat and Audit Analytics from 2000 to 2017. $C F O_{t^{+1}}, C F O_{t}$, and $A C C_{t}$ are truncated at the $0.5^{\text {th }}$ and $99.5^{\text {th }}$ percentile. Column (1) presents results of a basic cash flow prediction model. Column (2) presents the results of model 1 controlling for year and industry fixed effects. Column (3) also includes firm fixed effects. Column (4) presents the results using entropy balancing (Refer to Appendix 2B for more information on entropy balancing), while Column (5) presents the findings after propensity score matching. The results for columns (1), (2) and (3) are based on the same sample that is used for entropy balancing (column 4). Standard errors are clustered by industry except for column (3), where standard errors are clustered by firm. *, **, and *** indicate statistical significance at the $10 \%, 5 \%$, and $1 \%$ levels, respectively (twotailed). All variables are defined in Appendix 2A. 
industry specialist auditor is lower by 19 percent (-0.041/0.215). Importantly, we do not find a significant relation between industry specialists and the informativeness of current cash flows, as the interaction of CFO and IndLeader_Fee is not significant in any of the specifications. As auditors should mainly be concerned with evaluating the reasonableness of a firm's accrual choices, one would naturally expect the effect of industry specialist auditors to be concentrated on the accrual component, rather than the cash flow component of earnings. Our findings confirm this. Overall, these results show that, on average, industry specialist auditors are associated with a loss of accrual informativeness.

\subsubsection{Cross-sectional Variation}

In a next step, we investigate cross-sectional variation in the relation between industry specialist auditors and accrual informativeness. ${ }^{15}$ As determinants, we focus on characteristics of the client's industry and of the client itself. With respect to the industry, we explore the role of within-industry homogeneity. Prior studies provide evidence that auditors are more likely to specialize in industries with a greater homogeneity among clients' operations and investment opportunity sets (Cahan et al. 2008; Cairney and Young 2006). In addition, Bills et al. (2015) provide evidence that industry specialists charge lower fees in industries with homogenous operations. This finding is consistent with the argument that homogenous industries allow for economies of scale through the transfer of industry-specific knowledge and audit processes across clients.

We use several measures to capture the homogeneity of the industry. Our primary measure follows Hui et al. (2016) and Dopuch et al. (2012) and captures the within-industry dispersion in operating activities. Specifically, it is the average of the normalized rank (i.e., ranked such that all values lie between zero and one) of the standard deviation within an industry and year of the following four factors capturing firms' operating activities: (1) profit margin, (2) receivable turnover, (3) payable turnover, and (4) inventory turnover. Importantly, Dopuch et al. (2012) use this measure to capture heterogeneity in the accrual-generating process of firms in the industry. Industry knowledge and the application of standardized auditing procedures should be more beneficial (or less costly) in industries in which all firms have a similar accrual-generating process. The results reported in Table 2.3, column (1), indicate that the relation between industry specialist auditors and accrual informativeness is more negative in more heterogeneous industries. As Dopuch et al. (2012) find inconsistent results with inventory turnover, we also test a specification in which our measure of homogeneity in the accrual-generating process excludes the standard deviation in inventory turnover. As can be seen from the results in column (2), we again find a more negative relation between industry specialists and accrual informativeness in more heterogeneous industries. Interestingly, we do not find a negative relation between industry specialists and accrual informativeness in the most homogeneous industries (see the positive, but not significant interaction of $A C C$ and IndLeader_Fee).

\footnotetext{
${ }^{15}$ We estimate all cross-sectional regressions on the entropy-balanced sample to control for differences in audit engagements with or without industry specialists.
} 


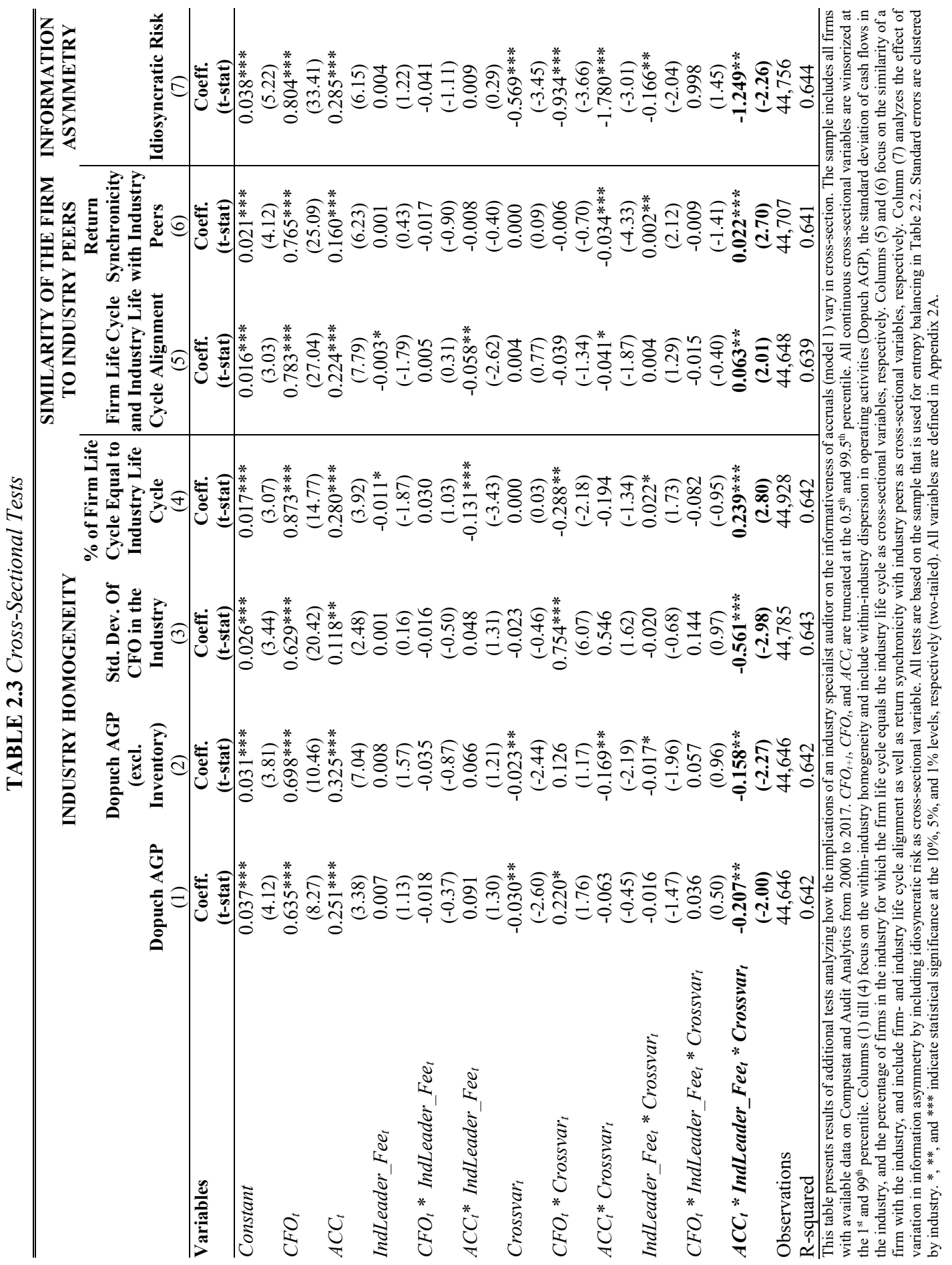


We also use two other measures to capture the homogeneity of the industry. Our second measure is closely related to the first measure, but instead captures the variation in performance across firms in the industry. As we argue that industry specialist auditors may impact the comparability of accruals in an industry, we use the dispersion in operating cash flows in an industry and year as our measure of performance variability. We again find that the negative relation between industry specialists and accrual informativeness is not present in the most homogeneous industries, but is increasingly so in more heterogeneous industries (Table 2.3, column (3)).

Our final measure is based on a combination of firm life cycle and industry life cycle. Previous literature has provided evidence on the importance of firm and industry life cycle in an accounting setting (Cantrell and Dickinson 2019; Dickinson 2011). For example, Anthony and Ramesh (1992) and Dickinson et al. (2018) show that firm life cycle has an impact on the valuerelevance of accounting constructs, while Hribar and Yehuda (2015) show that the role of accruals, whether they capture investments in future growth or adjust for the timing of cash flows, is different depending on the life cycle stage of the firm. As such, firm and industry life cycle are both fundamental drivers of accounting measures. To capture the life cycle homogeneity of the industry, we use the percentage of firms in the industry for which the firm life cycle is equal to the industry life cycle. We use the Dickinson (2011) cash flow-based measure to determine firm life cycle and following Cantrell and Dickinson (2019), we use the cumulative cash flows in the industry to determine industry life cycle. We expect that industry knowledge is more useful when a greater percentage of firms is in the same life cycle stage as the industry, as any life cycle knowledge of the industry specialist auditor likely resides at the industry level. We find that the relation between industry specialist auditors and accrual informativeness is less negative when a greater percentage of firms shares the life cycle stage with the industry (Table 2.3, column (4)). ${ }^{16}$

Overall, we find that the negative relation between industry specialists and accrual informativeness is stronger in less homogeneous industries. The fact that we do not find a relation between industry specialists, industry homogeneity, and cash flow informativeness is further consistent with the responsibility of (industry specialist) auditors for accruals.

Our second set of cross-sectional tests explores the impact of the extent to which the firm differs from its industry peers. Our first measure builds upon our final industry homogeneity measure and captures whether the life cycle stage of the firm is aligned with that of the industry. Our second measure captures the synchronicity of firm returns with market and industry returns. We create an industry index as the equal-weighted average stock return of all firms in the industry. We then use the natural logarithm of the R-Squared of a regression of firm returns on equal-weighted market returns and the equal-weighted industry index over the fiscal year as a measure of the

\footnotetext{
${ }^{16}$ In untabulated tests we find qualitatively similar results in two alternative specifications in which we look at variation in firm life cycle in an industry: (1) a life-cycle concentration index, and (2) the standard deviation of life cycle stages that incorporates that the difference between a decline and introduction firm is greater than that between a growth and mature firm.
} 
similarity of the firm with the other firms in the industry. ${ }^{17}$ The results reported in Table 2.3, columns (5) and (6) show that, in line with the results on within-industry homogeneity, using an industry specialist leads to lower accrual informativeness for firms that differ more from their industry peers.

Finally, we investigate the impact of idiosyncratic risk. Firms with higher levels of idiosyncratic risk might have more characteristics (e.g., risks) that are unique to the firm, such that industry knowledge is likely less useful for these firms. The results are reported in Table 2.3, column (7). Consistent with our expectation, we find that the negative relation between industry specialists and accrual informativeness is more pronounced for firms with higher idiosyncratic risk.

Overall, our findings reveal that there is considerable sample-wide variation in the association between industry specialist auditors and accrual informativeness. Whereas we document that auditor industry specialism, on average, is associated with lower accrual informativeness, the cross-sectional tests indicate that these findings are driven by industries that are less homogenous, by firms that are less similar to their industry peers and by firms with high idiosyncratic risk.

\subsubsection{Additional Analyses and Robustness Tests}

\subsubsection{Industry Specialist Auditors and Accrual Homogeneity}

As discussed in Section 2, industry specialist auditors can benefit from knowledge-sharing and building internal databases with industry-specific best practices and red flags, as well as the use of audit programs that are tailored to the industry. We argue that this can lead to standardization that increases the comparability of accounting across firms within an industry, but which can constrain the ability of management to alter their accrual choices, in which case a loss of (firm-specific) information can occur. The results reported thus far are consistent with this argument. Auditing studies indeed show that accruals of firms audited by the same auditor tend to be more comparable, however, none of the studies provide evidence of greater accrual comparability for industry specialist auditors specifically. Hence, to provide additional evidence that substantiates our discussion, we investigate the impact of industry specialist auditors on the similarity of accruals within an industry.

We estimate a regression of the within-industry standard deviation in accruals on the percentage of firms in the industry that are audited by industry-specialist auditors (i.e., the market share of the industry leader). If industry-specialists increase the comparability of accruals one would expect the within-industry standard deviation of accruals (Ind_StdACC) to be lower when the market share of the leader is higher (Mshare_Leader).

The results reported in Table 2.4 provide evidence consistent with this hypothesis. Specifically, we find a negative relation between the market share of the industry specialist auditor and the standard deviation of accruals within the industry. Moreover, these results hold after controlling for the standard deviation of operating cash flows (Ind_StdCFO) as a measure of inherent

\footnotetext{
${ }^{17}$ We find similar results when we measure synchronicity as the average R-Squared of a regression of firm returns on peer returns, using all available industry peers.
} 
comparability. We find similar results when we use the similarity in return on assets (Ind_StdROA) while still controlling for the similarity in operating cash flows to capture the degree of accrual homogeneity. Furthermore, consistent with industry specialist auditors driving the similarity in firms' accounting choices, rather than the firms being economically similar only, we do not find a significant relation between the market share of the industry leader and the standard deviation of operating cash flows within the industry. In our final specification, we also test whether industry specialist auditors are associated with industry-wide smoothing of earnings by investigating whether the industry-wide standard deviation of earnings is less than the industry-wide deviation of cash flows (Ratio; Ind_StdROA/Ind_StdCFO). However, whereas the coefficient on Mshare_Leader is negative, it is not significant. Overall, these results provide additional evidence that industry specialist auditors are associated with greater standardization and more similar accrual behavior within an industry.

TABLE 2.4

Industry Specialists and Industry Accrual Homogeneity

\begin{tabular}{|c|c|c|c|c|c|}
\hline & $\begin{array}{c}\text { Ind_StdACC } \\
(1)\end{array}$ & $\begin{array}{c}\text { Ind_StdACC } \\
(2)\end{array}$ & $\begin{array}{c}\text { Ind_StdROA } \\
\text { (3) }\end{array}$ & $\begin{array}{c}\text { Ind_StdCFO } \\
(4)\end{array}$ & $\begin{array}{c}\text { Ratio } \\
(5)\end{array}$ \\
\hline \multirow{2}{*}{ Variables } & Coeff. & Coeff. & Coeff. & Coeff. & Coeff. \\
\hline & (t-stat) & (t-stat) & (t-stat) & (t-stat) & (t-stat) \\
\hline Constant & $\begin{array}{c}0.075 * * * \\
(9.97)\end{array}$ & $\begin{array}{c}0.043 * * * \\
(5.65)\end{array}$ & $\begin{array}{l}0.002 \\
(0.38)\end{array}$ & $\begin{array}{c}0.041 * * * \\
(4.94)\end{array}$ & $\begin{array}{c}1.092 * * * \\
(17.19)\end{array}$ \\
\hline Mshare_Leader & $\begin{array}{c}-0.043 * * * \\
(-3.31)\end{array}$ & $\begin{array}{c}-0.027 * * \\
(-2.56)\end{array}$ & $\begin{array}{c}-0.015 * \\
(-1.90)\end{array}$ & $\begin{array}{l}-0.017 \\
(-1.35)\end{array}$ & $\begin{array}{l}-0.060 \\
(-0.64)\end{array}$ \\
\hline Ind_StdCFO & & $\begin{array}{c}0.341 \text { *** } \\
(6.20)\end{array}$ & $\begin{array}{c}1.123 * * * \\
(38.36)\end{array}$ & & \\
\hline Ind_StdACC & & & & $\begin{array}{c}0.684 * * * \\
(5.85)\end{array}$ & \\
\hline Year FE & YES & YES & YES & YES & YES \\
\hline Observations & 1,162 & 1,162 & 1,162 & 1,162 & 1,162 \\
\hline R-Squared & 0.206 & 0.391 & 0.767 & 0.289 & 0.086 \\
\hline
\end{tabular}

This table reports the results of a regression of the within-industry standard deviation of accruals, return on assets, and cash flows on the market share of the industry-leading auditor. The sample includes all firms with available data on Compustat and Audit Analytics from 2000 to 2017. Ind_StdACC is the standard deviation in accruals scaled by average total assets in an industry (two-digit SIC) and year. Ind_StdCFO is the standard deviation in operating cash flows scaled by average total assets in an industry (two-digit SIC) and year. Ind_StdROA is the standard deviation in income before extraordinary items scaled by average total assets in an industry (two-digit SIC) and year. Ratio is the ratio of Ind_StdROA to Ind_StdCFO. Standard errors are clustered by industry. *, **, and *** indicate statistical significance at the $10 \%, 5 \%$, and $1 \%$ levels, respectively (two-tailed).

\subsubsection{Alternative Auditor Industry Specialist Measures}

The results reported thus far are based on an industry specialist measure that captures whether the auditor is the national industry leader. Table 2.5 reports the results of several robustness tests in which we vary our measure of auditor industry specialism. Column (1) reports the results of a firmfixed effects specification in which we allow industry specialism to be continuous and find that 


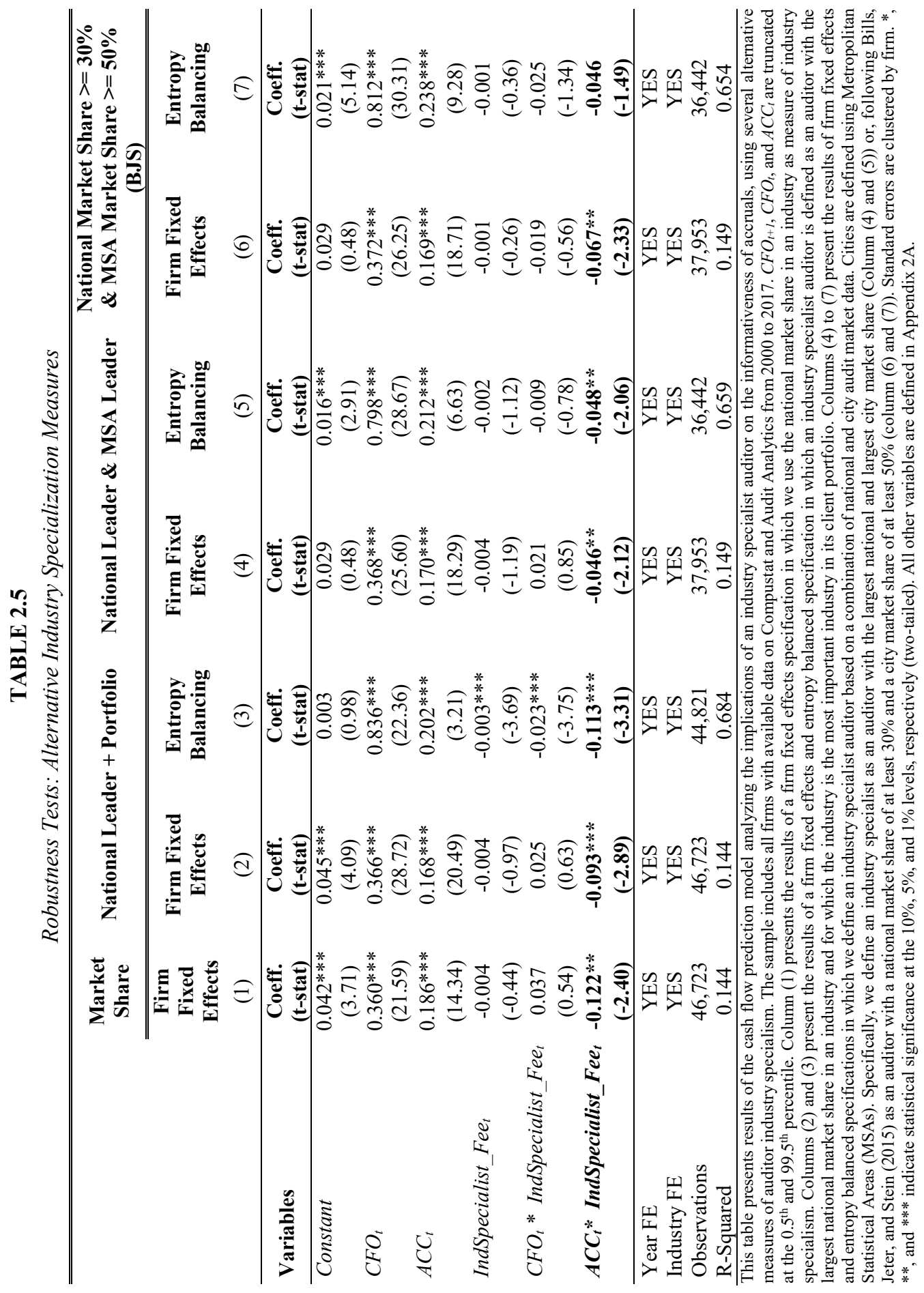


results are similar if we use the auditor's national market share in the industry. ${ }^{18}$ Columns (2) and (3) report the results of an industry specialism measure that further incorporates the importance of the industry in the auditor's client portfolio. Specifically, the results are based on a specialist measure that is equal to one if the auditor is the national industry leader and if the industry is the most important industry in the auditor's portfolio of clients, and zero otherwise. Although this reduces the number of auditors that we classify as industry specialists compared to our main specification, we continue to find that auditor industry specialism, on average, is associated with lower accrual informativeness. Columns (4) to (7) report the results of two specifications in which we further incorporate city-level data. We use Metropolitan Statistical Areas (MSA) to define cities and match it to county and state data in Audit Analytics. In Columns (4) and (5) we then define an industry specialist to be an auditor that is the industry leader at both the national and city level. Columns (6) and (7) report the results of an alternative measure that we borrow from Bills et al. (2015) and that defines an industry specialist as an auditor with a national market share of at least 30 percent and a city market share of at least 50 percent. As can be seen in Table 2.5, we find that, on average, industry specialist auditors are associated with lower accrual informativeness, also after incorporating city-level specialism.

In our main analyses, we base our industry specialist measure on audit fees. Existing literature stresses the importance of not relying on a single measure of industry specialism and as a result, often uses client size variables such as assets and sales to measure auditors' market shares (Audousset-Coulier et al. 2016). To investigate whether the inferences from our main analyses are not specific to the use of our fee-based measure of industry specialization, we create four alternative measures, using the largest within-industry market share based on the following variables: assets, sales, squared assets, and squared sales. We rerun our main tests and obtain (untabulated) qualitatively and quantitatively similar results to those reported in our tables.

\subsubsection{Two-Year Cash Flow Prediction}

Table 2.6 presents the findings of our main model where we investigate the extent to which accruals predict cash flows two years ahead. Such an analysis helps us to determine whether the impact of industry specialist auditors is limited to short-term, one-year ahead accrual informativeness, or whether the results extend to longer-term cash flow predictions as well. This is important as previous literature has documented the difficulties, even for sophisticated market participants, to predict longterm profitability (Bradshaw et al. 2012).

In line with the results reported in Table 2.2, we find that industry specialists reduce the informativeness of accruals to predict cash flows two years ahead across all four specifications, indicating a long-term reduction in accrual informativeness that extends beyond the estimation of current accruals only.

\footnotetext{
${ }^{18}$ As the measure is continuous, we cannot estimate an entropy balancing specification.
} 
TABLE 2.6

Robustness Tests: Next Two-Year Cash Flow Prediction Model

\begin{tabular}{|c|c|c|c|c|}
\hline & $\begin{array}{c}\text { Base Model } \\
(1) \\
\end{array}$ & $\begin{array}{c}\text { Firm Fixed } \\
\text { Effects } \\
(2) \\
\end{array}$ & $\begin{array}{c}\text { Entropy } \\
\text { Balancing } \\
(3) \\
\end{array}$ & $\begin{array}{c}\text { PSM } \\
(4) \\
\end{array}$ \\
\hline Variables & $\begin{array}{l}\text { Coeff. } \\
\text { (t-stat) }\end{array}$ & $\begin{array}{l}\text { Coeff. } \\
\text { (t-stat) }\end{array}$ & $\begin{array}{l}\text { Coeff. } \\
\text { (t-stat) }\end{array}$ & $\begin{array}{l}\text { Coeff. } \\
\text { (t-stat) }\end{array}$ \\
\hline Constant & $\begin{array}{c}0.016 \text { *** } \\
(3.00)\end{array}$ & $\begin{array}{c}0.080 * * * \\
(4.26)\end{array}$ & $\begin{array}{c}0.016^{* * *} \\
(3.23)\end{array}$ & $\begin{array}{c}0.025^{* * *} \\
(4.46)\end{array}$ \\
\hline$C F O_{t}$ & $\begin{array}{c}0.700 * * * \\
(18.09)\end{array}$ & $\begin{array}{c}0.172 * * * \\
(9.78)\end{array}$ & $\begin{array}{c}0.699 * * * \\
(16.46)\end{array}$ & $\begin{array}{c}0.675^{* * *} \\
(17.16)\end{array}$ \\
\hline$A C C_{t}$ & $\begin{array}{c}0.207 * * * \\
(8.45)\end{array}$ & $\begin{array}{c}0.102 * * * \\
(8.98)\end{array}$ & $\begin{array}{c}0.173^{* * *} \\
(5.78)\end{array}$ & $\begin{array}{c}0.169 * * * \\
(4.96)\end{array}$ \\
\hline IndLeader_Fee $_{t}$ & $\begin{array}{l}0.004 \\
(1.29)\end{array}$ & $\begin{array}{l}0.000 \\
(0.07)\end{array}$ & $\begin{array}{l}-0.002 \\
(-0.71)\end{array}$ & $\begin{array}{l}-0.002 \\
(-0.53)\end{array}$ \\
\hline $\mathrm{CFO}_{t} *$ IndLeader_Fee $\mathrm{F}_{t}$ & $\begin{array}{l}-0.011 \\
(-0.83)\end{array}$ & $\begin{array}{l}0.001 \\
(0.04)\end{array}$ & $\begin{array}{l}-0.007 \\
(-0.68)\end{array}$ & $\begin{array}{l}0.017 \\
(1.28)\end{array}$ \\
\hline$A C C_{t} *$ IndLeader_Fee $e_{t}$ & $\begin{array}{c}-0.069 * * * \\
(-3.21)\end{array}$ & $\begin{array}{c}-0.048 * * \\
(-2.53)\end{array}$ & $\begin{array}{c}-0.039 * * \\
(-2.06)\end{array}$ & $\begin{array}{l}-0.034 * \\
(-1.70)\end{array}$ \\
\hline Year FE & YES & YES & YES & YES \\
\hline Industry FE & YES & YES & YES & YES \\
\hline Observations & 39,563 & 39,563 & 39,563 & 20,079 \\
\hline R-Squared & 0.478 & 0.032 & 0.462 & 0.450 \\
\hline
\end{tabular}

This table presents results of the next two-year cash flow prediction model analyzing the implications of an industry specialist auditor on the informativeness of accruals for two-year ahead cash flows. The sample includes all firms with available data on Compustat and Audit Analytics from 2000 to 2016. CFO ${ }_{t+1}, C F O_{t}$, and $A C C_{t}$ are truncated at the $0.5^{\text {th }}$ and $99.5^{\text {th }}$ percentile. Column (1) presents the results controlling for year and industry fixed effects. Column (2) also includes firm fixed effects. Column (3) presents the results using entropy balancing, while Column (4) presents the findings after propensity score matching. Standard errors are clustered by industry except for column (2), where standard errors are clustered by firm. *, $* *$, and $* * *$ indicate statistical significance at the $10 \%, 5 \%$, and $1 \%$ levels, respectively (two-tailed). All variables are defined in Appendix 2A.

\subsubsection{Expanded Cash Flow Prediction Model}

Table 2.7 reports the results using an expanded cash flow prediction model, in which we further allow the informativeness of accruals and cash flows to vary across profit and loss firms. Hayn (1995) provides evidence that losses are less persistent and less informative about firms' future performance. Although we already include a loss indicator variable and the return on assets as covariates in the entropy balancing specifications, the results in Table 2.7 further confirm that our results are not driven by differences in performance or the propensity to report losses across audit engagements with and without an industry specialist auditor. Consistent with Hayn (1995), we find that the mapping of accruals into future cash flows is weaker for loss firms. More importantly, we continue to find that industry specialist auditors, on average, are associated with less informative accruals. 


\subsubsection{Industry Shocks}

As discussed earlier, we expect industry knowledge to be less relevant in heterogeneous industries in which firms have different business models and in which the accrual-generating process differs widely. In this section, we investigate the importance of industry shocks as these relate to withinindustry changes in business models and should directly impact the measurement of accruals. For example, the development of a new technology (e.g., resulting from R\&D investments) can impact the valuation of assets for all firms in the industry. Hui et al. (2016) investigate the impact of industry shocks on the persistence of (industry-wide) earnings, while Guay et al. (2015) investigate how industry shocks affect CEO turnover. We follow those two studies and measure industry shocks as the normalized rank (i.e., ranked such that all values lie between zero and one) of the absolute (percentage) change in (1) industry total assets, (2) industry sales, (3) industry capital expenditures, (4) industry R\&D investments, (5) industry average percentage foreign (non-US) sales, (6) industry average market-to-book ratio's, and (7) the industry Herfindahl index. We expect that industry knowledge is less useful in industries that experience a shock, as the past accumulation of industry knowledge is likely less applicable to the newly changed environment. Our results (untabulated) are consistent with this expectation. Specifically, we find that the relation between industry specialist auditors and accrual informativeness is more negative in industry-years in which there is an industrywide shock. ${ }^{19}$

\subsubsection{Alternative Industry Classifications}

Cahan et al. (2011) investigate the overlap between industry specialists identified based on marketshare thresholds using 3-digit SIC codes and self-proclaimed areas of industry expertise (key industries) as listed by auditors on their websites. Although their findings show that industry specialization based on SIC codes is meaningful and corresponds to how audit firms themselves define areas of expertise, we still investigate whether our results hold if we use alternative industry definitions. We find similar results (untabulated) using a more granular three-digit SIC industry definition as well as other industry definitions (such as Fama-French industry classifications and GICS sector codes).

\subsubsection{Alternative Entropy Balancing Specifications}

To investigate the robustness of the entropy balancing design, we investigate several other alternatives. First, whereas in the main results we balance the mean and variance of all covariates, we also estimate the regressions using regression weights balanced on the covariates' mean, variance, and skewness. We find results that are statistically and economically comparable to the results reported in Table 2.2. Second, we investigate the impact of variations in the covariates on which we balance, and we find comparable results even after adding additional audit-specific controls such as audit lags. Finally, we investigate whether the results change if we further balance

\footnotetext{
${ }^{19}$ Moreover, we do not find a negative relation between industry specialists and accrual informativeness in the most stable industry-years.
} 
on $C F O$ and $A C C$ and we again find results comparable to the main results reported in Table 2.2. Whereas we are interested in the effect of auditor industry specialism on accrual informativeness, balancing on $C F O$ and $A C C$ assures that the results are not driven by differences in the levels of accruals and cash flows between specialist and non-specialist auditors. In addition, as we also balance the covariates' variance, this test also provides evidence that the results are not driven by differences in the inherent variability of accruals and cash flows across specialist and non-specialist auditors.

TABLE 2.7

Robustness Tests: Expanded Cash Flow Prediction Model

\begin{tabular}{|c|c|c|c|c|}
\hline & $\begin{array}{c}\text { Base Model } \\
\text { (1) }\end{array}$ & $\begin{array}{c}\text { Firm Fixed } \\
\text { Effects } \\
(2)\end{array}$ & $\begin{array}{c}\text { Entropy } \\
\text { Balancing } \\
(3)\end{array}$ & $\begin{array}{c}\text { PSM } \\
\text { (4) }\end{array}$ \\
\hline Variables & $\begin{array}{c}\text { Coeff. } \\
\text { (t-stat) }\end{array}$ & $\begin{array}{l}\text { Coeff. } \\
\text { (t-stat) }\end{array}$ & $\begin{array}{l}\text { Coeff. } \\
\text { (t-stat) }\end{array}$ & $\begin{array}{l}\text { Coeff. } \\
\text { (t-stat) }\end{array}$ \\
\hline Constant & $\begin{array}{c}0.026^{* * *} \\
(5.60)\end{array}$ & $\begin{array}{c}0.053 * * * \\
(4.79)\end{array}$ & $\begin{array}{c}0.023 * * * \\
(4.52)\end{array}$ & $\begin{array}{c}0.038^{* * *} \\
(6.08)\end{array}$ \\
\hline$C F O_{t}$ & $\begin{array}{c}0.711 * * * \\
(35.87)\end{array}$ & $\begin{array}{c}0.377 * * * \\
(22.19)\end{array}$ & $\begin{array}{c}0.767 * * * \\
(36.51)\end{array}$ & $\begin{array}{c}0.754 * * * \\
(22.88)\end{array}$ \\
\hline$A C C_{t}$ & $\begin{array}{c}0.318 * * * \\
(11.86)\end{array}$ & $\begin{array}{c}0.296 * * * \\
(17.96)\end{array}$ & $\begin{array}{c}0.333 * * * \\
(12.36)\end{array}$ & $\begin{array}{c}0.332 * * * \\
(10.36)\end{array}$ \\
\hline Loss $_{t}$ & $\begin{array}{c}-0.019 * * * \\
(-5.61)\end{array}$ & $\begin{array}{c}-0.007 * * * \\
(-3.50)\end{array}$ & $\begin{array}{c}-0.015^{* * *} \\
(-3.61)\end{array}$ & $\begin{array}{c}-0.016^{* * *} \\
(-3.03)\end{array}$ \\
\hline$C F O_{t} * \operatorname{Loss}_{t}$ & $\begin{array}{c}0.084 * * \\
(2.55)\end{array}$ & $\begin{array}{l}0.007 \\
(0.29)\end{array}$ & $\begin{array}{l}0.039 \\
(1.03)\end{array}$ & $\begin{array}{l}0.052 \\
(1.16)\end{array}$ \\
\hline$A C C_{t} * \operatorname{Loss}_{t}$ & $\begin{array}{c}-0.142 * * * \\
(-4.43)\end{array}$ & $\begin{array}{c}-0.158 * * * \\
(-7.98)\end{array}$ & $\begin{array}{c}-0.172 * * * \\
(-5.33)\end{array}$ & $\begin{array}{c}-0.176^{* * *} \\
(-4.98)\end{array}$ \\
\hline IndLeader_Fee ${ }_{t}$ & $\begin{array}{l}0.000 \\
(0.22)\end{array}$ & $\begin{array}{l}-0.003 \\
(-1.11)\end{array}$ & $\begin{array}{c}-0.002 * \\
(-1.71)\end{array}$ & $\begin{array}{l}-0.002 \\
(-1.05)\end{array}$ \\
\hline $\mathrm{CFO}_{t} *$ IndLeader_Fee ${ }_{t}$ & $\begin{array}{l}0.012 \\
(1.37)\end{array}$ & $\begin{array}{l}0.017 \\
(0.77)\end{array}$ & $\begin{array}{l}-0.002 \\
(-0.20)\end{array}$ & $\begin{array}{l}0.001 \\
(0.06)\end{array}$ \\
\hline ACC $_{t} *$ IndLeader_Fee ${ }_{t}$ & $\begin{array}{c}-0.052 * * * \\
(-4.53)\end{array}$ & $\begin{array}{c}-0.033 * * \\
(-2.08)\end{array}$ & $\begin{array}{l}-0.036 * \\
(-1.89)\end{array}$ & $\begin{array}{c}-0.037 * \\
(-1.87)\end{array}$ \\
\hline Year FE & YES & YES & YES & YES \\
\hline Industry FE & YES & YES & YES & YES \\
\hline Observations & 44,928 & 44,928 & 44,928 & 22,622 \\
\hline R-Squared & 0.648 & 0.149 & 0.643 & 0.645 \\
\hline $\begin{array}{l}\text { This table presents results of } \\
\text { auditor on the informativene } \\
\text { Analytics from } 2000 \text { to } 201 \\
\text { presents the results controllin } \\
\text { (3) presents the results using } \\
\text { Standard errors are clustered } \\
* * * \text { indicate statistical signi } \\
\text { in Appendix } 2 \mathrm{~A} \text {. }\end{array}$ & $\begin{array}{l}\text { anded cash floy } \\
\text { accruals. The sa } \\
O_{t+1}, C F O_{t} \text {, an } \\
\text { year and indust } \\
\text { y balancing, wh } \\
\text { dustry except fo } \\
\text { at the } 10 \%, 5 \%\end{array}$ & $\begin{array}{l}\text { iction model an } \\
\text { includes all fir } \\
t \text { are truncated } \\
\text { d effects. Colu } \\
\text { lumn (4) prese } \\
\text { mn (2), where } \\
1 \% \text { levels, res }\end{array}$ & $\begin{array}{l}\text { g the implicati } \\
\mathrm{h} \text { available da } \\
0.5^{\text {th }} \text { and } 99 \\
\text { also includes } \\
\text { findings after } \\
\text { rd errors are c } \\
\text { ely (two-tailec }\end{array}$ & $\begin{array}{l}\text { an industry specialist } \\
\text { compustat and Audit } \\
\text { centile. Column (1) } \\
\text { xed effects. Column } \\
\text { sity score matching. } \\
\text { d by firm. *, **, and } \\
\text { variables are defined }\end{array}$ \\
\hline
\end{tabular}




\subsection{Conclusion}

Prior research has devoted considerable attention to the costs and benefits of auditor industry specialization. An important part of this literature has focused on the impact of auditor industry specialization on a firm's discretionary accruals. Whereas some studies find evidence of lower discretionary accruals for industry specialist auditors (Gaver and Utke 2019; Reichelt and Wang 2010), others do not (Minutti-Meza 2013). In this study, we take a different perspective and investigate the relation between auditor industry specialization and accrual informativeness.

The ability of accruals to inform a wide range of users, including investors, creditors, suppliers, and employees, about the future net cash inflows of an entity has been recognized by the FASB as one of the main objectives of financial reporting. Moreover, it directly relates to faithful representation and relevance that are defined as the two fundamental qualities of accounting information in the FASB's conceptual framework. Furthermore, it is consistent with an expanded role of the auditor that is broader than assuring that the financial statements of the client are in technical compliance with GAAP, but also whether the financial statements reflect the firm's underlying economics. Hence, we examine the relation between auditor industry specialization and accrual informativeness by investigating the extent to which current accruals map into future operating cash flows.

The impact of industry specialist auditors on the informativeness of accruals is not clear exante. Whereas previous literature has provided some evidence of a negative relation between industry specialists and discretionary accruals, such findings do not necessarily imply greater informativeness. Managers can use (discretionary) accrual choices to reveal (private) information to investors and hence restricting managers' ability to do so can lead to a loss of information (see for example Badertscher et al. 2012). Therefore, it remains an empirical question whether industry knowledge and the use of standardized procedures tailored to the industry improve the informativeness of earnings, or whether standardization by industry specialist auditors comes at a cost of lower informativeness.

We use a cash flow prediction model to examine the extent to which this year's operating cash flows and accruals map into next year's operating cash flows and begin our analyses on a pooled sample of all U.S. public companies over the period 2000-2017. We find that, on average, the accruals of clients audited by an industry specialist auditor are less predictive of future cash flows.

In a next step, we investigate cross-sectional variation in this relation. More specifically, we investigate the effect of industry homogeneity, the similarity of the firm to the other firms in the industry, and firm-specific information asymmetry, on the association between industry specialist auditors and accrual informativeness. We find that the negative effect of industry specialists on accrual informativeness is driven by less homogenous industries, firms that differ more from their industry peers, and firms with higher idiosyncratic risk. In these cases, it is more difficult to transfer knowledge about audit risks and audit procedures across clients, however, if still done, it is associated with a loss of relevant private information. Moreover, we find that the negative relation 
between industry specialists and accrual informativeness is more pronounced after industry-wide shocks that likely cause a change in the industry-wide accrual-generating process. Our findings are robust to alternative matching techniques, different measures of industry specialization, and alternative industry definitions.

The insights of our study shed new light on the effects of industry specialist auditors and contribute to the literature on auditor industry specialization by considering another dimension of high-quality accounting information. Our findings should, therefore, be of interest to standardsetters, but also to audit firms as they attach great importance to investing in industry-specific expertise. One limitation of our study is that we focus only on the predictive value of accounting information and ignore the confirmatory role that accounting information plays. Future research could investigate whether industry specialists affect the confirmatory role of accounting information in line with Ball et al. (2012). 


\section{Appendix 2A - Variable Definitions}

\begin{tabular}{|c|c|c|}
\hline Variable & Description & Source \\
\hline \multicolumn{3}{|c|}{ Industry Specialist Variable } \\
\hline IndLeader_Fee & $\begin{array}{l}\text { Indicator variable that is equal to one if the auditor is the auditor with } \\
\text { the largest national market share based on audit fees in a two-digit } \\
\text { historical SIC code and fiscal year, zero otherwise. }\end{array}$ & $\begin{array}{l}\mathrm{AA}^{*} \\
\text { Compustat }\end{array}$ \\
\hline Mshare_Leader & $\begin{array}{l}\text { The national market share based on audit fees in a two-digit historical } \\
\text { SIC code and fiscal year of the industry leader. }\end{array}$ & $\begin{array}{l}\text { AA* } \\
\text { Compustat }\end{array}$ \\
\hline \multicolumn{3}{|c|}{ Cash Flow Model Variables } \\
\hline$C F O_{t+1}$ & $\begin{array}{l}\text { Next year's operating cash flows (OANCF) divided by average total } \\
\text { assets (AT). }\end{array}$ & Compustat \\
\hline$C F O_{t}$ & Operating cash flows (OANCF) divided by average total assets (AT). & Compustat \\
\hline$A C C_{t}$ & Total Accruals (IB - OANCF) divided by average total assets (AT). & Compustat \\
\hline$A C C_{t}{ }^{*}$ IndLeader ${ }_{t}$ & Interaction of IndLeader_Fee and $A C C_{t}$. & Compustat \\
\hline$C F O_{t} *$ IndLeader ${ }_{t}$ & Interaction of IndLeader_Fee and $C F O_{t .}$ & Compustat \\
\hline \multicolumn{3}{|c|}{ Cross-Sectional Measures } \\
\hline Dopuch AGP & $\begin{array}{l}\text { The average of the normalized rank (ranked such that all values lie } \\
\text { between } 0 \text { and } 1 \text { ) of the within-industry standard deviation of profit } \\
\text { margin, receivable turnover, payable turnover, and inventory } \\
\text { turnover. Profit margin is calculated as net profit (IB) divided by } \\
\text { sales. Receivable turnover is calculated as average accounts } \\
\text { receivable (RECT) divided by sales. Payable turnover is calculated as } \\
\text { average accounts payable (APT) divided sales multiplied by one } \\
\text { minus profit margin. Inventory turnover is calculated as g divided by } \\
\text { one minis profit margin, where g is the coefficient on sales of a } \\
\text { regression of inventory on sales and the change in sales, estimated by } \\
\text { firm on the previous } 10 \text { years of data. }\end{array}$ & Compustat \\
\hline Pct_FLC_ILC & $\begin{array}{l}\text { The percentage of firms in an industry and year for which the firm } \\
\text { life cycle stage is equal to the life cycle stage of the industry. }\end{array}$ & Compustat \\
\hline LC_Align & $\begin{array}{l}\text { An indicator variable that is equal to one if the life cycle stage of the } \\
\text { firm is equal to the life cycle stage of the industry, zero otherwise. }\end{array}$ & Compustat \\
\hline Return_Synch & $\begin{array}{l}\text { The natural logarithm of the R-Squared of a regression of daily firm } \\
\text { returns on equal-weighted market returns and an equal-weighted } \\
\text { industry index. A daily Equal-weighted industry return index is } \\
\text { calculated as the average return of all firms in an industry and day. }\end{array}$ & CRSP \\
\hline IdioRisk & $\begin{array}{l}\text { Idiosyncratic risk, calculated as the standard deviation of the residuals } \\
\text { from a regression of daily returns on equal-weighted market returns } \\
\text { and an equal-weighted index of industry returns, calculated for every } \\
\text { firm-year. }\end{array}$ & CRSP \\
\hline Ind_StdACC & $\begin{array}{l}\text { The standard deviation in } A C C \text { in an industry (two-digit SIC) and } \\
\text { fiscal year. }\end{array}$ & Compustat \\
\hline
\end{tabular}




\begin{tabular}{|c|c|c|}
\hline Variable & Description & Source \\
\hline Ind_StdCFO & $\begin{array}{l}\text { The standard deviation in } C F O \text { in an industry (two-digit SIC) and } \\
\text { fiscal year. }\end{array}$ & Compustat \\
\hline Ind_StdROA & $\begin{array}{l}\text { The standard deviation in } R O A \text { in an industry (two-digit SIC) and } \\
\text { fiscal year. }\end{array}$ & Compustat \\
\hline Ratio & $\begin{array}{l}\text { Measure of industry-wide earnings smoothing calculated as } \\
\text { Ind_StdROA divided by Ind_StdCFO. }\end{array}$ & Compustat \\
\hline \multicolumn{3}{|c|}{ Other Variables } \\
\hline$R O A$ & $\begin{array}{l}\text { Income before extraordinary items (IB) divided by average total } \\
\text { assets (AT). }\end{array}$ & Compustat \\
\hline Loss & $\begin{array}{l}\text { Indicator variable that is equal to one if income before extraordinary } \\
\text { items (IB) is negative, zero otherwise. }\end{array}$ & Compustat \\
\hline Segments & The natural logarithm of one plus the number of business segments. & Compustat \\
\hline Growth & The percentage change in sales [(SALE/lag SALE ) -1]. & Compustat \\
\hline Risk & $\begin{array}{l}\text { Inventory plus accounts receivable divided by total assets } \\
\text { [(INVT+RECT)/AT]. }\end{array}$ & Compustat \\
\hline Leverage & Total Debt (DLTT + DLC) divided by total assets. & Compustat \\
\hline Size & The natural logarithm of total assets. & Compustat \\
\hline LnSale & The natural logarithm of total sales. & Compustat \\
\hline$B T M$ & Book-to-Market ratio [CEQ / $\left.\left(\mathrm{PRCC} \_\mathrm{F} * \mathrm{CSHO}\right)\right]$. & Compustat \\
\hline Tobins $Q$ & $\left.\left(\mathrm{PRCC} \_\mathrm{F} * \mathrm{CSHO}\right)+\mathrm{PSTK}+\mathrm{DLC}+\mathrm{DLTT}\right) / \mathrm{AT}$. & Compustat \\
\hline Return & Market-adjusted returns over the fiscal year. & CRSP \\
\hline$B i g N$ & $\begin{array}{l}\text { An indicator variable that is equal to one if the firm is audited by a } \\
\text { Big N audit firm. }\end{array}$ & $\mathrm{AA}^{*}$ \\
\hline Tenure & $\begin{array}{l}\text { The number of years the firm has been an audit client of the audit } \\
\text { firm. }\end{array}$ & $\mathrm{AA}^{*}$ \\
\hline Opinion & $\begin{array}{l}\text { An indicator variable that is equal to one if the auditor has issued a } \\
\text { going-concern opinion, zero otherwise }\end{array}$ & $\mathrm{AA}^{*}$ \\
\hline Audit_Lag & $\begin{array}{l}\text { Natural logarithm of the number of calendar days between the end of } \\
\text { the fiscal year and the signature date in the audit report }\end{array}$ & $\mathrm{AA}^{*}$ \\
\hline
\end{tabular}

* AA = Audit Analytics 


\section{Appendix 2B - Entropy Balancing}

Many studies in the accounting and finance literature rely on propensity score matching to achieve covariate balance and address issues such as functional form misspecification. However, as discussed in Shipman et al. (2016) there are several limitations associated with the use of propensity score matching techniques. These relate to the sensitivity of the estimates to researcher-made design choices and the usual loss of observations which reduces the power of the tests, increases the risk of Type 2 errors, and limits the external validity of the observed treatment effects. Hainmueller (2012) introduces entropy balancing as a generalization of commonly used matching approaches that overcomes many of these limitations and that has several benefits over the use of traditional propensity score matching techniques. Entropy balancing has gained increased traction, with recent studies applying entropy balancing techniques in accounting as well. For example, McMullin and Schonberger (2018) use entropy balancing to adjust for inherent accrual determinants and obtain better estimates of discretionary accruals.

Whereas propensity score matching (PSM) techniques aim to create covariance balance by first estimating a model that predicts treatment and then matching observations based on the closest propensity score, entropy balancing does not rely on treatment models. In contrast entropy balancing directly uses the information that is available about the sample moments and the balance constraints imposed on them. Specifically, after specifying the sample moments to balance (mean, variance, and skewness), the set of variables on which to achieve covariate balance (i.e., the predictors of treatment in the PSM specification), and the tolerance level (the maximum difference in any variable across treated and untreated observations), the entropy balancing algorithm will reweigh the sample to create covariate balance on the moments that were specified and within the maximum tolerance level. As such, an important difference between the two approaches is that whereas with propensity score matching observations are either included (weight equal to one) or completely discarded (weight equal to zero), entropy balanced weights are continuous and can be less than unity.

The fact that the original base weights form the starting point from which the adjusted weights are calculated and the greater flexibility in determining the adjusted weights (1) results in a lower risk of remaining covariate imbalances, (2) ensures that one can achieve covariate balance on variance and skewness as well, and (3) makes the observed treatment effects less sensitive to small changes in the research design. Moreover, by keeping a greater number of observations in the reweighted sample, efficiency is increased and subsequent testing is less likely to suffer from a lack of power, thereby increasing the external validity of the treatment effects measured. 




\title{
3. RELEVANCE OF DIFFERENTIAL PERSISTENCE OF EARNINGS COMPONENTS IN THE PRICING OF MERGERS AND ACQUISITIONS
}

\begin{abstract}
$^{20}$
This study examines the valuation role of the differential persistence of earnings in mergers and acquisitions. Specifically, I investigate to what extent differences in the persistence of disaggregate earnings components are considered in deal values. I find that, relative to equity investors, acquirers place significantly larger weights on (less persistent) accrual components than on cash flow components. This suggests that the components' perceived informativeness about future firm value is not in line with their general persistence levels. Cross-sectional tests show that the relative greater weights on accruals are concentrated in subsets of deals with non-common auditors, high accounting quality targets, targets benefiting from highly persistent industry earnings, and for diversifying transactions. Furthermore, I find a significantly higher overall importance of earnings in transactions with non-common auditors, high accounting quality targets, and targets with a high industry earnings persistence, but not in diversifying deals. My study adds to the understanding of valuation in the merger market and provides evidence on the relevance of the differential persistence of earnings components in the pricing of mergers and acquisitions.
\end{abstract}

\footnotetext{
${ }^{20}$ Acknowledgements: I would like to thank Peter Easton for his helpful comments and suggestions.
} 


\subsection{Introduction}

This paper examines the relevance of differences in the persistence of earnings components in the pricing of mergers and acquisitions (M\&As). M\&A transactions are significant corporate investments with wide-ranging (financial) implications for shareholders, (executive) employees and the markets acquirers and targets operate in (Martin and Shalev 2017). Though on average mergers may create value, not all transactions are successful. Mispricing of target firms can lead to acquirers incurring negative returns around the announcement period (e.g., Han et al. 1998) or a negative longrun post-acquisition performance (e.g., Campa and Hajbaba 2016). Acquirers often misprice targets and overpay for them, causing a wealth transfer from acquirer to target shareholders (Moeller et al. 2005). As this provides a strong incentive for acquiring firms to properly value and accurately price targets, a substantial body of literature analyses (determinants of) bid prices. For example, overpayment has been found to be related to, amongst others, merger waves, bid competition and target earnings management at the time of the transaction (e.g., Black 1989; Campa and Hajbaba 2016; McNichols and Stubben 2015; Moeller et al. 2005; Rabier 2018; Rhodes-Kropf et al. 2005). Prior literature has also related targets' accounting quality to bid prices (e.g., McNichols and Stubben 2015; Raman et al. 2013; Skaife and Wangerin 2013), while Rabier (2018) examines the relative valuation roles of aggregate earnings and book value of equity in merger pricing. Together, this body of research suggests that accounting information plays a fundamental role in target valuation.

In general, deal prices are based on future firm value and reflect the present value of the expected future payoffs to the acquirer. Burgstahler and Dichev (1997) argue that firm value is a function of earnings and book value of equity. Prior literature on valuation in both the capital and merger market, respectively, suggests that when current operations and the accompanying earnings stream are expected to persist (change) in the future, investors perceive earnings to be relatively more (less) informative about future firm performance than book value of equity, as indicated by larger (smaller) implicit weights in both stock prices and M\&A deal values (Burgstahler and Dichev 1997; Rabier 2018).

Besides these two studies, where variation in aggregate earnings persistence stems from acquirer intent or market expectations, research in the capital market setting has shown that disaggregate earnings components themselves also vary in persistence. For example, cash flows are shown to be more persistent than accruals (Sloan 1996), and industry-wide earnings components vary less than firm-specific earnings components (Hui et al. 2016). However, both studies find that capital market investors fixate on aggregate earnings and fail to incorporate the differential persistence of disaggregate earnings components into stock prices (Hui et al. 2016; Sloan 1996). Thus, investors seem to recognize when aggregate earnings are relatively more (or relatively less) important than book value of equity and attach weights accordingly (Burgstahler and Dichev 1997), but misprice earnings by not recognizing differences in persistence levels of disaggregate earnings components (Hui et al. 2016; Sloan 1996). 
In this study, I focus on the merger market and explore whether variation in the persistence of disaggregate earnings components is incorporated by acquirers during their target valuation process and priced accordingly. It is not clear whether and how findings on the capital market transfer to the merger market. The capital market reflects perceptions of all investors jointly, which results in an average stock price, whereas the M\&A deal price reflects a judgement call of an individual acquirer. The valuation role of earnings components in M\&A transactions may differ, for example, due to acquirer's strategic considerations and expected synergies. However, how this impacts the importance of individual earnings components is unclear ex ante. I provide three potential arguments. First, like capital market investors, acquirers may not recognize the persistence differences in disaggregate earnings and value firms similar to the market. Second, more detailed and in-depth analyses during the due diligence could provide acquirers with more precise forecasts and thus enable them to better incorporate information contained in disaggregate earnings components. To the extent that acquirers perceive more persistent components as more informative about future firm value and reflect this in their valuation, they may price disaggregate earnings according to their persistence levels. Third, however, it may also be the case that while acquirers have an understanding of persistence differences, it is of little interest to them and they deliberately attach greater weights to (potentially less persistent) components that they perceive as more informative about future firm value. Ultimately, whether acquirers consider how current earnings map into future performance and price components according to their persistence levels is an empirical question that I investigate in this study.

I begin my analyses by exploring the weighting of disaggregate accounting components in M\&A deal values for a sample of 2,313 completed transactions involving U.S. public acquirers and targets over a period from 1992 to 2014 . Only transactions in which the acquirer holds less than 50 percent of the target before the deal announcement and 100 percent after deal completion are included. I further restrict the sample to profit-generating firms. ${ }^{21}$ Furthermore, I use capital market pricing as benchmark for M\&A pricing. After controlling for the weights capital market participants place on financial accounting variables, I regress the M\&A price on a target's pre-acquisition cash flows, accruals, and book value of equity. Results show that, compared to capital market investors, acquirers place a significantly larger weight on accruals than on cash flows. In addition, after decomposing cash flows and accruals in an industry-wide and firm-specific component, I find that acquirers place a relatively low weight on industry-wide cash flows - the most persistent component - and place a relatively high weight on firm-specific accruals - the least persistent component. Together, these results suggest that acquirers perceive accruals as relatively more informative for estimating future firm performance, and additionally do not exploit the informational value of common earnings driven by industry dynamics.

\footnotetext{
${ }^{21}$ Prior literature shows that earnings of loss-making firms are less persistent and informative about future performance (Hayn 1995). This decreases the usability of earnings-based valuation models when valuing loss firms (Joos and Plesko 2005). As other information will be more leading in determining a bid price, including loss firms in my sample would bias the results.
} 
Next, I run cross-sectional tests to investigate conditions under which the use of persistence differences in M\&A pricing may be moderated by variation in information asymmetry. In these tests, information asymmetry differs either due to the information available to acquirers or due to the quality of accounting information itself. First, I examine the relevance of the differential persistence of earnings conditional on acquirers and targets sharing the same auditor. Prior literature has shown that common auditors act as information intermediaries and as a result affect the overall transaction price (Cai et al. 2016; Dhaliwal et al. 2016). However, these studies do not address the question whether the overall M\&A price is affected through different weighting of individual earnings components, or whether common auditors add value on a more strategic level, which would decrease the overall importance of earnings in the presence of common auditors. Results indicate that earnings become overall less important when common auditors are present in an M\&A transaction. I also no longer observe a significant difference between cash flows and accruals in the basic regression. For the decomposed model, I do observe that firm-specific accruals carry a significantly lower weight. This suggests that persistence of disaggregate earnings components is partially considered when auditors are shared in M\&A transactions. However, accounting information is of lesser overall importance when common auditors are present. Together, these results suggest that more accurate pricing - in terms of persistence - is likely not the main mechanism by which common auditors influence M\&A pricing. They are more likely to add value through strategic information transfers that directly affect the valuation of a target, making current earnings less important in setting a bid price.

The second cross-sectional test I run investigates the relevance of differences in earnings persistence conditional on targets having a high or low overall accounting quality. Prior research shows that acquirers generally incorporate a target's overall level of earnings quality in their transaction price (e.g., McNichols and Stubben 2015; Raman et al. 2013). ${ }^{22}$ Higher quality information results in lower information asymmetry, enabling acquirers to value targets more precisely (McNichols and Stubben 2015). I examine whether the increased precision only affects the overall acquisition price, or whether it also leads to a shift in implicit weights on individual earnings components. Results show that the general importance of earnings (book value of equity) in M\&A pricing is significantly larger (smaller) for high accounting quality targets. Additionally, when earnings quality is high, significantly more weight is placed on accruals compared to cash flows. Stated differently, acquirers only perceive accruals as more informative about future performance when the target firm has a higher level of accounting quality.

Next, I examine whether and how cross-sectional variation in the persistence of total industry earnings affects the relevance of earnings components in M\&A pricing. Highly persistent industry earnings reflect a relatively stable environment and/or benefit from more recurring cash flows, which may affect the perceived informativeness of earnings components due to lower information asymmetry. Results show that current cash flows and accruals are relatively more important for

${ }^{22}$ I use accounting quality and earnings quality interchangeably throughout this study. 
M\&A pricing when targets operate in a rather stable industry, whereas the importance of book value of equity is not significantly affected. Furthermore, the perceived superior informativeness of accruals is concentrated in the subset of deals with highly persistent industry earnings. In sum, these results suggest that next to forward-looking earnings persistence due to strategic intent (Rabier 2018), acquirers also consider the persistence of historical industry earnings during their target valuation process. They value current earnings, and accruals in particular, as more informative when the operating environment is relatively stable.

Last, I explore the relative role of earnings components in M\&A pricing conditional on deals being (non-)diversifying. In diversifying transactions, acquirers likely lack experience and insider knowledge about the target's industry, which may result in greater information asymmetry. Given the informational disadvantage, I expect acquirers to rely more on publicly available accounting information during inter-industry transactions. Results show, however, that although cash flows and accruals do receive slightly greater weights, their weights and thus overall importance are not significantly different between the two subsamples. A potential reason could be that in diversifying deals, acquirers consult additional information intermediaries to decrease information asymmetry. Note that book value of equity does play a significantly larger role in diversifying deals. This is consistent with book value of equity being a relatively 'safe' valuation input if information asymmetry is higher, as it reflects the value of the resources currently in place. Finally, with respect to the relative valuation roles of cash flows and accruals, results show that the perceived superior informativeness of accruals is driven by diversifying deals.

Overall, results of the cross-sectional tests provide additional insights and indicate that acquiring firms rationally act on settings where earnings and its components are relatively more (or less) useful in determining bid prices. Especially the test on industry earnings persistence indicates that acquirers are aware of the impact industry fundamentals can have on the persistence of earnings and (at least partially) incorporate this into bid prices. Yet, acquirers do not incorporate all fundamentals-driven persistence differences, as they do not price industry-wide and firm-specific cash flows and accruals according to their persistence levels. As such, acquirers seem to (rationally) make alternative valuation choices based on the perceived informativeness of disaggregate earnings components, rather than considering their general persistence levels. Based on these findings, I conclude that while acquirers do understand general differences in persistence, variation in the persistence of disaggregate earnings components is not relevant in the pricing of mergers and acquisitions.

This paper contributes to a growing body of literature on the role of publicly available accounting information in M\&A pricing. Several studies link aggregate accounting fundamentals and overall target information quality to M\&A pricing and outcomes (e.g., Marquardt and Zur 2015; McNichols and Stubben 2015; Rabier 2018; Raman et al. 2013; Skaife and Wangerin 2013). This study extends this literature by exploiting the variation in persistence within accounting fundamentals and shows to what extent it is considered in target pricing. I show that acquirers (rationally) price earnings components according to its perceived informativeness, rather than their 
general persistence levels. Evidence should be of interest to accountants in academia and practice, as it broadens our understanding of the relevance of disaggregate accounting fundamentals in target valuation.

The remainder of the paper is organized as follows: Section 3.2 provides background information and develops the main hypothesis. Section 3.3 discusses the research design and the sample. Results are presented and discussed in section 3.4. Finally, section 3.5 concludes.

\subsection{Background and Hypothesis Development}

In general, investors price firms based on their expectations of future firm value. In the capital market, for example, a firm's market value of equity reflects investors' expectations of future cash flows. Likewise, in M\&A transactions, firm value is expressed through a deal price that captures the value of expected future payoffs to the acquirer. The following subsections describe to what extent equity investors as well as acquirers utilize and value more and less persistent accounting information in estimating a firm's value.

\subsubsection{Equity Valuation and the Persistence of Accounting Information}

Burgstahler and Dichev (1997) underline the importance of accounting information for equity valuation and argue that firm value is a function of both earnings and book value of equity. ${ }^{23}$ Specifically, a firm's earnings stream is informative about the current use of available resources, while its book value of equity specifies the value of those resources, independent of their use. They show that the relative importance in the market, as indicated by the implicit weights on earnings and book value in stock prices, varies with the level of expected adaptation. If current operations, and hence also the accompanying earnings stream, are expected to persist, stock prices show a relatively larger weight on earnings than on book value of equity, and vice versa. In short, investors seem to incorporate the (expected) persistence of aggregate earnings and book value of equity into stock prices.

Disaggregate earnings components themselves also vary in persistence. Generally, studies use cross-sectional forecasting models to examine persistence differences (e.g., Dechow et al. 2008; Nissim and Penman 2001; Richardson et al. 2005; Sloan 1996), while Call et al. (2016) examine firm-specific estimates of differential persistence. In a seminal paper on this topic, Sloan (1996) shows that the cash flow component is more persistent than the accrual component, yet capital market investors fixate on aggregate earnings and fail to incorporate the differential persistence of cash flows and accruals into stock prices. Hui et al. (2016) further decompose these two earnings components and argue that the level of persistence depends on the earnings component reflecting industry fundamentals or firm-specific information. More specifically, industry-wide accruals and cash flows capture long-term industry-wide trends and economy-wide forces such as broad consumer preferences and production technologies, whereas firm-specific accruals and cash flows

\footnotetext{
${ }^{23}$ In this study, 'equity valuation' refers to equity valuation in the capital market.
} 
represent individual firms' deviations from such industry norms (Ayers and Freeman 1997; Brown and Ball 1967; Hui and Yeung 2013). These deviations are shorter lived as competitive forces induce performance to revert to the industry mean relatively quickly (e.g., Mueller 1977; Waring 1996). Consistently, Hui et al. (2016) predict and find that industry-wide earnings components are more persistent. Given their underlying assumption that persistence proxies for earnings quality, and to the extent that greater persistence yields greater predictive value, industry-wide components should receive a larger weight in the pricing of earnings. Their findings, however, show that the market does not fully incorporate the differential persistence levels in stock prices and thus misprices earnings. Industry-wide cash flows, the most persistent component, are underweighted, while firmspecific accruals, the least persistent, are overweighted.

Collectively, these results suggest that investors recognize when aggregate earnings are relatively more (or less) important than book value and attach weights accordingly (Burgstahler and Dichev 1997), while they fail to price the differential persistence of individual earnings components (Hui et al. 2016; Sloan 1996).

\subsubsection{Role of Accounting Information and its Persistence in M\&A Pricing}

Generally, in an M\&A transaction, information on firm fundamentals is translated into a price that reflects the present value of a target firm's expected future payoffs to the acquirer. The price paid consists of a stand-alone part, reflecting the value of the target based on its current infrastructure, and a markup reflecting additional value due to strategic intent, such as expected synergies. As is the case for equity valuation, prior research in the M\&A setting suggests that accounting information forms the basis to determine bid prices (e.g., Marquardt and Zur 2015; McNichols and Stubben 2015; Raman et al. 2013; Skaife and Wangerin 2013). ${ }^{24}$ Rabier (2018) examines the theoretical predictions of Burgstahler and Dichev (1997) in the merger market and finds a decreasing (increasing) relative importance of targets' earnings (book values) as determinant of bid prices when current earnings are less likely to persist due to expected after-deal restructuring (i.e., adaptation) at the target firm. These results thus suggest that acquirers consider the persistence of the aggregate earnings stream in determining bid prices.

In this study, I examine the role of within-earnings variation in persistence in target pricing relative to equity valuation. While prior literature provides evidence that capital market investors do not fully exploit the differential persistence of disaggregated earnings components, it is not clear whether and how these findings transfer to the merger market, and thus, whether acquirers also fail to price individual earnings components according to their persistence levels. The merger market is different in various ways. For example, stock prices reflect the behavior of all market participants, resulting in an average price, whereas in the M\&A setting, transaction prices reflect judgements made by individual acquiring firms. Additionally, acquirers incur a larger investment risk than

\footnotetext{
24 The importance of accounting information for firm valuation is also reflected by the fact that current and future predicted earnings are main input variables in several widely used valuation models, such as the discounted cash flow (DCF) model and the residual income model.
} 
investors. ${ }^{25}$ As there is no consensus on whether deals on average create or destroy value (e.g., Andrade et al. 2001; Berger and Ofek 1995; Moeller et al. 2005), this provides incentives for acquirers to perform proper valuations by incorporating all decision-useful information into bid prices. Furthermore, research has shown that for a single target firm, bid prices from various acquirers can diverge due to differences in expected synergies and other strategic arguments per target-acquirer combination (e.g., Gupta and Gerchak 2002). As such, strategic intent and expected synergies potentially affect the valuation role of disaggregate earnings. ${ }^{26,27}$

It is ex ante unclear how these merger market characteristics impact the importance of individual earnings components in target pricing. I provide three potential arguments. First, similar to capital market investors, acquiring firms may not recognize the persistence differences in disaggregate earnings components and price firms in a similar way as the market. Second, given the investment risk, acquirers have an incentive to analyze fundamentals at a more disaggregate level. More detailed and in-depth analyses as part of the due diligence process should result in more precisely forecasted numbers, and thus enable acquirers to better incorporate information contained in disaggregate earnings components. ${ }^{28}$ To the extent that acquirers perceive more persistent components as more informative about future firm value and incorporate this in their valuation, bid prices, relative to stock prices, better reflect the differential persistence levels of earnings components. And third, even in the case that acquirers have an understanding of the differential persistence, they may rationally make alternative valuation choices and attach greater weights to (potentially less persistent) components that they perceive as more informative about future firm value. ${ }^{29}$ For example, accruals hold two relative roles, i.e., investment in firm growth or timing adjustment for cash flows (Bushman et al. 2011; Hribar and Yehuda 2015). Acquirers may place a relatively greater weight on targets' accruals, especially when those largely reflect investments in growth. These accrual components may be interpreted as more informative as they contain relevant forward-looking information and, in case of a good fit with the acquirer's strategic intent and expected synergies, may then also become relatively more important determinants of bid prices. Given that equity investors fixate on aggregate earnings, and acquirers potentially value

\footnotetext{
${ }^{25}$ The downside risk for investors is limited to their own investment in a firm, whereas acquirers' investment risk further increases once they obtain control over a target firm.

${ }^{26}$ For example, if a deal is of such strategic importance to the acquiring firm, proper valuation of disaggregate earnings - in terms of persistence - may become of secondary importance. Also, the overall importance of current earnings may decrease if a large part of the estimated target value originates from future growth or identified strategies.

${ }^{27}$ Here, the question arises to what extent share prices may already reflect expected synergies to be paid to target shareholders of a potential deal - in case capital market investors can predict which firms will be acquired. Given this possibility, it is unclear how M\&A pricing differs from market pricing.

${ }_{28}$ More specifically, more thorough analyses should enable acquirers to place relatively greater weights on more persistent components.

${ }^{29}$ To the extent that acquirers' 'average base case' about targets' future performance reflects a relatively stable and/or homogeneous environment, persistence can be treated as a quality attribute such that more persistent earnings are interpreted as being more informative about future performance (e.g., Hui et al. 2016). Whether acquirers indeed recognize within-earnings differences in persistence as a quality attribute and weigh earnings components accordingly remains an open question that will be examined in this paper.
} 
disaggregate accruals when the perceived information content is large, bid prices would then show relatively larger weights on (less persistent) accrual components than in stock prices.

Whether acquirers understand and incorporate the extent to which current earnings map into future performance and price components according to persistence levels remains an empirical question that I investigate in this study. Nevertheless, given the merger market characteristics and acquirers' incentives, I do not expect the first argument to hold and thus expect acquirers to value disaggregate earnings components differently than the market. This implies that even though both acquirers and capital market investors value aggregate earnings and book value similarly depending on expected adaptation (Burgstahler and Dichev 1997; Rabier 2018), I do not expect acquirers to price disaggregate earnings components similarly as the market. As I expect M\&A pricing to differ from equity valuation, the second and third arguments lead me to formulate the following hypothesis in alternative form:

H: Bid prices show a different relative weighting of disaggregate earnings components than stock prices.

\subsection{Research Design}

\subsubsection{Sample Selection}

I obtain my sample of M\&A transactions from the Securities Data Corporation's (SDC) Mergers and Acquisitions Database. The sample comprises all completed M\&A transactions involving U.S. public acquirers and targets with announcement dates between 1992 and 2014. I require matching data from Compustat and CRSP to calculate the variables of interest. Following previous literature, smaller deals with a transaction value of less than $\$ 5$ million and/or less than 1 percent of the acquirer's market capitalization are excluded. Furthermore, I only include transactions where the acquirer holds less than 50 percent of the target before the deal announcement and 100 percent after deal completion. Since the pricing of firms that incur losses is likely different, I delete loss-making firms from the sample. This yields a final sample of 2,313 successfully completed acquisitions.

\subsubsection{M\&A Pricing}

Hui et al. (2016) show that investors fail to see through the differential persistence of earnings components and consequently misprice earnings by undervaluing industry-wide cash flows and overvaluing firm-specific accruals. To investigate the role of within-earnings variation in persistence in target valuation, I analyze how acquirers price targets compared to how equity investors value them. Specifically, I use the market pricing model as a baseline, from which deviations in M\&A pricing are analyzed. ${ }^{30}$ This allows for a direct examination whether there are significant weighting

\footnotetext{
${ }^{30}$ A firm's market value of equity generally serves as the lower boundary of what should be paid for the target in an M\&A transaction. The sample also shows that earnings components map into M\&A prices more often than in the market value of equity, attributable to the higher overall price paid in a transaction. The question, however, is whether deal
} 
differences compared to market pricing. First, to examine the weights placed on individual earnings components by investors, i.e., the benchmark, I estimate the following Ohlson model (1995) per year:

$\operatorname{PRICE}_{i}=\alpha_{0}+\alpha_{1} C F O_{i}+\alpha_{2} A C C_{i}+\alpha_{3} B V E_{i}+\varepsilon$

PRICE is the price per share two months prior to the deal announcement. ${ }^{31}$ Operating cash flows (CFO) are measured as net cash flows from operating activities scaled by the number of shares outstanding two months before the deal announcement. Following Hribar and Collins (2002), accruals $(A C C)$ are measured from the cash flow statement as the difference between earnings (income before extraordinary items) and operating cash flows, and book value of equity ( $B V E$ ) represents the difference between total assets and total liabilities. Both $A C C$ and $B V E$ are also scaled by the number of outstanding shares two months prior to the deal announcement. By looking at the implicit weights, the Ohlson model above shows how earnings components and the book value of equity map into the stock price. As a next step, I extract the predicted coefficients from the yearly market pricing regressions and multiply the variables of interest with these coefficients to create the weighted input variables for the following M\&A pricing model: ${ }^{32}$

$D_{V A L U E} E_{i, t}=\beta_{0}+\beta_{1} C F O_{i, t}+\beta_{2} A C C_{i, t}+\beta_{3} B V E_{i, t}+\varepsilon$

Deal value (DVALUE) represents the initial offer price per share in a transaction. Though accounting information plays an important role throughout all stages of M\&A pricing, it is especially valuable in early due diligence stages where private information is still limited (Lajoux and Elson 2000). Accordingly, early or initial bid prices are based on an information set that is most comparable to the information available to capital market investors, enabling a meaningful comparison of the valuation role of the differential persistence of earnings in target pricing and equity valuation. The variables of interest, $C F O, A C C$ and $B V E$ are defined as before, except that they are now multiplied by the coefficients from the market pricing regression.

To analyze the role of within-earnings variation in persistence in more detail, I further partition accruals and cash flows into an industry-wide and firm-specific component. I follow Hui et al. (2016) and decompose $C F O$ and $A C C$ as follows: assuming $N$ firms in industry $j$, the industrywide $C F O$ component of industry $j$ in year $t$ is defined as

\footnotetext{
values reflect a systematic different mapping of earnings components into M\&A prices. As such, analyzing the weights on earnings components in market prices provides a meaningful starting point to investigate whether acquirers assign significantly different weights to earnings components.

${ }^{31}$ Following Cai and Sevilir (2012), I scale the variables by the number of shares outstanding two months prior to the deal announcement. Schwert (1996) documents that on average, target share prices start to increase around two months before the first bid announcement. Hence, a period of two months before the deal is announced seems reasonable to assume a market price that is not yet impacted by investor anticipation or information leakage on the upcoming deal.

${ }^{32}$ Since the market pricing regressions are run per year and the input variables for the M\&A regression are therefore already corrected for year effects, no (additional) year fixed effects are added to the M\&A regression.
} 
$\operatorname{IndCFO}_{j, t}=1 / N \sum_{i=1}^{N} C F O_{i, j, t}$

Where IndCFO represents the average cash flows for all firms in the industry, based on sixdigit GICS codes. The firm-specific cash flows of firm $i$ in industry $j$ and year $t$ is defined as:

$\operatorname{FirmCFO}_{i, j, t}=\mathrm{CFO}_{i, j, t}-\operatorname{IndCFO}_{j, t}$

Where Firm CFO is the difference between a firm's total cash flows $(C F O)$ and the industry average cash flows (IndCFO). I apply the same approach to calculate industry-wide and firmspecific accruals by substituting $C F O$ in (2a) and (2b) with $A C C$, and obtain industry-wide and firmspecific accrual components, so that $A C C=\operatorname{Ind} A C C+$ Firm $A C C$. I then estimate the market pricing model per year with these decomposed earnings variables to obtain new baseline coefficients, multiply the decomposed variables of interest with the predicted market weights and estimate the following M\&A pricing model:

$\operatorname{DVALUE}_{i, t}=\beta_{0}+\beta_{1} \operatorname{IndCFO}_{i, t}+\beta_{2}$ FirmCFO $_{i, t}+\beta_{3} \operatorname{IndACC}_{i, t}+\beta_{4} \operatorname{FirmACC}_{i, t}+\beta_{5} B V E_{i, t}+\varepsilon(3)$

From the M\&A pricing models (1) and (3), I can directly analyze whether and how the pricing of targets differs for acquirers compared to regular investors, as the input variables already control for differences in weights placed on earnings and $B V E$ by the market. Given the diverging arguments outlined earlier it is not clear to what extent acquirers consider the differential persistence of earnings components and price them accordingly. If acquirers price earnings and $B V E$ similarly as the market, I expect coefficients greater than one (assuming a higher overall transaction value compared to $M V E$ ), but no significant differences among the earnings coefficients. ${ }^{33}$ If acquirers price financial information more accurately in terms of persistence, I expect significantly greater weights to be placed on industry-wide cash flows, the most persistent component, and significantly lower weights on firm-specific accruals, the least persistent component. However, if acquirers perceive accruals to be highly informative, I expect bid prices to show relatively larger weights on (less persistent) accrual components.

\footnotetext{
${ }^{33}$ Theoretically, coefficients equal to one would render the exact same pricing by acquirers compared to the market, both in levels and weighting. This implies that acquirers weigh individual earnings components in the same way as investors. As a firm's market value of equity generally serves as the lower boundary of what should be paid for a target, I expect deal values to be larger than the firms' market value of equity. This larger deal value is then reflected by the constant, as well as coefficients on the weighted input variables greater than one.
} 


\subsection{Results}

\subsubsection{Descriptive Statistics}

Summary statistics are reported in Table 3.1, Panel A. As expected, the average price in an M\&A transaction ( $\$ 29.63$ per share) is larger than the average market price ( $\$ 22.33$ per share). On average, cash flows (per share) are positive (2.34) and accruals are negative (-1.00), consistent with prior research (Hui et al. 2016). Compared to IndCFO and IndACC, the standard deviations for FirmCFO and FirmACC are somewhat larger. This is consistent with prior literature and shows that the firmspecific components are more volatile than the industry-wide components. $27.6 \%$ of the transactions deal with common auditors, consistent with prior literature (Cai et al. 2016). When using three-digit historical SIC codes, $50.1 \%$ of the deals are diversifying, compared to $36.3 \%$ when based on twodigit SIC (untabulated).

TABLE 3.1

Descriptive Statistics

\begin{tabular}{|c|c|c|c|c|c|c|c|c|c|}
\hline \multicolumn{10}{|c|}{ Panel A: Summary Statistics } \\
\hline \multicolumn{2}{|l|}{ PRICE } & \multicolumn{2}{|c|}{2315} & 22.330 & 17.158 & \multicolumn{2}{|c|}{10.063} & 17.800 & 29.100 \\
\hline \multicolumn{2}{|l|}{$D V A L U E$} & \multicolumn{2}{|c|}{2315} & 29.628 & 22.866 & \multicolumn{2}{|c|}{13.800} & 23.510 & 38.610 \\
\hline $\mathrm{CFO}$ & & \multicolumn{2}{|c|}{2315} & 2.341 & 3.310 & \multicolumn{2}{|c|}{0.590} & 1.485 & 3.011 \\
\hline$A C C$ & & \multicolumn{2}{|c|}{2315} & -1.003 & 2.758 & \multicolumn{2}{|c|}{-1.467} & -0.523 & 0.026 \\
\hline IndCFO & & \multicolumn{2}{|c|}{2315} & 4.308 & 4.520 & \multicolumn{2}{|c|}{1.417} & 2.896 & 5.673 \\
\hline Firm $C F O$ & & \multicolumn{2}{|c|}{2315} & -1.967 & 4.847 & \multicolumn{2}{|c|}{-3.626} & -1.131 & 0.277 \\
\hline Ind $A C C$ & & \multicolumn{2}{|c|}{2315} & -2.384 & 2.631 & \multicolumn{2}{|c|}{-3.159} & -1.507 & -0.804 \\
\hline FirmACC & & \multicolumn{2}{|c|}{2315} & 1.381 & 3.389 & \multicolumn{2}{|c|}{0.137} & 0.968 & 2.480 \\
\hline$B V E$ & & \multicolumn{2}{|c|}{2315} & 11.820 & 11.387 & \multicolumn{2}{|c|}{4.767} & 8.718 & 14.946 \\
\hline$C A$ & & \multicolumn{2}{|c|}{2237} & 0.276 & 0.447 & \multicolumn{2}{|c|}{0.000} & 0.000 & 1.000 \\
\hline$a b s D A C$ & & \multicolumn{2}{|c|}{2051} & 0.056 & 0.068 & \multicolumn{2}{|c|}{0.013} & 0.034 & 0.071 \\
\hline IndPersiste & & \multicolumn{2}{|c|}{2315} & 0.761 & 0.152 & \multicolumn{2}{|c|}{0.696} & 0.803 & 0.863 \\
\hline Diversify & & \multicolumn{2}{|c|}{2307} & 0.501 & 0.500 & \multicolumn{2}{|c|}{0.000} & 1.000 & 1.000 \\
\hline Panel B: & Inti & & & & & & & & \\
\hline Variable & PRICE & DVALUE & $\mathrm{CFO}$ & $A C C$ & IndCFO & FirmCFO & Ind $A C C$ & FirmACC & $B V E$ \\
\hline PRICE & 1.000 & 0.933 & 0.476 & -0.289 & 0.148 & 0.187 & -0.111 & -0.150 & 0.488 \\
\hline DVALUE & 0.940 & 1.000 & 0.398 & -0.228 & 0.111 & 0.168 & -0.077 & -0.125 & 0.433 \\
\hline $\mathrm{CFO}$ & 0.555 & 0.513 & 1.000 & -0.885 & 0.264 & 0.437 & -0.246 & -0.529 & 0.627 \\
\hline$A C C$ & -0.316 & -0.290 & -0.835 & 1.000 & -0.204 & -0.414 & 0.210 & 0.651 & -0.463 \\
\hline IndCFO & 0.172 & 0.147 & 0.358 & -0.272 & 1.000 & -0.752 & -0.926 & 0.553 & 0.203 \\
\hline Firm $C F O$ & 0.219 & 0.211 & 0.338 & -0.310 & -0.667 & 1.000 & 0.695 & -0.877 & 0.239 \\
\hline Ind $A C C$ & -0.122 & -0.103 & -0.342 & 0.313 & -0.882 & 0.576 & 1.000 & -0.606 & -0.164 \\
\hline FirmACC & -0.147 & -0.140 & -0.364 & 0.479 & 0.527 & -0.849 & -0.560 & 1.000 & -0.250 \\
\hline$B V E$ & 0.571 & 0.524 & 0.597 & -0.394 & 0.283 & 0.167 & -0.225 & -0.143 & 1.000 \\
\hline
\end{tabular}

This table presents the descriptive statistics of the main variables. Panel A provides summary statistics and panel B shows the Pearson correlations among the main variables (all significant at the $1 \%$ level). The sample includes all firms with available data on the SDC M\&A Database, Compustat and CRSP from 1992 to 2014. Continuous variables are winsorized at the $1^{\text {st }}$ and $99^{\text {th }}$ percentile. All variables are defined in Appendix $3 \mathrm{~A}$. 
Table 3.1, Panel B, presents the Pearson (top) and Spearman (bottom) correlations. PRICE and DVALUE show a high correlation (0.93), which is (alongside their mean values) reflective of the market price serving as the lower boundary of what is usually paid for a target in an M\&A transaction. This also suggests that the market price is a good starting point to analyze subsequent deviations in the M\&A pricing model. As expected, $C F O$ and $A C C$ are negatively correlated.

\subsubsection{Main Results}

Table 3.2 presents the results for the basic and decomposed M\&A pricing model. As expected, all coefficients are larger than one, which reflects the higher M\&A price covering the earnings components and the BVE more often than the market. To analyze the relative importance of accounting components in M\&A pricing, I look at significant differences between the variables of interest. For the basic regression, I observe a significant difference between $C F O$ and $A C C$ (F = $5.022, \mathrm{p}=0.025$ ) with a higher weight placed on accruals. This suggests that acquirers perceive accruals as relatively more informative about future firm value than cash flows. Moreover, as the M\&A models control for market pricing and knowing that equity investors overweigh accruals relative to cash flows, results imply that acquirers place an even higher relative weight on accruals compared to equity investors. A potential explanation for the perceived superior informativeness of accruals relates to the observation that the role of accruals varies per firm life cycle stage. Hribar and Yehuda (2015) argue that accruals of growth firms largely reflect investments in firm growth, indicated by larger working capital and capitalization accruals, and thus offer considerable valuable forward-looking information. Descriptives on the main sample show that the largest group of target firms are growth firms $(41.51 \%)$, followed by mature firms $(40.08 \%){ }^{34}$ Hence, despite the lower persistence of accruals in general, the prevalence of growth targets may explain acquirers' focus on accruals as important determinant of M\&A prices. ${ }^{35}$

For the decomposed regression, pricing according to persistence levels would be indicated by higher implied weights for industry-wide cash flows and lower weights for firm-specific accruals. However, results show that the estimated coefficient for IndCFO is not significantly higher than the coefficients for the other variables of interest. As can be seen in Table 3.2, the lowest implied weight is attached to IndCFO (=1.195) and acquirers price both accrual components (IndACC and FirmACC) significantly more than IndCFO ( $\mathrm{F}=12.2, \mathrm{p}<0.001$; and $\mathrm{F}=3.318, \mathrm{p}=0.069$, respectively). Additionally, firm-specific accruals are not priced significantly less than its industrywide counterpart IndACC $(\mathrm{F}=0.113, \mathrm{p}=0.737)$. Together, results suggest that acquirers 'underreact' to industry-wide cash flows and 'overreact' to information captured by accruals. Yet, although they rely relatively more on industry-wide as well as firm-specific accruals, this test does

\footnotetext{
34 The cash flow based proxy by Dickinson (2011) is used to classify target firms into one of the five life cycle stages, being Introduction, Growth, Maturity, Shakeout, and Decline.

${ }^{35}$ Because firms can move across life cycle stages in a nonsequential manner and ideally maintain a position somewhere between the growth and mature stages (Dickinson 2011), accruals of mature firms are possibly also perceived as relatively more informative. Especially for target firms that switch between growth and maturity back and forth, acquirers may treat their accruals as highly informative and assign relative weights accordingly.
} 
TABLE 3.2 M\&A Pricing Regressions

\begin{tabular}{|c|c|c|}
\hline $\begin{array}{l}\text { Dependent Variable: Deal Value } \\
\text { Variables }\end{array}$ & BASIC & DECOMP \\
\hline Constant & $\begin{array}{l}15.79 * * * \\
(25.63)\end{array}$ & $\begin{array}{c}16.99 * * * \\
(26.17)\end{array}$ \\
\hline$C F O$ & $\begin{array}{c}1.196 * * * \\
(16.57)\end{array}$ & \\
\hline$A C C$ & $\begin{array}{c}1.285^{* * *} \\
(13.61)\end{array}$ & \\
\hline$B V E$ & $\begin{array}{c}1.173 * * * \\
(12.31)\end{array}$ & \\
\hline IndCFO & & $\begin{array}{c}1.195^{* * *} \\
(18.84)\end{array}$ \\
\hline FirmCFO & & $\begin{array}{c}1.226^{* * *} \\
(18.48)\end{array}$ \\
\hline Ind $A C C$ & & $\begin{array}{c}1.309^{* * *} \\
(16.60)\end{array}$ \\
\hline FirmACC & & $\begin{array}{c}1.290^{* * *} \\
(16.09)\end{array}$ \\
\hline$B V E$ & & $\begin{array}{c}1.211^{* * *} \\
(13.21)\end{array}$ \\
\hline Observations & 2,313 & 2,313 \\
\hline Adj. R-squared & 0.334 & 0.357 \\
\hline$C F O=A C C$ & $\begin{array}{c}5.022 \\
(p=0.025)\end{array}$ & \\
\hline$C F O=B V E$ & $\begin{array}{c}0.0317 \\
(\mathrm{p}=0.859)\end{array}$ & \\
\hline$A C C=B V E$ & $\begin{array}{c}0.625 \\
(p=0.429)\end{array}$ & \\
\hline IndCFO $=$ Firm $C F O$ & & $\begin{array}{c}0.856 \\
(p=0.355)\end{array}$ \\
\hline $\operatorname{Ind} C F O=\operatorname{In} d A C C$ & & $\begin{array}{c}12.2 \\
(p<0.001)\end{array}$ \\
\hline IndCFO $=$ Firm $A C C$ & & $\begin{array}{c}3.318 \\
(p=0.069)\end{array}$ \\
\hline Ind $C F O=B V E$ & & $\begin{array}{c}0.0208 \\
(\mathrm{p}=0.885)\end{array}$ \\
\hline Firm $C F O=$ IndACC & & $\begin{array}{c}2.583 \\
(\mathrm{p}=0.108)\end{array}$ \\
\hline Firm $C F O=$ Firm $A C C$ & & $\begin{array}{c}3.952 \\
(p=0.047)\end{array}$ \\
\hline Firm $C F O=B V E$ & & $\begin{array}{c}0.0158 \\
(p=0.900)\end{array}$ \\
\hline Ind $A C C=$ Firm $A C C$ & & $\begin{array}{c}0.113 \\
(\mathrm{p}=0.737)\end{array}$ \\
\hline Ind $A C C=B V E$ & & $\begin{array}{c}0.698 \\
(p=0.404)\end{array}$ \\
\hline Firm $A C C=B V E$ & & $\begin{array}{c}0.433 \\
(\mathrm{p}=0.511) \\
\end{array}$ \\
\hline
\end{tabular}

This table presents results of the basic and decomposed M\&A pricing model, which analyzes how, relative to equity valuations, earnings components and book value of equity map into M\&A prices. The sample includes all firm-year observations with matching data in SDC, Compustat and CRSP from 1992 to 2014. Continuous variables are winsorized at the $1^{\text {st }}$ and $99^{\text {th }}$ percentile. T-statistics and p-values are based on standard errors clustered at the acquirer level. T-statistics are reported in parentheses below the coefficients. *** indicate statistical significance at the $1 \%$ level (two-tailed). Variable definitions can be found in Appendix $3 \mathrm{~A}$. 
not shed light on whether acquirers do not fully understand how current earnings map into future performance, or whether they are aware of the persistence differences but do not act on them and deliberately make alternative valuation choices. Both accrual components are perceived to have greater informational value, even though they are shown to be generally less persistent compared to industry-wide cash flows (Hui et al. 2016). I further explore this question in the cross-sectional tests.

In sum, results of the main tests show that within-earnings differences in persistence do not play a significant role in M\&A pricing, as indicated by the relative importance of earnings components in bid prices. Acquirers do not price earnings according to their persistence levels, but rather focus on those earnings components, i.e., accruals, that they perceive as more informative about future firm value. Furthermore, contrary to what prior literature states about capital market investors, I conclude that acquirers are not fixated on aggregate earnings, as I find significant differences in the use of disaggregate earnings components.

\subsubsection{Cross-sectional Tests}

In this section, I explore conditions that may influence the relevance of the differential persistence of earnings in M\&A pricing. Specifically, I focus on conditions that affect the level of information asymmetry between the acquirer and the target firm, where information asymmetry differs either due to the information available to acquirers (common auditors and diversification) or due to the quality of the accounting information itself (accounting quality and industry earnings persistence). ${ }^{36}$ Part of the factors have already been linked to M\&A pricing, but have not yet been linked to the relative importance of individual earnings components in bid prices (e.g., Cai et al. 2016; Dhaliwal et al. 2016; McNichols and Stubben 2015; Raman et al. 2013), while other factors reflect variation in information asymmetry that may affect the relevance of earnings persistence in M\&A pricing.

\subsubsection{Common Auditors}

First, I examine the relevance of the differential persistence of earnings in M\&A pricing conditional on acquirers and targets sharing the same auditor. Previous literature has shown that in an M\&A transaction with a common auditor, the auditor acts as an information intermediary and affects deals in several ways. Dhaliwal et al. (2016) find that shared auditors are associated with a higher likelihood to receive a takeover bid and a higher deal completion rate. Additionally, acquirers benefit from lower deal premiums and higher announcement returns, whereas targets obtain lower returns. This suggests that the benefits of reduced information asymmetry mainly accrue to acquirers. Cai et al. (2016) show that common auditors are associated with higher quality deals due to reduced uncertainty throughout the transaction process and through various other mechanisms. Common

\footnotetext{
${ }^{36}$ For consistency and comparability between the subsamples (left and right columns of tables 3.3, 3.4, 3.5, 3.6), I use the coefficients from yearly market pricing regressions on the pooled sample. Allowing the coefficients to vary between subsamples makes comparability between the subsamples problematic, since differences may arise from both different weighting by market investors, as well as different weighting by acquirers. Nevertheless, re-estimating the benchmark market weights within each subsample results in qualitatively similar results, and does not alter the main conclusions.
} 
auditors affect M\&A transactions through (informal) discussions with both parties. In addition, financial statements are found to be more comparable when audited by the same auditor, which decreases uncertainty for the acquirer on how to interpret the target's accounting information. Lastly, they find limited misreporting for both parties. The resulting higher quality financial information enables acquirers to use the information and allocate capital more efficiently throughout a transaction.

Altogether, prior research provides evidence that common auditors act as information intermediaries, thereby reduce the level of information asymmetry between acquirers and targets, and as a result affect the overall transaction price. However, these studies do not elaborate on whether and how the pricing of earnings components itself is influenced by common auditors. In theory, decreased information asymmetry provides the opportunity to price earnings more accurately. ${ }^{37}$ Yet, it is unknown whether information transfers affect only the overall transaction price (through the premium) or whether the earnings components themselves are also priced differently. It is also not clear whether the overall importance of earnings in target pricing remains constant when common auditors are present.

Common auditors know the (quality of the) financials of their client firms very well, which places them in a unique position to interpret the accounting information adequately and transfer their knowledge to the acquiring firm. This suggests that common auditors may especially be helpful to acquirers in early phases of the due diligence, where one mostly relies on publicly available accounting information to determine initial bid prices (Lajoux and Elson 2000). If earnings are still equally important in the presence of common auditors, I expect a shift in weights placed on earnings components, i.e., greater weights on more persistent earnings components and lower weights on the less persistent ones. At the same time, one could argue for a lower overall importance of current earnings in the target pricing process. Besides understanding the financials very well, auditors likely have private information, which they obtain through informal discussions with management (Cai et al. 2016). This information is of potential strategic value and may include strategic initiatives such as the acquisition or disposition of assets (Dhaliwal et al. 2016). If the information is predictive for a target's future performance, it may influence the persistence of current earnings. Potential information transfers by common auditors may then lead to current earnings becoming overall less important for M\&A pricing. Instead, acquirers can obtain other information from their auditor that affects the future value of a target and incorporate it into their bid prices. In that case, common auditors may not be associated with the pricing of specific earnings components, but rather influence pricing via more strategic information transfers. Following this line of argumentation, I expect a lower emphasis and lower overall weights placed on current earnings components.

To explore which of the above-mentioned diverging arguments have the largest effect on the relationship between common auditors and the relevance of disaggregate earnings components in

\footnotetext{
${ }^{37}$ Lower uncertainty with respect to targets' accounting information enables acquirers to better interpret current information and to learn about past persistence levels. This in turn facilitates more precise forecasts of future performance and more accurate pricing, i.e., pricing according to its persistence levels.
} 
M\&A pricing, I run the M\&A pricing models as defined under (1) and (3) on a partitioned sample where I distinguish between deals involving a common auditor (CA) versus no common auditor (NON-CA).

Results for the basic model are presented in Table 3.3, Panel A. ${ }^{38}$ With respect to variables within a subsample, I only observe a significantly larger weight on $A C C$ compared to $C F O$ for the NON-CA subsample $(\mathrm{F}=4.714, \mathrm{p}=0.0301)$, implying that deals without common auditors drive the results from the pooled M\&A pricing model (Table 3.2). Furthermore, I observe that earnings become overall less important when common auditors are involved in an M\&A transaction. For the CA subsample, one can see that the coefficients of both earnings variables, $C F O$ and $A C C$, as well as $B V E$ fall below market pricing, i.e., below one. Chi-square statistics indicate significantly different coefficients across the two subsamples. Finally, the adjusted $\mathrm{R}^{2}$ for the sample with common auditors is only $22.1 \%$ compared to $38.4 \%$ for the non-common auditor sample, which further shows that the explanatory power of current earnings and $B V E$ is limited when common auditors are involved. In sum, results show that current financial accounting information overall becomes less important when CA are present, as indicated by the lower adjusted $\mathrm{R}^{2}$ and the smaller implied weights on earnings and BVE in CA transactions. This suggests that more accurate pricing is likely not the main mechanism through which common auditors influence M\&A pricing, but that they rather add value in a strategic way.

TABLE 3.3

Including Common Auditors

\begin{tabular}{|c|c|c|c|}
\hline $\begin{array}{l}\text { Panel A: Basic Regressions } \\
\text { Variables }\end{array}$ & CA & NON-CA & Chi-2 \\
\hline Constant & $\begin{array}{c}18.52 * * * \\
(15.58)\end{array}$ & $\begin{array}{l}14.74 * * * \\
(22.56)\end{array}$ & \\
\hline$C F O$ & $\begin{array}{l}0.889^{* * *} \\
(7.70)\end{array}$ & $\begin{array}{l}1.350 * * * \\
(16.26)\end{array}$ & $\begin{array}{c}13.22 \\
(p<0.001)\end{array}$ \\
\hline$A C C$ & $\begin{array}{l}0.876^{* * * *} \\
(5.81)\end{array}$ & $\begin{array}{l}1.472 * * * \\
(12.32)\end{array}$ & $\begin{array}{c}10.89 \\
(p=0.001)\end{array}$ \\
\hline$B V E$ & $\begin{array}{c}0.756^{* * *} \\
(4.18)\end{array}$ & $\begin{array}{c}1.285^{* * *} \\
(11.39)\end{array}$ & $\begin{array}{c}6.01 \\
(p=0.0142)\end{array}$ \\
\hline $\begin{array}{l}\text { Observations } \\
\text { Adj. R-squared }\end{array}$ & $\begin{array}{c}617 \\
0.221\end{array}$ & $\begin{array}{l}1,620 \\
0.384\end{array}$ & \\
\hline$C F O=A C C$ & $\begin{array}{c}0.0312 \\
(p=0.860)\end{array}$ & $\begin{array}{c}4.714 \\
(p=0.0301)\end{array}$ & \\
\hline$C F O=B V E$ & $\begin{array}{c}0.379 \\
(p=0.539)\end{array}$ & $\begin{array}{c}0.176 \\
(p=0.675)\end{array}$ & \\
\hline$A C C=B V E$ & $\begin{array}{c}0.339 \\
(p=0.560)\end{array}$ & $\begin{array}{c}1.046 \\
(p=0.307)\end{array}$ & \\
\hline
\end{tabular}

${ }^{38}$ Re-estimating the benchmark market weights for the slightly smaller common auditor sample yields qualitatively and quantitatively similar results. 
TABLE 3.3 (continued)

\begin{tabular}{|c|c|c|c|}
\hline \multicolumn{3}{|c|}{ Panel B: Decomposed Regressions } & Chi-2 \\
\hline Constant & $\begin{array}{c}19.41 * * * \\
(14.80)\end{array}$ & $\begin{array}{c}16.08 * * * \\
(23.47)\end{array}$ & \\
\hline IndCFO & $\begin{array}{c}0.995^{* * * *} \\
(8.27)\end{array}$ & $\begin{array}{c}1.317 * * * \\
(18.30)\end{array}$ & $\begin{array}{c}6.85 \\
(p=0.0103)\end{array}$ \\
\hline FirmCFO & $\begin{array}{c}0.891 * * * \\
(8.59)\end{array}$ & $\begin{array}{c}1.388 * * * \\
(18.33)\end{array}$ & $\begin{array}{c}18.79 \\
(p<0.001)\end{array}$ \\
\hline Ind $A C C$ & $\begin{array}{c}1.111^{* * * *} \\
(7.04)\end{array}$ & $\begin{array}{c}1.444 * * * \\
(14.92)\end{array}$ & $\begin{array}{c}3.78 \\
(p=0.0517)\end{array}$ \\
\hline FirmACC & $\begin{array}{c}0.845^{* * * *} \\
(7.24)\end{array}$ & $\begin{array}{c}1.490^{* * *} \\
(14.84)\end{array}$ & $\begin{array}{c}20.16 \\
(p<0.001)\end{array}$ \\
\hline$B V E$ & $\begin{array}{c}0.772 * * * \\
(4.36)\end{array}$ & $\begin{array}{c}1.344 * * * \\
(12.67)\end{array}$ & $\begin{array}{c}7.56 \\
(p=0.006)\end{array}$ \\
\hline $\begin{array}{l}\text { Observations } \\
\text { Adj. R-squared }\end{array}$ & $\begin{array}{c}617 \\
0.238\end{array}$ & $\begin{array}{l}1,620 \\
0.410\end{array}$ & \\
\hline IndCFO $=$ Firm $C F O$ & $\begin{array}{c}1.546 \\
(p=0.214)\end{array}$ & $\begin{array}{c}3.989 \\
(p=0.0460)\end{array}$ & \\
\hline IndCFO $=$ Ind $A C C$ & $\begin{array}{c}3.492 \\
(p=0.0622)\end{array}$ & $\begin{array}{c}7.966 \\
(p=0.00485)\end{array}$ & \\
\hline Ind $C F O=$ Firm $A C C$ & $\begin{array}{c}1.985 \\
(\mathrm{p}=0.160)\end{array}$ & $\begin{array}{c}7.035 \\
(p=0.00811)\end{array}$ & \\
\hline IndCFO $=B V E$ & $\begin{array}{c}1.054 \\
(\mathrm{p}=0.305)\end{array}$ & $\begin{array}{c}0.0441 \\
(\mathrm{p}=0.834)\end{array}$ & \\
\hline Firm $C F O=\operatorname{Ind} A C C$ & $\begin{array}{c}2.818 \\
(p=0.0938)\end{array}$ & $\begin{array}{c}0.858 \\
(\mathrm{p}=0.355)\end{array}$ & \\
\hline FirmCFO $=$ Firm $A C C$ & $\begin{array}{c}0.552 \\
(\mathrm{p}=0.458)\end{array}$ & $\begin{array}{c}4.991 \\
(p=0.0257)\end{array}$ & \\
\hline Firm $C F O=B V E$ & $\begin{array}{c}0.290 \\
(\mathrm{p}=0.591)\end{array}$ & $\begin{array}{c}0.105 \\
(\mathrm{p}=0.747)\end{array}$ & \\
\hline IndACC $=$ Firm $A C C$ & $\begin{array}{c}3.854 \\
(p=0.0502)\end{array}$ & $\begin{array}{c}0.533 \\
(\mathrm{p}=0.466)\end{array}$ & \\
\hline $\operatorname{Ind} A C C=B V E$ & $\begin{array}{c}2.325 \\
(p=0.128)\end{array}$ & $\begin{array}{c}0.480 \\
(\mathrm{p}=0.489)\end{array}$ & \\
\hline Firm $A C C=B V E$ & $\begin{array}{c}0.133 \\
(\mathrm{p}=0.715)\end{array}$ & $\begin{array}{c}0.963 \\
(\mathrm{p}=0.327)\end{array}$ & \\
\hline
\end{tabular}

This table presents results of the basic (Panel A) and decomposed (Panel B) M\&A pricing model analyzing the effect of a common auditor on the pricing of earnings and $B V E$. The sample includes all firm-year observations with matching data in SDC, Compustat and CRSP from 1992 to 2014. The two columns examine the pricing of earnings and $B V E$ conditional on acquirer and target sharing the same auditor (CA) or not (NON-CA). Chi-square statistics show whether variables are significantly different between the two subsamples. The test statistics at the bottom of Panels A and B indicate whether there are significant differences between the variables of interest. Continuous variables are winsorized at the $1^{\text {st }}$ and $99^{\text {th }}$ percentile. T-statistics and $\mathrm{p}$-values are based on standard errors clustered at the acquirer level. Tstatistics are reported in parentheses below the coefficients. $* * *$ indicate statistical significance at the $1 \%$ level (twotailed). Variable definitions can be found in Appendix 3A. 
Table 3.3, Panel B, presents results for the decomposed model. I observe a similar pattern as for the basic regressions that the overall weight on earnings components and $B V E$ is significantly lower when common auditors are present. ${ }^{39}$ However, there are some notable differences, as I now do observe within-model variation. In both subsamples a significantly greater weight is placed on IndACC than on IndCFO, which suggests that acquirers generally underreact to industry-wide cash flows. At the same time, transactions involving common auditors are associated with a significant difference between IndACC and FirmACC (F $=3.854, \mathrm{p}=0.0502$ for the CA subsample), with a larger weight placed on the more persistent industry-wide accruals. ${ }^{40}$ This suggests that common auditors are aware of the low persistence level of firm-specific accruals and transfer this knowledge to acquirers who integrate such information in their bid prices. Altogether, results suggest that common auditors add value by helping acquirers to partly see through the differential persistence levels of individual earnings components. At the same time, however, current financial accounting information becomes overall less important in the presence of common auditors, as indicated by the lower power of earnings and $B V E$ in explaining deal values. From this, I conclude that common auditors mainly add value through strategic information transfers that affect the future value of a target and consequently the overall transaction price. As a result, current earnings with their differential persistence levels become less important determinants for M\&A pricing.

\subsubsection{Accounting Quality}

In the second cross-sectional test, I examine the relevance of the differential persistence of earnings for bid prices conditional on targets having a high or low overall accounting quality. Prior literature has shown that accounting quality is associated with the price paid in an acquisition (e.g., McNichols and Stubben 2015; Raman et al. 2013). For example, McNichols and Stubben (2015) argue that for targets with higher accounting quality, acquirers can value the target more precisely through the use of better-quality information. As a result, they find that acquirers pay less for the target and capture a larger portion of the acquisition gains, as indicated by the relatively greater announcement returns compared to the target. Raman et al. (2013) show that in negotiated takeovers acquirers pay a higher premium for targets with poor earnings quality, justified by valuable private information obtained through negotiations. Additionally, they find that acquirers are more likely to pay with equity than cash when earnings quality is low. The two studies suggest that acquiring firms are informed as to when more information is desired to partially reduce information asymmetry, and know how to effectively use higher quality information at an overall level.

Higher quality accounting information, often indicated amongst others by more persistent earnings (e.g., Dechow et al. 2010), decreases information asymmetry and would justify a higher overall importance of earnings components in determining bid prices. As prior literature shows that

\footnotetext{
${ }^{39}$ Chi-square statistics show significant differences for all variables of interest, as shown in Table 3.3, Panel B.

${ }^{40}$ In the NON-CA subsample, firm-specific accruals share a similarly high weight with industry-wide accruals and receive a significantly larger weight compared to both IndCFO and FirmCFO. Transactions without common auditors thus drive the overweight on firm-specific accruals in the pooled decomposed M\&A pricing model (Table 3.2).
} 
acquirers consider overall earnings quality and use it effectively, I expect a higher total weight to be placed on earnings components and a lower weight on $B V E$ when accounting quality is high, and vice versa. Note that earnings and $B V E$ alternate in valuation importance, depending on the persistence of current aggregate earnings (e.g., Burgstahler and Dichev 1997; Rabier 2018). In addition, I explore how variation in targets' overall accounting quality affects the pricing of individual earnings components. Higher accounting quality should give acquirers more confidence in using targets' earnings numbers when determining bid prices. As such, I expect the differential weighting of disaggregate earnings components to be more pronounced for target firms with higher accounting quality, i.e., a relatively greater increase in weights placed on these earnings components that are the most important determinant(s) of bid prices in the main analysis.

I use absolute discretionary accruals based on the modified Jones model as a proxy for a target firm's overall earnings quality (Dechow et al. 1995). ${ }^{41}$ To obtain discretionary accruals (DAC) I estimate the following model per industry-year, where industries are defined by two-digit SIC codes and each industry-year is required to have at least ten observations:

$\operatorname{ACC}_{i, t}=\beta_{0}+\beta_{1} 1 /$ Assets $_{i, t-1}+\beta_{2} \Delta$ Sales $_{i, t}+\beta_{3} P P E_{i, t}+\varepsilon_{i, t}$

Total accruals $(A C C)$ are measured as income before extraordinary items less cash flows from operating activities, scaled by lagged total assets. $\triangle$ Sales is measured as the change in sales from year $t-1$ to year $t$, minus the change in accounts receivables from year $t-1$ to $t$, scaled by lagged total assets. $P P E$ is defined as net property, plant and equipment, scaled by lagged total assets. I use the absolute residual from this model $\left(\varepsilon_{i, t}\right)$ as my measure of discretionary accruals. To investigate differences in the M\&A pricing model conditional on firms having a high or low overall accounting quality, I run the basic pricing model on partitioned samples where I distinguish between high and low accounting quality (AQ) firms. High AQ firms are targets in the bottom $50 \%$ of absolute DAC, whereas low AQ includes firms whose DAC belong to the highest $50 \%$.

Results for the basic regression model are presented in Table 3.4, Panel A. ${ }^{42}$ In line with expectations, I observe higher overall weights for cash flows and accruals, and a lower weight for $B V E$ when accounting quality is high. For low accounting quality firms, $C F O$ and $A C C$ are priced closer to how the market prices earnings. Chi-square statistics indicate significant differences for the variables of interest between the partitioned samples. To analyze pricing of individual earnings components, I look at significant differences within one regression model. When accounting quality

\footnotetext{
${ }^{41}$ Theoretically, the accounting quality measure as used by McNichols and Stubben (2015) is preferred, as it captures a target firm's inherent accounting quality, rather than earnings management prior to the acquisition. However, data requirements would (non-randomly) decrease the sample by almost a half, dropping important transactions, leading to a biased sample and possibly biased inferences. Furthermore, Chen et al. (2018) have developed a single-step regression procedure to mitigate biased coefficients and standard errors (both Type I and Type II errors) related to the two-step approach typically used to obtain discretionary accruals. However, this method is not applicable in this study, as I use discretionary accruals to indicate cross-sectional variation in the sample, rather than using it as a dependent variable.

42 Re-estimating the benchmark market weights for the smaller accounting quality sample yields qualitatively and quantitatively similar results.
} 
is high, significantly more weight is placed on $A C C$ compared to $C F O$, as can be seen from the Ftests $(\mathrm{F}=8.426, \mathrm{p}=0.00381)$. This implies that accounting quality is positively associated with perceived relevance of accruals, as indicated by the higher implicit weight for $A C C$. For low accounting quality firms, no significant difference between $C F O$ and $A C C$ is found $(\mathrm{F}=1.017, \mathrm{p}=$ 0.313). Table 3.4, Panel B, presents results for the decomposed model. Again, I observe that significantly higher weights are placed on earnings components and a lower weight on $B V E$ when accounting quality is high, and vice versa. For both subsamples, however, I find that the estimated coefficient for IndCFO - the most persistent earnings component - is not significantly larger than for the other variables of interest. Furthermore, FirmACC is not priced significantly less than its industry-wide counterpart IndACC. High AQ is thus not associated with acquirers pricing earnings according to their persistence levels. Lastly, similar to the results of the basic model, significant differences between earnings components are only observed in the high AQ subsample.

In sum, results presented in Panels A and B of Table 3.4 confirm findings of prior studies that acquirers consider a target firm's comprehensive accounting quality by placing greater overall weights on earnings when AQ quality is high, and vice versa. I also observe that the main results (Table 3.2) are more pronounced in the high AQ subsample. Specifically, results show that the perceived superior informativeness of accruals in M\&A pricing (from the main analysis) is driven by deals with high AQ target firms, as significant differences between earnings components are absent in the low AQ subsample.

TABLE 3.4

Including Accounting Quality

\begin{tabular}{|c|c|c|c|}
\hline $\begin{array}{l}\text { Panel A: Basic Regressions } \\
\text { Variables }\end{array}$ & HIGH AQ & LOW AQ & Chi-2 \\
\hline Constant & $\begin{array}{c}15.97 * * * \\
(17.01)\end{array}$ & $\begin{array}{c}15.78 * * * \\
(19.30)\end{array}$ & \\
\hline$C F O$ & $\begin{array}{l}1.453 * * * \\
(12.62)\end{array}$ & $\begin{array}{c}1.095 * * * \\
(12.23)\end{array}$ & $\begin{array}{c}6.36 \\
(p=0.0117)\end{array}$ \\
\hline$A C C$ & $\begin{array}{l}1.652 * * * \\
(10.28)\end{array}$ & $\begin{array}{l}1.151^{* * *} \\
(9.69)\end{array}$ & $\begin{array}{c}6.30 \\
(p=0.0121)\end{array}$ \\
\hline$B V E$ & $\begin{array}{l}0.929 * * * \\
(6.93)\end{array}$ & $\begin{array}{l}1.506^{* * *} \\
(9.16)\end{array}$ & $\begin{array}{c}7.54 \\
(p=0.006)\end{array}$ \\
\hline $\begin{array}{l}\text { Observations } \\
\text { Adj. R-squared }\end{array}$ & $\begin{array}{l}1,023 \\
0.381\end{array}$ & $\begin{array}{l}1,026 \\
0.315\end{array}$ & \\
\hline$C F O=A C C$ & $\begin{array}{c}8.426 \\
(p=0.00381)\end{array}$ & $\begin{array}{c}1.017 \\
(\mathrm{p}=0.313)\end{array}$ & \\
\hline$C F O=B V E$ & $\begin{array}{c}7.321 \\
(p=0.00697)\end{array}$ & $\begin{array}{c}4.594 \\
(p=0.0324)\end{array}$ & \\
\hline$A C C=B V E$ & $\begin{array}{c}10.35 \\
(p=0.00135)\end{array}$ & $\begin{array}{c}3.002 \\
(p=0.0836)\end{array}$ & \\
\hline
\end{tabular}


TABLE 3.4 (continued)

\begin{tabular}{|c|c|c|c|}
\hline $\begin{array}{l}\text { Panel B: Decomposed Regressions } \\
\text { Variables }\end{array}$ & HIGH AQ & LOW AQ & Chi-2 \\
\hline Constant & $\begin{array}{c}17.43 * * * \\
(18.20)\end{array}$ & $\begin{array}{c}17.23 * * * \\
(19.08)\end{array}$ & \\
\hline IndCFO & $\begin{array}{l}1.371^{* * *} \\
(14.47)\end{array}$ & $\begin{array}{c}1.054 * * * \\
(12.51)\end{array}$ & $\begin{array}{c}6,71 \\
(p=0.0096)\end{array}$ \\
\hline FirmCFO & $\begin{array}{c}1.398 * * * \\
(13.61)\end{array}$ & $\begin{array}{c}1.149 * * * \\
(13.33)\end{array}$ & $\begin{array}{c}3,64 \\
(p=0.0564)\end{array}$ \\
\hline Ind $A C C$ & $\begin{array}{c}1.558^{* * *} \\
(12.77)\end{array}$ & $\begin{array}{c}1.087 * * * \\
(10.07)\end{array}$ & $\begin{array}{c}8,67 \\
(p=0.0032)\end{array}$ \\
\hline FirmACC & $\begin{array}{c}1.544 * * * \\
(11.88)\end{array}$ & $\begin{array}{c}1.167 * * * \\
(11.03)\end{array}$ & $\begin{array}{c}4,98 \\
(p=0.0256)\end{array}$ \\
\hline$B V E$ & $\begin{array}{c}1.029 * * * \\
(7.78)\end{array}$ & $\begin{array}{l}1.507 * * * \\
(9.42)\end{array}$ & $\begin{array}{c}5,36 \\
(p=0.0206)\end{array}$ \\
\hline $\begin{array}{l}\text { Observations } \\
\text { Adj. R-squared }\end{array}$ & $\begin{array}{l}1,023 \\
0.398\end{array}$ & $\begin{array}{l}1,026 \\
0.333\end{array}$ & \\
\hline IndCFO $=$ Firm $C F O$ & $\begin{array}{c}0.225 \\
(\mathrm{p}=0.635)\end{array}$ & $\begin{array}{c}2.702 \\
(p=0.101)\end{array}$ & \\
\hline $\operatorname{Ind} C F O=\operatorname{Ind} A C C$ & $\begin{array}{c}14.42 \\
(p<0.001)\end{array}$ & $\begin{array}{c}0.432 \\
(p=0.511)\end{array}$ & \\
\hline IndCFO $=$ Firm $A C C$ & $\begin{array}{c}3.579 \\
(p=0.0589)\end{array}$ & $\begin{array}{c}1.842 \\
(\mathrm{p}=0.175)\end{array}$ & \\
\hline IndCFO $=B V E$ & $\begin{array}{c}4.080 \\
(p=0.0437)\end{array}$ & $\begin{array}{c}6.643 \\
(p=0.0101)\end{array}$ & \\
\hline Firm $C F O=\operatorname{Ind} A C C$ & $\begin{array}{c}3.448 \\
(p=0.0637)\end{array}$ & $\begin{array}{c}0.499 \\
(\mathrm{p}=0.480)\end{array}$ & \\
\hline FirmCFO $=$ Firm $A C C$ & $\begin{array}{c}6.626 \\
(p=0.0102)\end{array}$ & $\begin{array}{c}0.185 \\
(p=0.668)\end{array}$ & \\
\hline Firm $C F O=B V E$ & $\begin{array}{c}4.303 \\
(p=0.0384)\end{array}$ & $\begin{array}{c}4.004 \\
(p=0.0457)\end{array}$ & \\
\hline Ind $A C C=$ Firm $A C C$ & $\begin{array}{c}0.0201 \\
(\mathrm{p}=0.887)\end{array}$ & $\begin{array}{c}0.699 \\
(\mathrm{p}=0.403)\end{array}$ & \\
\hline $\operatorname{Ind} A C C=B V E$ & $\begin{array}{c}8.562 \\
(p=0.00354)\end{array}$ & $\begin{array}{c}5.215 \\
(p=0.0227)\end{array}$ & \\
\hline Firm $A C C=B V E$ & $\begin{array}{c}7.453 \\
(p=0.00648)\end{array}$ & $\begin{array}{c}3.437 \\
(p=0.0641)\end{array}$ & \\
\hline
\end{tabular}

This table presents results of the basic (Panel A) and decomposed (Panel B) M\&A pricing model analyzing the effect of cross-sectional variation in accounting quality on the pricing of earnings and $B V E$. The sample includes all firm-year observations with matching data in SDC, Compustat and CRSP from 1992 to 2014. The two subsamples analyze the pricing of earnings and $B V E$ conditional on targets having a high accounting quality (HIGH AQ) or targets having a low overall accounting quality (LOW AQ). The chi-square statistics show whether variables are significantly different between the two subsamples. Test statistics at the bottom of Panels A and B indicate whether there are significant differences between the variables of interest. Continuous variables are winsorized at the $1^{\text {st }}$ and $99^{\text {th }}$ percentile. Tstatistics and $\mathrm{p}$-values are based on standard errors clustered at the acquirer level. T-statistics are reported in parentheses below the coefficients. ${ }^{* * *}$ indicate statistical significance at the $1 \%$ level (two-tailed). Variable definitions can be found in Appendix 3A. 


\subsubsection{Industry Earnings Persistence}

In the next additional test, I explore whether and how cross-sectional variation in the persistence of total industry earnings affects the relevance of earnings components in M\&A pricing. Compared to industries where total earnings are much more volatile, highly persistent earnings in a certain industry reflect a relatively stable environment and/or benefit from more recurring cash flows. Persistence can then be treated as a quality attribute, as in such environment current earnings should have a higher informational value about future performance and information asymmetry should be lower. If, next to considering forward-looking earnings persistence due to strategic intent (Rabier 2018), acquirers also consider general performance persistence based on prior years, I expect earnings components to play a larger role in M\&A pricing for industry-years with a high persistence level of total industry earnings.

To determine the persistence of industry earnings, I estimate the following model per industry and year using a rolling regression window on a sample covering the preceding eight years:

$\operatorname{Earn}_{i, t}=\beta_{0}+\beta_{1} \operatorname{Earn}_{i, t-1}+\varepsilon_{i, t}$

Where $\operatorname{Earn}_{i, t}$ is taken from the cash flow statement and reflects the income before extraordinary items, scaled by the number of shares outstanding two months prior to the deal announcement. To examine the effects of industry earnings persistence, I repeat the basic main analysis partitioning the sample on high versus low persistence, i.e., above-median persistence and below-median persistence. ${ }^{43}$

Results are reported in Table 3.5 and show that current cash flows and accruals play a significantly larger role in M\&A pricing when firms operate in a relatively stable industry. The Rsquared is higher with $7.9 \%$ and Chi-2 statistics indicate significant differences for cash flows (chi2: $8.25, \mathrm{p}=0.0041$ ) and accruals (chi-2:5.48, $\mathrm{p}=0.0192$ ) between the two subsamples. I do not observe a significant difference for $B V E$, which shows that the relevance of $B V E$ is less dependent on the persistence of total industry earnings. Furthermore, relative to equity investors, the greater implied weight on accruals is concentrated in the subset of deals with high industry earnings persistence (F-test 4.07, $\mathrm{p}=0.0441)$.

In sum, results suggest that next to forward-looking earnings persistence, acquirers do consider the persistence of historical industry earnings. Acquirers seem to understand that current earnings components have a greater informational value when the environment is relatively stable or when the industry benefits from a more recurring cash flow stream. Also, compared to cash flows, accruals are only perceived as particularly informative about future firm value in deals with high industry earnings persistence.

\footnotetext{
${ }^{43}$ I do not rerun the decomposed M\&A pricing model, as I would then use industry fundamentals to both partition the sample and create the variables of interest. This makes it difficult to draw useful inferences from regression results.
} 
TABLE 3.5

Industry Earnings Persistence

\begin{tabular}{|c|c|c|c|}
\hline Variables & HIGH IND. PERSISTENCE & LOW IND. PERSISTENCE & Chi-2 \\
\hline Constant & $\begin{array}{c}14.82 * * * \\
(16.54)\end{array}$ & $\begin{array}{c}16.72 * * * \\
(20.64)\end{array}$ & \\
\hline CFO & $\begin{array}{c}1.392 * * * \\
(14.05)\end{array}$ & $\begin{array}{c}1.009 * * * \\
(10.96)\end{array}$ & $\begin{array}{c}8.25 \\
(p=0.0041)\end{array}$ \\
\hline$A C C$ & $\begin{array}{c}1.509 * * * \\
(11.01)\end{array}$ & $\begin{array}{c}1.080 * * * \\
(8.87)\end{array}$ & $\begin{array}{c}5.48 \\
(p=0.0192)\end{array}$ \\
\hline$B V E$ & $\begin{array}{c}1.063 * * * \\
(7.61)\end{array}$ & $\begin{array}{c}1.287^{* * * *} \\
(9.96)\end{array}$ & $\begin{array}{c}1.34 \\
(p=0.2475)\end{array}$ \\
\hline Observations & 1,154 & 1,159 & \\
\hline Adj. R-squared & 0.375 & 0.296 & \\
\hline$C F O=A C C$ & $\begin{array}{c}4.065 \\
(p=0.0441)\end{array}$ & $\begin{array}{c}1.92 \\
(p=0.166)\end{array}$ & \\
\hline$C F O=B V E$ & $\begin{array}{c}3.674 \\
(p=0.0556)\end{array}$ & $\begin{array}{c}2.635 \\
(\mathrm{p}=0.105)\end{array}$ & \\
\hline$A C C=B V E$ & $\begin{array}{c}5.282 \\
(p=0.0218)\end{array}$ & $\begin{array}{c}1.209 \\
(p=0.272)\end{array}$ & \\
\hline
\end{tabular}

This table presents results of the basic M\&A pricing model analyzing the effect of cross-sectional variation in the persistence of historical industry earnings on the pricing of earnings and $B V E$. The sample includes all firm-year observations with matching data in SDC, Compustat and CRSP from 1992 to 2014. The two columns examine the pricing of earnings and $B V E$ conditional on target firms operating in an industry with a high or low persistence of industry earnings, respectively. Chi-square statistics show whether variables are significantly different between the two groups (high and low industry earnings persistence). The test statistics at the bottom show whether there are significant differences between the variables of interest. Continuous variables are winsorized at the $1^{\text {st }}$ and $99^{\text {th }}$ percentile. Tstatistics and $\mathrm{p}$-values are based on standard errors clustered at the acquirer level. T-statistics are reported in parentheses below the coefficients. ${ }^{* * *}$ indicate statistical significance at the $1 \%$ level (two-tailed). Variable definitions can be found in Appendix 3A.

\subsubsection{Diversification}

In the next cross-sectional test, I partition the sample in diversifying and non-diversifying deals. Information asymmetry is expectedly larger in diversifying deals where the acquirer and the target are not operating in the same industry. As acquirers likely lack experience in the target firm's industry they do not benefit from additional insights, and thus experience an information disadvantage compared to non-diversifying deals. I therefore expect acquirers to rely more on publicly available accounting information (i.e., earnings and $B V E$ ) when estimating future firm value and formulating bid prices.

I rerun the main analysis on subsamples including non-diversifying and diversifying deals, respectively. I label a deal as diversifying if the acquirer and target do not share the same three-digit historical SIC code, with SIC codes obtained from Compustat. Results for the basic model are presented in Table 3.6, Panel A. Although the weights on (and relevance of) $C F O$ and $A C C$ are somewhat larger in the diversifying sample, the differences between the subsamples are not significant. Yet, I do observe that book value of equity becomes a significantly more relevant 
determinant of M\&A prices when acquirers engage in inter-industry transactions. This is consistent with book value of equity being a relatively safe valuation input if information asymmetry is higher, as it generally reflects the minimum value to be paid for a target firm, i.e., it reflects the value of the resources currently in place. Combined, earnings and BVE explain 5.1\% more of the variation in deal values, as indicated by the adjusted R-squares. A possible explanation for the relatively small additional weight on earnings in diversifying deals may be that acquiring firms make use of additional information intermediaries, such as advisors or analysts, to decrease the information gap and obtain supplementary information beyond financial statement numbers. Finally, the larger focus on accruals compared to cash flows in the main analysis seems to be driven by diversifying deals, consistent with the need to obtain more forward-looking information via accruals if other forwardlooking information based on industry experience is limited or absent. Results and inferences from the decomposed regression model (Table 3.6, Panel B) are similar to the ones from the basic model.

Overall, results of the cross-sectional tests suggest that acquiring firms are aware of settings where earnings and its components are relatively more (or less) useful as determinants of bid prices, and as such make rational valuation decisions. Specifically, they find earnings information a relatively more useful valuation input when other information advantages such as common auditors are absent. They also act on the overall quality of accounting information by attaching greater weights to earnings information when a firm's accounting quality is higher and when industry

TABLE 3.6

(Non)-Diversifying Deals

\begin{tabular}{lccc}
\hline \hline Panel A: Basic Regressions & & & \\
Variables & NON-DIVERSIFY & DIVERSIFY & Chi-2 \\
\hline Constant & $16.57^{* * *}$ & $14.99^{* * *}$ & \\
& $(18.90)$ & $(18.08)$ & \\
$C F O$ & $1.159^{* * *}$ & $1.238^{* * *}$ & 0.34 \\
& $(11.72)$ & $1.359^{* * *}$ & $(p=0.5602)$ \\
$A C C$ & $1.209^{* * *}$ & $(11.18)$ & 0.69 \\
& $(8.73)$ & $1.356^{* * *}$ & $(p=0.4062)$ \\
$B V E$ & $0.982^{* * *}$ & $(10.07)$ & $\mathbf{3 . 9 1}$ \\
& $(7.47)$ & & \\
Observations & & 1,154 & \\
Adj. R-squared & 1,151 & 0.361 & \\
& 0.310 & & \\
$C F O=A C C$ & & $\mathbf{5 . 9 3 5}$ & \\
$C F O=B V E$ & 0.65 & $(\mathbf{p}=\mathbf{0 . 0 1 5 1})$ & \\
$A C C=B V E$ & $(\mathrm{p}=0.420)$ & 0.461 & \\
& 0.963 & $(\mathrm{p}=0.497)$ & \\
& $(\mathrm{p}=0.327)$ & 0.000197 & \\
& 1.188 & $(\mathrm{p}=0.989)$ & \\
\end{tabular}


TABLE 3.6 (continued)

\begin{tabular}{|c|c|c|c|}
\hline $\begin{array}{l}\text { Panel B: Decomposed Regressions } \\
\text { Variables }\end{array}$ & NON-DIVERSIFY & DIVERSIFY & Chi-2 \\
\hline Constant & $\begin{array}{c}18.08 * * * \\
(19.95)\end{array}$ & $\begin{array}{c}15.87 * * * \\
(17.69)\end{array}$ & \\
\hline IndCFO & $\begin{array}{c}1.167 * * * \\
(14.35)\end{array}$ & $\begin{array}{l}1.250 * * * \\
(13.12)\end{array}$ & $\begin{array}{c}0.48 \\
(p=0.4863)\end{array}$ \\
\hline FirmCFO & $\begin{array}{c}1.221 * * * \\
(14.15)\end{array}$ & $\begin{array}{c}1.234 * * * \\
(12.86)\end{array}$ & $\begin{array}{c}0.01 \\
(p=0.9147)\end{array}$ \\
\hline Ind $A C C$ & $\begin{array}{l}1.234 * * * \\
(11.66)\end{array}$ & $\begin{array}{l}1.415^{* * *} \\
(12.00)\end{array}$ & $\begin{array}{c}1.37 \\
(p=0.2416)\end{array}$ \\
\hline FirmACC & $\begin{array}{c}1.218^{* * *} \\
(11.26)\end{array}$ & $\begin{array}{c}1.347 * * * \\
(12.08)\end{array}$ & $\begin{array}{c}0.73 \\
(p=0.3919)\end{array}$ \\
\hline$B V E$ & $\begin{array}{l}0.999 * * * \\
(8.29)\end{array}$ & $\begin{array}{c}1.407 * * * \\
(10.57)\end{array}$ & $\begin{array}{c}5.11 \\
(p=0.0237)\end{array}$ \\
\hline $\begin{array}{l}\text { Observations } \\
\text { Adj. R-squared }\end{array}$ & $\begin{array}{l}1,151 \\
0.347\end{array}$ & $\begin{array}{l}1,154 \\
0.372\end{array}$ & \\
\hline IndCFO $=$ Firm $C F O$ & $\begin{array}{c}1.851 \\
(\mathrm{p}=0.174)\end{array}$ & $\begin{array}{c}0.0911 \\
(\mathrm{p}=0.763)\end{array}$ & \\
\hline IndCFO $=$ Ind $A C C$ & $\begin{array}{c}2.114 \\
(p=0.146)\end{array}$ & $\begin{array}{c}12.16 \\
(\mathrm{p}<0.001)\end{array}$ & \\
\hline IndCFO $=$ Firm $A C C$ & $\begin{array}{c}0.53 \\
(\mathrm{p}=0.467)\end{array}$ & $\begin{array}{c}1.768 \\
(\mathrm{p}=0.184)\end{array}$ & \\
\hline Ind $C F O=B V E$ & $\begin{array}{c}1.235 \\
(p=0.267)\end{array}$ & $\begin{array}{c}0.903 \\
(p=0.342)\end{array}$ & \\
\hline Firm $C F O=\operatorname{Ind} A C C$ & $\begin{array}{c}0.0382 \\
(\mathrm{p}=0.845)\end{array}$ & $\begin{array}{c}5.112 \\
(p=0.024)\end{array}$ & \\
\hline Firm $C F O=$ Firm $A C C$ & $\begin{array}{c}0.00569 \\
(\mathrm{p}=0.940)\end{array}$ & $\begin{array}{c}6.917 \\
(p=0.0087)\end{array}$ & \\
\hline FirmCFO $=B V E$ & $\begin{array}{c}2.002 \\
(\mathrm{p}=0.157)\end{array}$ & $\begin{array}{c}1.085 \\
(p=0.298)\end{array}$ & \\
\hline Ind $A C C=$ Firm $A C C$ & $\begin{array}{c}0.0486 \\
(\mathrm{p}=0.826)\end{array}$ & $\begin{array}{c}0.64 \\
(\mathrm{p}=0.424)\end{array}$ & \\
\hline $\operatorname{Ind} A C C=B V E$ & $\begin{array}{c}2.114 \\
(\mathrm{p}=0.146)\end{array}$ & $\begin{array}{c}0.00222 \\
(\mathrm{p}=0.962)\end{array}$ & \\
\hline Firm $A C C=B V E$ & $\begin{array}{c}1.696 \\
(\mathrm{p}=0.193)\end{array}$ & $\begin{array}{c}0.125 \\
(p=0.723)\end{array}$ & \\
\hline
\end{tabular}

This table presents results of the basic (Panel A) and decomposed (Panel B) M\&A pricing model analyzing the effect of (non)-diversifying transactions on the pricing of earnings and $B V E$. The sample includes all firm-year observations with matching data in SDC, Compustat and CRSP from 1992 to 2014. The two columns examine the pricing of earnings and $B V E$ conditional on acquirer and target operating in the same industry (NON-DIVERSIFY), based on three-digit historical SIC codes, or different industries (DIVERSIFY). Chi-square statistics show whether variables are significantly different between the two subsamples. The test statistics at the bottom show whether there are significant differences between the variables of interest. Continuous variables are winsorized at the $1^{\text {st }}$ and $99^{\text {th }}$ percentile. T-statistics and $\mathrm{p}$ values are based on standard errors clustered at the acquirer level. T-statistics are reported in parentheses below the coefficients. $* * *$ indicate statistical significance at the $1 \%$ level (two-tailed). Variable definitions can be found in Appendix 3A. 
earnings are more persistent. Note that the relative greater weights on accruals are concentrated in those subsets of deals where earnings enjoy a higher overall importance for valuation, including diversifying deals. Results of the test on industry earnings persistence are particularly informative, as it shows that acquirers do (at least partly) incorporate the impact of industry fundamentals on earnings persistence. While this indicates that acquirers are aware of fundamentals-driven persistence differences in earnings and consider it in their target valuation process, results show that they do not price individual earnings components according to their persistence levels. Hence, acquirers seem to rationally make alternative valuation choices where the disaggregate components' perceived informativeness about future firm value is not in line with their general persistence levels. Altogether, I conclude that persistence differences in disaggregate earnings components do not play a relevant role in M\&A pricing.

\subsubsection{Robustness Tests}

To test the robustness of the reported results, I perform several tests. First, to obtain discretionary accruals, being the proxy for overall accounting quality, I apply the commonly used two-digit SIC codes to define industries in the discretionary accruals model. For consistency with the industry measure used to partition earnings components in the decomposed pricing models, I also measure DAC based on six-digit GICS industry codes. I then rerun both the basic and decomposed pricing regressions, and substitute the original AQ measure with the alternative mentioned above. Results (untabulated) are qualitatively similar to those reported in Table 3.4.

Second, given the relatively small differences between the diversifying and non-diversifying subsamples, I rerun the pricing regressions with a diversification variable based on the two-digit historical SIC code. Some deals that were originally classified as diversifying $(\mathrm{N}=1,154)$ are now be labeled as non-diversifying, reflecting instances where the three-digit SIC codes and thus subindustries of the acquirer and target are closely related. This may lead to variation in the level of information asymmetry. The new samples include 836 diversifying and 1,469 non-diversifying transactions, respectively. Results (untabulated) are qualitatively and quantitatively similar to the results reported in Table 3.6, Panels A and B.

\subsection{Conclusion}

Research has shown that not all mergers are successful and that mispricing targets (overpayment) is one of the reasons why mergers can be value destructive to acquirer shareholders (e.g., Moeller et al. 2005). As this provides incentives to acquirers to properly value targets, (determinants of) bid prices have gained considerable attention in the academic literature. Motivated by the essential role publicly available accounting information plays in target valuation, I add to this literature by investigating the relevance of the differential persistence of earnings components in the pricing of targets.

Studies in the capital market setting show that while investors recognize the persistence of aggregate earnings in equity valuation and know when earnings are relatively more (or less) 
important than book value of equity (Burgstahler and Dichev 1997), they fail to incorporate the differential persistence levels of disaggregate earnings components and hence misprice earnings (e.g., Hui et al. 2016; Sloan 1996). Rabier (2018) extends this research to the merger market and sheds light on the relative valuation roles of aggregate earnings and book value of equity in M\&A deals, taking into account the extent to which the current earnings stream is expected to persist. In this study, I explore whether differential persistence levels of disaggregate earnings components are relevant to acquirers and are priced accordingly.

The results documented in this study show that relative to equity valuation, accruals receive significantly greater weights than cash flows. After further decomposition, results show that acquirers 'underreact' to industry-wide cash flows - the most persistent component- and 'overreact' to the less persistent accrual components. The main analyses show that within-earnings differences in persistence do not play a significant role in M\&A pricing. Instead, acquirers focus more on earnings components (i.e., accruals) that they perceive as more informative about future firm value. Results of cross-sectional tests show that the perceived superior informativeness of accruals is mainly driven by deals where the acquirer and the target do not share the same auditor, which is consistent with acquirers obtaining more forward-looking information from accruals when the informational advantage associated with common auditors is absent. For similar reasons, I find that the relative greater weight on accruals is concentrated in subsets of deals with high accounting quality target firms, targets operating in an industry with a history of high industry earnings persistence, and diversifying transactions. Furthermore, I find that the overall importance of earnings in M\&A prices is significantly higher for non-common auditor deals, deals involving target firms with a high accounting quality, and deals where targets' industry earnings are highly persistent. For diversifying transactions, I do not find a significant increase in earnings importance, potentially because acquirers consult additional information intermediaries to lower the information gap.

Collectively, results of the cross-sectional tests suggest that acquiring firms are aware of settings where earnings and its components are relatively more (or less) useful as determinants of bid prices - as indicated by acquirers' consideration of the role of industry fundamentals in the earnings generating process - and price disaggregate earnings components in a rational manner. While findings indicate that acquirers are aware of fundamentals-driven persistence differences in earnings and consider this in target pricing, results also show that they do not price industry-wide and firm-specific earnings components according to their persistence levels. As such, acquirers seem to (rationally) make alternative valuation choices based on the components' perceived informativeness and not general persistence levels. Based on these findings, I conclude that while acquirers recognize general differences in earnings persistence, within-earnings variation in persistence does not play a relevant role in the M\&A pricing process.

This study adds to the literature examining the link between (the quality of) accounting fundamentals and M\&A pricing (e.g., McNichols and Stubben 2015; Rabier 2018; Raman et al. 2013) by exploiting the variation in persistence within accounting fundamentals and analyzing to what extent this differential persistence is considered in target pricing. I show that acquirers 
(rationally) price earnings components according to their perceived informativeness, rather than their persistence levels. One limitation in this study stems from the research design, where I benchmark the analyses to capital market pricing. The current design enables a direct analysis of how M\&A pricing differs from how 'the majority', i.e., the market, values earnings. However, this design only gives insights into the relative importance and relative differences of earnings components and book value of equity, rather than providing information about the size or levels of the weighting coefficients for acquirers. A second limitation is that with the current set of analyses, I am not able to identify the extent to which M\&A pricing is affected by the expected synergies or strategic intent of the deals. As this likely impacts the valuation roles of the disaggregated earnings components, future studies could analyze M\&A pricing while accounting for the strategic importance of deals. Furthermore, in this study, I do not link merger pricing to deal outcomes. While persistence as a measure of earnings quality is often perceived to be positively related to relevance or decision-usefulness, it is unknown whether acquirers' focus on the less persistent accrual components reflects mispricing. Future research could examine post-deal performance to shed light on economic consequences related to variation in acquirer's weighting of financial accounting information. Finally, future studies could investigate the role of other fundamentals-driven earnings components in M\&A pricing. 


\section{Appendix 3A - Variable Definitions}

\begin{tabular}{|c|c|c|}
\hline Variable & Description & Source \\
\hline \multicolumn{3}{|l|}{ Main Variables } \\
\hline PRICE & The price per share two months prior to the deal announcement. & SDC* \\
\hline DVALUE & The initial offer price per share in a transaction. & SDC* \\
\hline CFO & $\begin{array}{l}\text { Net cash flows from operating activities (OANCF) scaled by the number } \\
\text { of shares outstanding two months before the deal announcement. }\end{array}$ & $\begin{array}{l}\text { Compustat } \\
\text { SDC* }\end{array}$ \\
\hline$A C C$ & $\begin{array}{l}\text { Measured from the cash flows statement as the difference between } \\
\text { earnings (income before extraordinary items; IBC) and operating cash } \\
\text { flows (OANCF), scaled by the number of shares outstanding two } \\
\text { months prior to the deal announcement. }\end{array}$ & $\begin{array}{l}\text { Compustat } \\
\text { SDC* }\end{array}$ \\
\hline IndCFO & $\begin{array}{l}\text { The average equal-weighted cash flows } C F O \text { per industry and year, } \\
\text { based on six-digit GICS codes. }\end{array}$ & $\begin{array}{l}\text { Compustat } \\
\text { SDC* }\end{array}$ \\
\hline FirmCFO & $\begin{array}{l}\text { The difference between a firm's reported cash flows } C F O \text { and industry- } \\
\text { wide cash flows IndCFO. }\end{array}$ & $\begin{array}{l}\text { Compustat } \\
\text { SDC* }\end{array}$ \\
\hline IndACC & $\begin{array}{l}\text { The average equal-weighted accruals } A C C \text { per industry and year, based } \\
\text { on six-digit GICS codes. }\end{array}$ & $\begin{array}{l}\text { Compustat } \\
\text { SDC* }\end{array}$ \\
\hline FirmACC & $\begin{array}{l}\text { The difference between a firm's reported accruals } A C C \text { and industry- } \\
\text { wide accruals } I n d A C C \text {. }\end{array}$ & $\begin{array}{l}\text { Compustat } \\
\text { SDC* }\end{array}$ \\
\hline$B V E$ & $\begin{array}{l}\text { The difference between total assets (AT) and total liabilities (LT), scaled } \\
\text { by the number of shares outstanding two months before the deal } \\
\text { announcement. }\end{array}$ & $\begin{array}{l}\text { Compustat } \\
\text { SDC* }\end{array}$ \\
\hline \multicolumn{3}{|c|}{ Cross-sectional Test Variables } \\
\hline$C A$ & $\begin{array}{l}\text { Indicator variable equal to one if the acquirer and target share the same } \\
\text { auditor in an M\&A transaction, zero otherwise. }\end{array}$ & Compustat \\
\hline$a b s D A C$ & $\begin{array}{l}\text { The absolute discretionary accruals based on the modified Jones model } \\
\text { (Dechow et al. 1995). }\end{array}$ & Compustat \\
\hline IndPersistence & $\begin{array}{l}\text { The persistence of total industry earnings: estimated per industry (two- } \\
\text { digit SIC) and year using a rolling regression window covering the } \\
\text { preceding eight years. Earnings are defined as income before } \\
\text { extraordinary items (IBC) scaled by the number of shares outstanding } \\
\text { two months prior to the deal announcement. }\end{array}$ & $\begin{array}{l}\text { Compustat } \\
\text { SDC* }\end{array}$ \\
\hline Diversify & $\begin{array}{l}\text { Indicator variable equal to one if the acquirer and target do not share the } \\
\text { same three-digit historical SIC code and thus operate in different } \\
\text { industries. }\end{array}$ & Compustat \\
\hline
\end{tabular}

* SDC $=$ Securities Data Corporation's (SDC) Mergers and Acquisitions Database 




\title{
4. THE ROLE OF LIFE CYCLE-WIDE EARNINGS IN FORECASTING AND VALUATION
}

\begin{abstract}
$^{44,45}$
In this study, we investigate the existence and informational value of life cycle-wide and firmspecific earnings, and examine the extent to which these components are reflected in stock prices. We find that life cycle-wide earnings are significantly more persistent than firm-specific earnings. Investors misprice these earnings by underreacting to the common component and overreacting to the firm-specific component. Consistent with our results reflecting mispricing, we find a predictable drift in future abnormal stock returns in the direction of life cycle earnings. We additionally find that our results are not affected by industry dynamics, which further illustrates the added value of life cycle as a fundamental driver of firm profitability. Finally, we find that analysts do recognize the importance of life cycle information, and, at least partly, incorporate such information in their earnings forecasts. Our study adds to the understanding of a firm's earnings generating process and provides additional evidence on the relevance of life cycle information in forecasting and valuation.
\end{abstract}

\footnotetext{
44 This chapter is based on a working paper co-authored with Patrick Vorst.

45 Acknowledgements: We would like to thank Dongning Yu (discussant) and participants at the 2020 Hawaii Accounting Research Conference for their helpful comments and suggestions.
} 


\subsection{Introduction}

Persistence of earnings as an attribute of earnings quality has received great attention in prior literature, with a major focus on its usefulness for equity valuation purposes (Dechow et al. 2010). To the extent that a higher persistence improves the accuracy of valuation outcomes, more persistent earnings hold stronger predictive power over future firm performance and should therefore receive a larger weight in equity valuation. Early studies mainly focused on the persistence and pricing of total earnings and its components as defined by the accounting system, i.e., (subparts of) cash flows and accruals (e.g., Allen et al. 2013; Dechow et al. 2008; Richardson et al. 2005; Sloan 1996). For example, Sloan (1996) suggests that the market focuses on aggregate earnings and fails to incorporate the differential persistence of cash flows and accruals. Reported earnings, however, are a joint product of the accounting system and a firm's fundamental performance (Dechow et al. 2010).

Fewer studies examine the effect of firm fundamentals on the persistence of earnings. Lev (1983) associates persistence with firm fundamentals, such as product type, industry competition, capital intensity, and firm size. Other studies have linked the persistence of earnings to firm strategy, i.e., differentiation versus cost leadership strategy (e.g., Fairfield and Yohn 2001; Nissim and Penman 2001; Soliman 2008). Hui et al. (2016) depart from Sloan (1996) by basing the disaggregation of earnings directly on industry fundamentals. Average industry performance is found to be more persistent than firm-specific deviations from the industry norm. Results show, however, that investors do not seem to account for the differential persistence of industry-wide and firm-specific earnings components and consequently misprice earnings. Such analyses on common industry earnings have contributed to a stream of literature that has primarily focused on industry as an important economic determinant of a firm's earnings generating process and firm growth (e.g., Dechow et al. 1995; Fairfield et al. 2009). Consequently, industry models are now extensively used in forecasting and valuation.

In this study, we depart from this major focus on industry models and focus on organizational life cycle as a driver of a firm's fundamental performance. Specifically, we investigate the existence and informational value of life cycle-wide and firm-specific earnings, and examine the extent to which these components are reflected in stock prices and analyst earnings forecasts. ${ }^{46}$ Recent studies show that accounting measures vary in a predictable way by firm life cycle, which shows that next to industry, organizational life cycle is an important determinant of firm performance. For example, the value-relevance of reported accounting measures and the behavior of accruals have been shown to vary predictably by life cycle stage (Anthony and Ramesh 1992; Dickinson et al. 2018; Hribar and Yehuda 2015). Other studies have documented the relevance of life cycle fundamentals for forecasting and valuation (Cantrell and Dickinson 2019; Dickinson 2011; Vorst and Yohn 2018; Vorst and Yohn 2019). Dickinson (2011) shows that there are substantial and persistent differences in average profitability across firm life cycle stages. Vorst and Yohn (2018) further find that mean-

\footnotetext{
${ }^{46}$ In this study, informational value refers to the persistence or sustainability of earnings components.
} 
reversion models for profitability and growth differ per life cycle stage, and show that life cycle models outperform economy-wide and industry-specific models on accuracy improvements. Their finding that profitability measures revert to a life cycle stage-specific mean suggests that a life cyclewide earnings component exists.

In this paper, we investigate the informational value of this common earnings component, i.e., how sustainable or persistent it is, and the use of life cycle models in forecasting and valuation. Given the relatively sticky nature of the fundamentals underlying firm life cycle, we expect the common earnings component to be more persistent than firm-specific deviations from the life cyclewide average. Additionally, given prior findings that investors fail to fully incorporate the differential persistence of earnings components into stock prices, we expect the market to underreact to life cycle-wide earnings and overreact to firm-specific earnings.

To further explore the importance of organizational life cycle as a driver of a firm's fundamental performance, we follow prior literature (e.g., Hui et al. 2016; Konstantinidi et al. 2016; Sloan 1996) and use the Mishkin (1983) test. Here, we regress next year's profitability on current profitability to identify the persistence of both earnings components and obtain the implicit weights impounded in stock prices by regressing next year's abnormal returns on current profitability. We use return on net operating assets (RNOA) as our profitability measure and define life cycle-wide earnings as the average earnings of all firms in the same life cycle stage and year. Firm-specific earnings represent the difference between a firm's reported earnings and life cycle-wide earnings. We capture firm life cycle with the cash flow based life cycle measure of Dickinson (2011).

We find that life cycle-wide earnings are significantly more persistent than firm-specific deviations from the norm. The market does not fully utilize this differential, as the weights attributed to both components in forecasting next year's earnings are statistically indistinguishable. Consequently, we find that the average investor significantly underprices life cycle-wide earnings and overprices firm-specific earnings. These results are in line with prior research that shows that the average market participant fixates on aggregate earnings, but fails to fully recognize the value of life cycle information for forecasting and valuation. Consistent with these results reflecting investor mispricing, we find that firm life cycle earnings significantly predict future abnormal stock returns. Results from a decile test show a predictable drift in future abnormal returns in the direction of life cycle-wide earnings, and a significant return spread between the highest and lowest decile of life cycle-wide earnings.

Similar to the literature on industry, the organization literature documents that firm life cycle is characterized by a combination of internal and external fundamentals (Miller and Friesen 1984). To the extent that industry and firm life cycle may share some underlying fundamentals, such as the competitive environment, we rerun our main market analysis and include industry-wide earnings to examine whether life cycle earnings add incremental value over industry earnings. Results show that even after accounting for industry, the adjusted life cycle-wide earnings are significantly more persistent than firm-specific as well as industry earnings, and again underreacted to by the market. This suggests that the common life cycle component is incrementally relevant and is complementary 
to industry earnings. Interesting to note is that these results do not hold the other way around. When we adjust industry earnings for life cycle earnings, the industry component is no longer more persistent than the firm-specific component, nor is it priced significantly different by the market. Life cycle earnings are still highly persistent and underpriced. This suggests that the fundamentals that originally drive the higher persistence of industry earnings are also captured by life cycle-wide earnings, while life cycle earnings capture additional fundamentals, independent of industry drivers. Together, these results suggest that life cycle is a comparatively more complete construct than industry as a driver of earnings persistence. These findings complement Vorst and Yohn (2018), who conclude that life cycle models outperform industry models in profitability mean-reversion models.

Cantrell and Dickinson (2019) use both firm-specific and industry-wide life cycle information to define leaders and laggards and find that profitability depends on the firm life cycle stage relative to the industry life cycle stage. We examine industry life cycle as a relevant characteristic of a firm's earnings generating process. Results show a marginally higher persistence for the common component, which suggests that industry life cycle is a driver of earnings persistence. Also, in this model we find that common earnings are underpriced whereas firm-specific deviations are overpriced. To mitigate the concern that persistence in firm life cycle earnings is largely driven by industry life cycle information, and as such is influenced by industry dynamics, we rerun our main test on subsamples where firm and industry life cycle stages are either aligned or not aligned. Results show that also in the sample of non-aligned firms, the common component is relatively more persistent and underpriced, whereas the firm-specific component remains overpriced. This strengthens our earlier finding that firm life cycle persistence is not dependent on industry dynamics and supports the view that firm life cycle information is an important driver of a firm's fundamental performance.

We next investigate whether our main results hold for more sophisticated market participants such as analysts. Analysts typically consider a wider range of information in forming expectations of future profitability, and may have access to more information than an average investor. To investigate whether analysts consider life cycle in their forecasts, we build on Vorst and Yohn (2018) and examine whether analyst return on equity (ROE) and return on assets (ROA) forecasts are more strongly associated with life cycle model profitability forecasts than forecasts based on aggregate earnings. Results show that the predictions based on life cycle models explain significantly more of the variation in analyst forecasts, which suggests that analysts do incorporate life cycle information in forming their expectations. As such, we conclude that analysts perform better than the average market participant by recognizing the importance of life cycle fundamentals for forecasting and valuation, and as a result, (at least) partially incorporate this information in their profitability forecasts.

Next, we also examine the sensitivity of earnings persistence (and pricing) to dropping single life cycle stages, life cycle tenure, profit or loss-making firms, and alternative life cycle proxy specifications. First, while the persistence of life cycle-wide earnings is not driven by one dominant 
life cycle stage, investors react differently to the common earnings component depending on the life cycle stage of the firm. Second, while the persistence of life cycle-wide earnings is higher when a firm is in the same life cycle stage for more than a year, we still observe that common earnings are relatively more informative about next year's profitability even when life cycle tenure is limited to only one year. We further find that the mispricing of life cycle-wide earnings is driven by firms whose tenure exceeds one year, indicating the absence of a learning effect. Third, even though profitmaking firms enjoy a higher persistence, the life cycle-wide component for loss-making firms is still significantly more persistent than firm-specific earnings and thus benefits from a greater informational value. Fourth, the relative persistence of life cycle-wide and firm-specific earnings is robust to our life cycle measure being determined over the last two and three year cash flows, respectively. Finally, the relative persistence is robust to scaling our profitability measure by average assets, as well as to truncating the earnings components per year.

Our study contributes to the literature on earnings persistence as a measure of earnings quality and its role in forecasting and valuation. Prior studies have mainly focused on the persistence and pricing of aggregate earnings and its components as defined by the accounting system (e.g., Konstantinidi et al. 2016; Sloan 1996), or have focused on widely-used industry fundamentals to address earnings persistence (Hui et al. 2016). We extend the research on economic fundamentals and earnings quality (e.g., Hui et al. 2016; Owens et al. 2017) by documenting the importance of firm life cycle as a driver of a firm's fundamental performance.

This study also contributes to the literature on firm life cycle by showing that commonalities shared by firms in the same stage are captured by a common earnings component that impacts earnings persistence in a predictable way. While these results have implications for forecasting and valuation, we show that investors do not recognize the higher persistence of life cycle-wide earnings and as a result, misprice earnings. Analysts appear more efficient and do consider life cycle fundamentals in their forecasts. Finally, we provide evidence that life cycle-wide earnings predict future abnormal stock returns, consistent with investor underreaction. Together, our paper adds to the growing body of evidence on the relevance of firm life cycle in forecasting and valuation.

Our study extends two related studies on the effect of firm life cycle on firm profitability. Dickinson (2011) analyses firm performance per life cycle stage and finds persistent differences in levels and future changes in profitability, as well as differences in the degree of mean reversion across life cycle stages. Vorst and Yohn (2018) further find that mean-reverting models based on life cycle stages improve the accuracy of profitability and growth forecasts. While both studies show that life cycle stage commonalities affect earnings dynamics and suggest that a life cycle-wide earnings component exist, they do not directly identify this common component nor are they informative about its persistence. In our study, we extend previous literature by investigating the existence and informational value of life cycle-wide and firm-specific earnings. Moreover, rather than considering total profitability per life cycle stage, we capture the effect of life cycle fundamentals on earnings in one component. As such, we are able to distinguish between earnings 
generated by commonalities per life cycle stage and earnings driven by individual firm characteristics.

The remainder of this paper is organized as follows. Section two discusses the role of firm life cycle in the persistence and pricing of earnings. Section three discusses the research design. We present and discuss our results in section four, and use section five to conclude.

\subsection{Life Cycle and Earnings Persistence}

\subsubsection{Earnings Persistence}

Reported earnings are a joint product of the accounting measurement system and a firm's fundamental performance (Dechow et al. 2010). Accordingly, the persistence of earnings is also driven by these two factors. While there is ample research on the persistence of earnings components as defined by the accounting system, with accruals being the most studied determinant (e.g., Nissim and Penman 2001; Richardson et al. 2005; Sloan 1996), studies on how economic fundamentals influence earnings persistence are relatively scarce. Yet, studying this relationship is important to evaluate persistence as a measure of earnings quality (Dechow et al. 2010). Studies have associated the sustainability of earnings with individual fundamentals, such as product type, industry competition, capital intensity, and firm size (Lev 1983), and differentiation versus cost leadership strategy (e.g., Fairfield and Yohn 2001; Nissim and Penman 2001; Soliman 2008). Hui et al. (2016) capture multiple underlying factors at once by basing the earnings decomposition on industry. They argue that industry fundamentals such as production technology, consumer taste, and regulatory environment are relatively long-lasting. Earnings based on these fundamentals - i.e., industry-wide earnings - should therefore enjoy a higher persistence than firm-specific deviations, which are earnings that dissipate quicker due to competitive forces within an industry.

\subsubsection{Firm Life Cycle}

Similar to the literature on industry, the organization literature on firm life cycle suggests that each life cycle stage is defined by a typical combination of internal and external characteristics. Miller and Friesen (1984) show that firms in a specific life cycle stage differ from firms in other stages along several dimensions, being external environment, organizational structure, decision-making style, and firm strategy. More specific examples of internal factors that have been shown to vary systematically with life cycle stage include human resource management practices (Milliman et al. 1991), organizational designs needed to aid innovation (Koberg et al. 1996), and management accounting systems (Moores and Yuen 2001), including the application of activity-based costing (Kallunki and Silvola 2008). Examples of external factors that differ across life cycle stages are the importance of stakeholders (Jawahar and McLaughlin 2001), the competitive environment and market structure (Gort and Klepper 1982; Klepper 1996), and firm networks (Hite and Hesterly 
2001). ${ }^{47}$ Contrary to a firm's industry, which is rather fixed, a firm's life cycle is likely to vary over time. As firms transition between different corporate development phases, they experience predictable changes in these underlying characteristics. In sum, firm life cycle reflects the interdependencies of a firm's fundamentals, and as a single construct captures the interplay of a diverse set of factors.

\subsubsection{Firm Life Cycle and Earnings Persistence}

Prior studies have documented the importance of a firm's life cycle in its earnings generating process. Hribar and Yehuda (2015) show that the relative role of accruals, i.e., timing adjustment for cash flows or investment in firm growth, varies with life cycle stage. Firm life cycle also explains variation in the value-relevance of reported accounting measures, such as sales growth, capital investment, earnings and book values, as well as analysts' earnings forecasts (Anthony and Ramesh 1992; Dickinson et al. 2018). Additionally, recent accounting studies show that life cycle is relevant in analyzing, predicting and valuing a firm's financial performance (Cantrell and Dickinson 2019; Dickinson 2011; Vorst and Yohn 2018). Dickinson (2011) shows persistent differences in firm performance across life cycle stages. She further documents differences in the degree of meanreversion, with profitability for firms in the introduction and decline stages being less persistent compared to firms in the growth and maturity stages. Vorst and Yohn (2018) build on these results and examine the usefulness of life cycle in modeling mean-reversion for profitability and growth forecasts. They find improvements in the accuracy of out-of-sample forecasts for profitability and growth, and additionally show that life cycle models significantly outperform economy-wide and industry-specific models.

The above suggests that firm profitability tends to mean-revert to life cycle stage-specific averages. This indicates the existence of a common component in earnings, which captures the part of firm performance that is driven by shared characteristics of firms in the same life cycle stage. These studies, however, do not shed light on the persistence of the life cycle component itself. Triggered by these findings, we investigate the existence and informational value of life cycle-wide and firm-specific earnings, and examine whether and to what extent it is priced by market participants. Generally, the fundamentals underlying firm life cycle are relatively sticky and are less susceptible to change, which leads us to expect that the earnings generated by these factors are relatively long-lasting. Performance that deviates from the norm may reflect for example one-time events or a firm's competitive edge and is expected to dissipate rather quickly. We therefore evaluate whether the common earnings component is more persistent than the firm-specific deviations. ${ }^{48}$

\footnotetext{
${ }^{47}$ Other characteristics that the accounting and finance literature has documented to vary with firm life cycle include a firm's board composition (Lynall et al. 2003), merger and acquisition activity (Owen and Yawson 2010), dividend policy (DeAngelo et al. 2006; Grullon et al. 2002), diversification (Arikan and Stulz 2016), and the role of life cycle peers in relative performance evaluation (Drake and Martin 2018).

${ }^{48}$ Earnings persistence is often used as proxy for earnings quality (EQ) and relies on the premise that "firms with more persistent earnings have a more "sustainable" earnings / cash flow stream that will make it a more useful input into discounted cash flow (DCF)-based equity valuations" (Dechow et al. 2010, p.351). Although many users of financial
} 
We also examine whether market participants are aware of the expected differential persistence of life cycle-wide and firm-specific earnings. For our main analyses, we focus on the average market participant. Prior literature suggests that the market fixates on aggregate earnings and fails to incorporate the varying persistence levels of its components into stock prices (Sloan 1996). Hui et al. (2016) find similar results and document that investors predictably misprice earnings components by significantly underpricing the more persistent industry-wide earnings and overpricing firm-specific earnings. Given these prior findings, we expect the market to underreact to the higher persistence of life cycle-wide earnings and overreact to firm-specific deviations.

\subsection{Research Design}

\subsubsection{Sample Selection}

The main sample includes all observations for which we have matching data in Compustat and CRSP over the period 1987 to 2016 for firms with shares listed on the NYSE, AMEX, and NASDAQ. ${ }^{49}$ We exclude financial institutions (sic 6000-6999) and further require non-missing data on firm life cycle, six-digit Global Industry Classification Standard (GICS) code, and our profitability measure RNOA. Following Fairfield et al. (2009), we exclude firm-year observations where sales revenue or average net operating assets are less than $\$ 10$ million. We further exclude firm-years with an absolute RNOA greater than 1, resulting in 89,356 firm-year observations which we use to calculate our life cycle-wide and firm-specific earnings components. After matching Compustat with return data, we obtain a final sample of 70,386 firm-year observations for our main analysis.

\subsubsection{Life Cycle Measure}

We measure firm life cycle using Dickinson's (2011) cash flow based proxy. Based on systematic patterns in firms' operating, investing, and financing cash flows, firms are classified into one of the five life cycle stages, being Introduction, Growth, Maturity, Shakeout, and Decline. ${ }^{50}$ As cash flow

\footnotetext{
statement information perceive persistence as a measure of $\mathrm{EQ}$, higher persistence does not always lead to actual increased earnings quality, for instance if persistence is achieved through earnings management. In this study, individual adjustments up or down should to a great extent cancel out among life cycle-year groups, such that the life cycle-wide earnings component is largely unaffected and at most picks up a small bias if there are relatively more or greater upward adjustments. Here, increased persistence due to earnings management would be mostly captured by, and hence inflate, the firm-specific earnings component. Altogether, persistence through earnings management should not be problematic for the results and inferences of our study, as these now provide a rather conservative view. Specifically, if higher persistence due to earnings management would be fully absent, we expect to observe an even lower persistence coefficient for firm-specific earnings and thus a more pronounced difference between life cycle-wide and firm-specific earnings.

${ }^{49} \mathrm{We}$ start our sample in 1987 as this is the first year for which we have (limited) cash flow data available in Compustat. Broader coverage only starts one year later, in 1988.

${ }^{50}$ The following classification table is used to classify firm-year observations to the specific life cycle stages (retrieved from Dickinson 2011, p. 1974): (footnote continues on next page)
} 
patterns do not move in a pre-defined way, the measure allows firms to transition across different life cycle stages nonsequentially and along individual time paths, which is in line with life cycle theory (Miller and Friesen 1984).

\subsubsection{Earnings Disaggregation: Life Cycle-Wide and Firm-Specific Earnings}

To investigate the persistence of earnings driven by life cycle fundamentals, we partition earnings into life cycle-wide and firm-specific components. Life cycle-wide earnings capture the common component of earnings for all firms in the same life cycle stage, while firm-specific earnings represent individual firms' deviations from the life cycle-wide average. We define our profitability measure $E A R N$ as operating income after depreciation (Compustat OIADP) scaled by average net operating assets. Net operating assets is equal to the sum of common stock (Compustat CEQ), preferred stock (Compustat PSTK), long- and short-term debt (Compustat DLTT and DLC), and minority interest (Compustat MIB), minus cash and short-term investments (Compustat CHE). Following the approach used in prior literature on industry earnings (e.g., Hui et al. 2016) EARN is then decomposed as follows: assuming $N$ firms in life cycle stage $j$, the life cycle-wide earnings component of life cycle stage $j$ in year $t$ is defined as

$\operatorname{LCEARN}_{j, t}=1 / N \sum_{i=1}^{N} E A R N_{i, j, t}$

where $L C E A R N$ depicts the value-weighted average earnings of firms in the same life cycle stage and year. Firm-specific earnings of firm $i$ in life cycle stage $j$ and year $t$ is defined as

$\operatorname{FirmEARN}_{i, j, t}=E A R N_{i, j, t}-\operatorname{LCEARN}_{j, t}$

where FirmEARN is the difference between a firm's reported earnings ( $E A R N)$ and the life cycle-wide earnings ( $L C E A R N)$. All earnings variables are truncated at the $0.5 \%$ and $99.5 \%$ level.

\subsubsection{Market Pricing}

To test the joint hypothesis that life cycle-wide earnings are relatively more persistent and that the market fails to incorporate the differential persistence levels, we follow prior literature (e.g., Hui et al. 2016; Konstantinidi et al. 2016; Sloan 1996) and use the Mishkin (1983) test. We first estimate the following ordinary least square (OLS) regression to test whether the common component is more persistent than the firm-specific earnings:

\begin{tabular}{|c|c|c|c|c|c|c|c|c|}
\hline \multirow[b]{2}{*}{ Cash Flow Type } & \multirow{2}{*}{$\begin{array}{c}\text { Life Cycle Stages } \\
\text { Introduction } \\
1 .\end{array}$} & \multirow{2}{*}{$\begin{array}{c}\text { Growth } \\
2 .\end{array}$} & \multirow{2}{*}{$\begin{array}{c}\text { Mature } \\
3 .\end{array}$} & \multicolumn{3}{|c|}{ Shakeout } & \multicolumn{2}{|c|}{ Decline } \\
\hline & & & & 4. & 5. & 6. & 7. & 8. \\
\hline Operating Activities & - & + & + & - & + & + & - & - \\
\hline Investing Activities & - & - & - & - & + & + & + & + \\
\hline Financing Activities & + & + & - & - & + & - & + & - \\
\hline
\end{tabular}


$\operatorname{EARN}_{i, j, t+1}=a_{0}+a_{1} L C E A R N_{j, t}+a_{2} \operatorname{FirmEARN}_{i, j, t}+\varepsilon_{1 i, j, t+1}$

where $E A R N_{t+1}$ equals next-year earnings, and $L C E A R N_{t}$ and FirmEARN $N_{t}$ represent the life cycle-wide and firm-specific earnings as defined earlier. We expect a relatively stronger association between life cycle-wide earnings and future earnings, such that $a_{1}>a_{2}$. Next, to obtain the implicit weights impounded in stock prices, we estimate the following Mishkin non-linear generalized least square pricing regression model: ${ }^{51}$

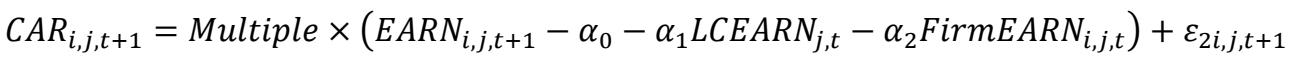

where $C A R_{t+1}$ is next year's abnormal return, defined as the size-adjusted 12-month buy-andhold stock return starting the fourth month after the end of fiscal year $t$, and Multiple equals the earnings response coefficient. If the market fails to fully incorporate life cycle information into stock prices and focus on aggregate earnings instead, we expect $\alpha_{1}=\alpha_{2}$. Additionally, we expect investors to underreact to life cycle-wide earnings and overreact to firm-specific earnings, such that $a_{1}>\alpha_{1}$ and $a_{2}<\alpha_{2}$.

\subsubsection{Life Cycle-Wide Earnings and Future Abnormal Returns}

If the market fails to incorporate differential persistence levels and thus misprices earnings, we would also expect higher future abnormal stock returns as life cycle-wide earnings increase. To examine this, we create decile portfolios of current life cycle-wide earnings and examine future abnormal returns $\left(C A R_{t+1}\right)$ for each decile. We impose two additional sample restrictions before partitioning $L C E A R N_{t}$. To avoid a look-ahead bias regarding the distribution of life cycle-wide earnings, we only select firms with a fiscal year-end in December. We additionally require the closing stock price to be above $\$ 1$ to mitigate noise due to for example infrequent trading or bid-ask spread bounces. Our final sample for the future abnormal returns test consists of 48,058 firm-years.

\subsection{Results}

\subsubsection{Descriptive Statistics}

Table 4.1 reports the descriptive statistics based on the market pricing sample, with summary statistics reported in Panel A and correlation tables presented in Panel B. Comparable to Vorst and Yohn (2018), mean $E A R N_{t}$ (i.e., RNOA) is $12.91 \%$ versus a mean $R O E$ of only $6.20 \%$, which shows that the return on operating activities is considerably greater than the returns on investing and financing activities. Compared to the common components $L C E A R N_{t}$, IndEARN , and $I N D L C E A R N_{t}$, we observe larger standard deviations for all corresponding firm-specific earnings. This is consistent with prior literature and our prediction that firm-specific deviations are more volatile than common earnings components that are driven by rather stable fundamentals. In our

${ }^{51}$ We perform the Mishkin test using non-linear least square estimation via the $n l s u r$ command in Stata. 
market pricing sample, the majority consists of firms in the growth or the mature stage $(34.0 \%$ and $44.5 \%$, respectively), whereas firms in the decline stage form the smallest group with only $3.3 \%$. The average length of time that a firm stays in the same life cycle stage is 2.24 years.

Panel B presents the Pearson (top) and Spearman (bottom) correlations. The correlation between $L C E A R N_{t}$ and IndEARN $N_{t}$ is quite low (Pearson 9.7\% and Spearman 10.5\%), which implies that, to a large extent, these common components capture different fundamentals. The correlations of $L C E A R N_{t}$ and IndEARN $N_{t}$ with INDLCEARN $N_{t}$ are slightly higher, as this variable is jointly determined by life cycle and industry.

TABLE 4.1

Descriptive Statistics

\begin{tabular}{|c|c|c|c|c|c|c|}
\hline \multicolumn{7}{|c|}{ Panel A: Summary Statistics } \\
\hline$C A R_{t+1}$ & 70,386 & 0.017 & 0.733 & -0.316 & -0.060 & 0.202 \\
\hline $\operatorname{Earn}_{t+1}$ & 70,386 & 0.114 & 0.219 & 0.040 & 0.117 & 0.206 \\
\hline $\operatorname{Earn}_{t}$ & 70,285 & 0.129 & 0.197 & 0.049 & 0.123 & 0.214 \\
\hline$L C E A R N_{t}$ & 70,386 & 0.123 & 0.059 & 0.101 & 0.130 & 0.162 \\
\hline FirmEARN $_{t(L C)}$ & 70,386 & 0.006 & 0.185 & -0.081 & -0.005 & 0.087 \\
\hline $\operatorname{IndEARN_{t}}$ & 69,561 & 0.159 & 0.070 & 0.114 & 0.152 & 0.196 \\
\hline FirmEARN $_{t(G I N D)}$ & 69,561 & -0.030 & 0.194 & -0.111 & -0.022 & 0.058 \\
\hline$I N D L C E A R N_{t}$ & 69,789 & 0.140 & 0.031 & 0.119 & 0.137 & 0.164 \\
\hline FirmEARN $N_{t(I N D L C)}$ & 69,789 & -0.010 & 0.195 & -0.093 & -0.016 & 0.076 \\
\hline INDLC_LCalign $_{t}$ & 70,386 & 0.452 & 0.498 & 0.000 & 0.000 & 1.000 \\
\hline LCtenure $_{t}$ & 70,386 & 2.235 & 2.122 & 1.000 & 1.000 & 3.000 \\
\hline$N E G_{t}$ & 70,386 & 0.161 & 0.368 & 0.000 & 0.000 & 0.000 \\
\hline$R O E_{t}$ & 67,292 & 0.062 & 0.202 & 0.008 & 0.093 & 0.159 \\
\hline$R O A_{t}$ & 67,292 & 0.031 & 0.095 & 0.004 & 0.041 & 0.079 \\
\hline Intro_stage & 70,386 & 0.099 & 0.298 & 0.000 & 0.000 & 0.000 \\
\hline Growth_stage & 70,386 & 0.340 & 0.474 & 0.000 & 0.000 & 1.000 \\
\hline Mature_stage & 70,386 & 0.445 & 0.497 & 0.000 & 0.000 & 1.000 \\
\hline Shake_stage & 70,386 & 0.084 & 0.277 & 0.000 & 0.000 & 0.000 \\
\hline Decline_stage & 70,386 & 0.033 & 0.178 & 0.000 & 0.000 & 0.000 \\
\hline $\begin{array}{l}\text { Panel B: Correlat } \\
\text { Variable }\end{array}$ & $C A R_{t^{+1}}$ & $\operatorname{Earn}_{t+1}$ & $\operatorname{Earn}_{t}$ & $L C E A R N_{t}$ & $\operatorname{IndEARN_{t}}$ & $I_{N D L C E A R N_{t}}$ \\
\hline$C A R_{t+1}$ & 1.000 & 0.158 & -0.009 & 0.018 & 0.012 & 0.015 \\
\hline $\operatorname{Earn}_{t+1}$ & 0.299 & 1.000 & 0.710 & 0.328 & 0.099 & 0.057 \\
\hline Earn $_{t}$ & 0.068 & 0.747 & 1.000 & 0.376 & 0.161 & 0.071 \\
\hline$L_{C E A R N_{t}}$ & 0.099 & 0.290 & 0.307 & 1.000 & 0.097 & 0.268 \\
\hline $\operatorname{IndEARN_{t}}$ & 0.013 & 0.142 & 0.194 & 0.105 & 1.000 & 0.348 \\
\hline$I N D L C E A R N_{t}$ & 0.046 & 0.058 & 0.074 & 0.293 & 0.359 & 1.000 \\
\hline
\end{tabular}

This table presents the descriptive statistics of the main variables. Panel A provides summary statistics and panel B shows the correlations among a subset of variables. The market sample consists of 70,386 firm-year observations over the period 1987-2016 and includes all firms with available data in Compustat and CRSP with shares listed on the NYSE, AMEX, and NASDAQ. The analyst sample requires additional non-missing data from I/B/E/S, which leads to decreased sample sizes for our analyst tests. Note that Intro_stage, Growth_stage, Mature_stage, Shake_stage, Decline_stage provide information on the distribution of firms in the five different life cycle stages. Continuous non-return measures are truncated at the $0.5 \%$ and the $99.5 \%$ level. All variables are defined in Appendix 4A. 


\subsubsection{Main Results}

\subsubsection{Mishkin Test}

Table 4.2 reports the results from the Mishkin (1983) test, which jointly examines the persistence and pricing of life cycle-wide and firm-specific earnings. Column (1) presents the results of the forecasting equation (model 3a). The coefficient for life cycle-wide earnings $\left(L C E A R N_{t}\right)$ equals 0.993 and is significantly larger than the estimated coefficient of 0.755 for firm-specific earnings $\left(\right.$ FirmEARN $\left.N_{t}\right)(\mathrm{p}<0.001)$. This implies that life cycle-wide earnings are relatively more persistent. Consistent with our expectations, these results provide evidence that within-life cycle stage commonalities in firm fundamentals drive a firm's earnings generating process such that the informational value can be captured by a common earnings component. Given the significant difference in persistence, earnings that are disaggregated based on life cycle fundamentals can be a useful input for equity valuation.

TABLE 4.2

Differential Persistence and Pricing of Life Cycle-wide and Firm-Specific Earnings

(1)

\section{Forecasting Equation}

Variables

Multiple

Intercept

LCEARN $_{t}$

FirmEARN $_{t}$

Observations

R-squared

$L C E A R N_{t}=$ FirmEARN $_{t}$
Earn $_{t+1}$

$-0.013 * * *$

$0.993 * * *$

(77.32)

$0.755^{* * *}$

(123.38)

70,386

0.5120

312.92

$(p<0.001)$
(2)

\section{Return Equation}

$1.120 * * *$

$0.768 * * *$

$0.821 * * *$

$(p<0.001)$

$(p<0.001)$
CAR $_{t+1}$

$-0.001$

(55.44)

15.66

17.88

Chi-2

70,386

0.0552

0.9

This table reports the results of our main market analysis testing the persistence and pricing of life cycle-wide and firmspecific earnings. The sample includes all firm-year observations with matching data in Compustat and CRSP over the period 1987 to 2016 for firms with shares listed on the NYSE, AMEX, and NASDAQ. Earnings variables are truncated at the $0.5 \%$ and $99.5 \%$ level. Z-statistics and p-values are based on standard errors clustered at firm level. Z-statistics are reported in parentheses below the coefficients. $* * *$ indicate statistical significance at the $1 \%$ level (two-tailed). Variable definitions can be found in Appendix 4A. 
Column (2) shows the implicit weights placed on life cycle-wide and firm-specific earnings in stock prices. The estimated coefficients for $\operatorname{LCEARN}_{t}(0.768)$ and FirmEARN $(0.821)$ are statistically indistinguishable ( $\mathrm{p}=0.344)$, which is in line with prior research that the average investor does not see through the differential persistence levels of earnings components, but instead fixates on aggregate earnings. Furthermore, the chi-2 tests compare the persistence coefficients (column 1) with the implicit market weights (column 2) and show that investors significantly underprice life cycle-wide earnings (i.e. $0.768<0.993$; chi-2=15.66, $<<0.001$ ) and overprice firm-specific earnings (i.e., $0.821>0.755$; chi- $2=17.88, \mathrm{p}<0.001$ ). Altogether, these results confirm our prediction that the average investor fails to incorporate life cycle information into stock prices.

\subsubsection{Life Cycle-Wide Earnings and Future Abnormal Returns}

Results of the Mishkin test show, amongst others, that investors underreact to life cycle-wide earnings. Seeing this as mispricing, we would additionally expect a positive correlation between future abnormal stock returns and life cycle-wide earnings. Table 4.3 reports the average future abnormal return per decile portfolio. Conform expectations, we observe a positive trend in returns as life cycle earnings increase. Furthermore, we find a spread in average $C A R_{t+1}$ of $8.77 \%$ between the lowest and highest earnings deciles that is statistically significant at the $1 \%$ level, with decile [1] reporting the lowest future abnormal return (-0.028) and decile [10] reporting the highest portfolio return (0.059). As future abnormal returns seem to move parallel to life cycle-wide earnings, results of this test strengthen our conclusion that the underreaction to $L C E A R N_{t}$ in the Mishkin test reflects investor mispricing.

TABLE 4.3

Future Stock Returns per Decile Portfolio of Life Cycle-wide Earnings

\begin{tabular}{lccc}
\hline \hline LCEARN Deciles & $\mathbf{N}$ & LCEARN $_{\mathbf{t}}$ & $\mathbf{C A R}_{\mathbf{t + 1}}$ \\
\hline 1 & 4,883 & -0.008 & -0.028 \\
2 & 4,889 & 0.075 & 0.017 \\
3 & 4,378 & 0.101 & 0.025 \\
4 & 4,962 & 0.111 & -0.007 \\
5 & 4,911 & 0.121 & -0.003 \\
6 & 4,842 & 0.135 & -0.010 \\
7 & 4,840 & 0.146 & 0.050 \\
8 & 4,724 & 0.165 & 0.054 \\
9 & 5,038 & 0.181 & 0.016 \\
10 & 4,591 & 0.200 & 0.059 \\
Total N & 48,058 & & \\
\hline
\end{tabular}

$\begin{array}{lr}\text { D10 - D1 } & 0.0877^{* * * *} \\ & (4.49)\end{array}$

This table reports the average future abnormal return per decile portfolio. We use current life cycle-wide earnings to create the decile portfolios. The sample size of 48,058 firm-years is smaller than the samples for our other market analyses, as we impose two additional sample restrictions before partitioning $L C E A R N_{t}$ : we require a December fiscal year-end and a closing stock price greater than $\$ 1$. The earnings variable is truncated at the $0.5 \%$ and $99.5 \%$ level. Variable definitions can be found in Appendix 4A. 


\subsubsection{Additional Analyses}

\subsubsection{Industry Adjustments}

Thus far, we have shown that the informational value for future earnings is relatively greater for common earnings driven by life cycle fundamentals. In this section, we examine whether firm life cycle adds value over and above industry earnings. Prior research has similarly shown that industry fundamentals also hold valuable information for future performance (Hui et al. 2016). Whereas industry and firm life cycle both capture a combination of internal and external fundamentals, a firm's industry is rather fixed while life cycle is transitory by nature. It is unclear to what extent these two classifications capture overlapping underlying characteristics, such as a firm's competitive environment, that possibly drive earnings in like manner. ${ }^{52}$

We extend our main market analysis (models $3 \mathrm{a}$ and $3 \mathrm{~b}$ ) and adjust life cycle-wide earnings for industry earnings to examine the life cycle earnings' incremental value. We define industry earnings (IndEARN) in the same way as life cycle-wide earnings, such that industry-wide earnings reflect the value-weighted average earnings of firms in the same industry (6-digit GICS) and year. We then subtract IndEARN from $L C E A R N$ to obtain the adjusted life cycle-wide earnings (Adj_LCEARN), and estimate the following forecasting (4a) and return (4b) equations using the Mishkin approach: ${ }^{53}$

$$
\begin{aligned}
& \text { EARN }_{t+1}=a_{0}+a_{1} \operatorname{IndEARN}_{t}+a_{2} \text { Adj_LCEARN }_{t}+a_{3} \text { FirmEARN }_{t(L C)}+\varepsilon_{1 t+1} \\
& \text { CAR }_{t+1}=\text { Multiple } \times\left(\text { EARN }_{t+1}-\alpha_{0}-\alpha_{1} \text { IndEARN }_{t}-\alpha_{2} \text { Adj_LCEARN }_{t}-\right. \\
& \left.\alpha_{3} \text { FirmEARN }_{t(L C)}\right)+\varepsilon_{2 t+1}
\end{aligned}
$$

Results are reported in Table 4.4, Panel A. As can be seen in column (1), the coefficients for IndEarn (0.934) and Adj_LCEARN (0.994) are both significantly larger than for firm-specific earnings (0.757). In addition, we observe a significant difference between the two common components, with a higher coefficient for Adj_LCEARN. This suggests that even after accounting for industry by taking out the 'shared' common earnings, the adjusted life cycle-wide earnings are significantly more persistent than firm-specific as well as industry-wide earnings. When we look at the implicit weights in stock prices (column 2), we find that investors significantly underreact to both common components, IndEarn (coeff. 0.613) and Adj_LCEARN (coeff. 0.790), and overreact to firm-specific earnings (coeff. 0.828) (all chi-2: $\mathrm{p}<0.001$ ). In sum, these results suggest that life cycle-wide earnings hold incremental value over and above industry earnings.

\footnotetext{
${ }^{52}$ For example, even though we cluster the competitive environment in a different way - within-life cycle and withinindustry, respectively - its effect on earnings persistence may still be comparable for certain life cycle stage-industry combinations.

${ }^{53}$ All earnings variables are truncated at the $0.5 \%$ and $99.5 \%$ level.
} 
TABLE 4.4

Industry-adjusted Life Cycle Earnings and Life Cycle-adjusted Industry Earnings

\begin{tabular}{|c|c|c|c|}
\hline $\begin{array}{l}\text { Panel A: Life Cycle-wide E } \\
\text { Variables }\end{array}$ & $\begin{array}{c}\text { d for Industry-wide Ea } \\
(1) \\
\text { Forecasting Equation } \\
\text { Earn }_{\mathbf{t}+1}\end{array}$ & $\begin{array}{l}\text { nings } \\
\text { (2) } \\
\text { Return Equation } \\
\text { CAR }_{\mathbf{t + 1}}\end{array}$ & Chi-2 \\
\hline Multiple & & $\begin{array}{c}1.124 * * * \\
(34.96)\end{array}$ & \\
\hline Intercept & $\begin{array}{l}-0.003 \\
(-1.27)\end{array}$ & $\begin{array}{c}0.025^{* * *} \\
(2.83)\end{array}$ & \\
\hline $\operatorname{IndEARN_{t}}$ & $\begin{array}{c}0.934 * * * \\
(58.74)\end{array}$ & $\begin{array}{c}0.613 * * * \\
(10.19)\end{array}$ & $\begin{array}{c}26.52 \\
(p<0.001)\end{array}$ \\
\hline Adj_LCEARN $N_{t}$ & $\begin{array}{c}0.994 * * * \\
(76.34)\end{array}$ & $\begin{array}{c}0.790 * * * \\
(13.99)\end{array}$ & $\begin{array}{c}12.56 \\
(p<0.001)\end{array}$ \\
\hline FirmEARN $_{t(L C)}$ & $\begin{array}{l}0.757 * * * \\
(121.22)\end{array}$ & $\begin{array}{c}0.828 * * * \\
(54.20)\end{array}$ & $\begin{array}{c}19.82 \\
(p<0.001)\end{array}$ \\
\hline Observations & 69,746 & 69,746 & \\
\hline R-squared & 0.5090 & 0.0552 & \\
\hline $\operatorname{IndEARN_{t}}=$ Adj_LCEARN $N_{t}$ & $\begin{array}{c}30.71 \\
(p<0.001)\end{array}$ & $\begin{array}{c}15.78 \\
(p<0.001)\end{array}$ & \\
\hline
\end{tabular}

Panel B: Industry-wide Earnings adjusted for Life Cycle-wide Earnings

(2)

\begin{tabular}{|c|c|c|}
\hline Variables & $\begin{array}{c}\operatorname{Earn}_{t+1} \\
\end{array}$ & $\begin{array}{c}\text { CAR }_{t+1} \\
\end{array}$ \\
\hline Multiple & & $\begin{array}{c}1.126^{* * *} \\
(34.76)\end{array}$ \\
\hline Intercept & $\begin{array}{l}-0.002 \\
(-0.79)\end{array}$ & $\begin{array}{c}0.027 * * * \\
(2.97)\end{array}$ \\
\hline$L C E A R N_{t}$ & $\begin{array}{c}0.929 * * * \\
(57.89)\end{array}$ & $\begin{array}{c}0.605 * * * \\
(10.03)\end{array}$ \\
\hline Adj_IndEARN $N_{t}$ & $\begin{array}{c}0.683 * * * \\
(57.90)\end{array}$ & $\begin{array}{c}0.642 * * * \\
(14.58)\end{array}$ \\
\hline FirmEARN $_{t(\text { (nd) }}$ & $\begin{array}{c}0.754 * * * \\
(120.11)\end{array}$ & $\begin{array}{c}0.833 * * * \\
(51.17)\end{array}$ \\
\hline Observations & 69,720 & 69,720 \\
\hline R-squared & 0.5064 & 0.0550 \\
\hline$L C E A R N_{t}=A d j \_I n d E A R N_{t}$ & $\begin{array}{c}326.47 \\
(p<0.001)\end{array}$ & $\begin{array}{c}0.44 \\
(p=0.5090)\end{array}$ \\
\hline
\end{tabular}

This table reports results of the market analysis including industry earnings. The samples include all firm-year observations with non-missing data in Compustat and CRSP over the period 1987 to 2016 for firms with shares listed on the NYSE, AMEX, and NASDAQ. Panel A reports the results of the forecasting and return regressions, and tests for the persistence and pricing of industry-wide earnings, adjusted life cycle-wide earnings, and firm-specific earnings $(\mathrm{LC})$.

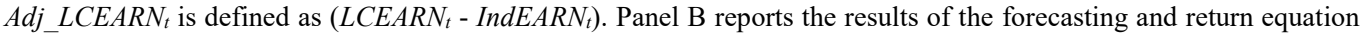
with life cycle-wide earnings, adjusted industry earnings, and firm-specific earnings ${ }_{(\mathrm{IND})}$ as independent variables.

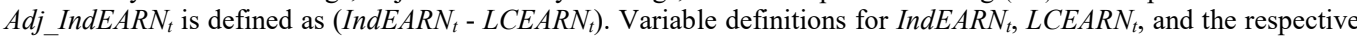
firm-specific deviations can be found in Appendix 4A. All earnings variables are truncated at the $0.5 \%$ and $99.5 \%$ level. Z-statistics and p-values are based on standard errors clustered at firm level. Z-statistics are reported in parentheses below the coefficients. $* * *$ indicate statistical significance at the $1 \%$ level (two-tailed). 
We also examine an alternative specification where we adjust the common industry component for life cycle earnings. Results are shown in Panel B of Table 4.4. Whereas life cyclewide earnings are still highly persistent (coeff. 0.929), the adjusted industry component (coeff. 0.683 ) is surprisingly no longer more persistent than firm-specific earnings (coeff. 0.754). Moreover, while $L C E A R N$ and FirmEARN $($ Ind) are significantly underpriced and overpriced, respectively, $A d j \_I n d E A R N$ is not priced significantly different by the market (chi-2 p=0.3635).

\subsubsection{Industry Life Cycle}

To this point, we have mainly focused on firm life cycle as a driver of firm performance. In a recent study, Cantrell and Dickinson (2019) compare firm life cycle with the life cycle of the entire industry to define industry leaders and laggards. They find that a firm's relative position has implications for future firm profitability and market mispricing. Specifically, they find that firms with a less advanced life cycle than the industry (i.e., laggards) are associated with larger improvements in future operating performance and greater risk-adjusted returns. Triggered by these findings that firms' earnings dynamics are affected by the life cycle of their industry, we start by examining whether industry life cycle is an important determinant of a firm's earnings persistence. If so, we then need to investigate to what extent our main results are driven by (non)alignment with the industry life cycle.

First, we use the total operating, investing, and financing cash flows per industry (six-digit GICS) and year to define industry life cycle stages. We then decompose reported (firm-level) earnings into an industry life cycle-wide component (INDLCEARN) and a firm-specific component (FirmEARN $N_{I N D L C}$ ), where INDLCEARN is the average value-weighted earnings per industry life cycle stage and year and FirmEARN INDLC reflects a firm's deviation from this average. The earnings variables are truncated at the $0.5 \%$ and $99.5 \%$ level. We use the Mishkin approach to test for the persistence and pricing of industry life cycle earnings and run an adapted version of models ( $3 \mathrm{a}$ ) and (3b). Results are presented in Table 4.5, Panel A. The persistence coefficient for INDLCEARN (0.811) is significantly greater than for FirmEARN (0.777) at the $10 \%$ level. Furthermore, we find that INDLCEARN is significantly underpriced (chi-2: 15.11, p<0.001) and FirmEARN overpriced (chi-2: $7.60, \mathrm{p}=0.0058$ ) by the market. As the common earnings component is marginally more persistent, results suggest that industry life cycle earnings serve as a determinant of the earnings generating process, albeit less powerful compared to firm life cycle.

Knowing that industry life cycle relies on the same underlying fundamentals as firm life cycle and also drives firm performance, a potential concern is that the persistence of firm life cycle-wide earnings (i.e., our main result) is largely driven by industry life cycle information, and as such is still affected by industry dynamics. To mitigate this concern, we rerun our main market analysis on partitioned samples, where firm- and industry life cycle stages are or are not aligned. If our main results are mainly driven by industry life cycle, we should not observe a relatively higher persistence of firm life cycle-wide earnings for those firms whose life cycle stage is not aligned with that from the industry. Results are reported in Panel B of Table 4.5. We find that even for non-aligned firms 
TABLE 4.5

Industry Life Cycle: Persistence, Pricing, and (Non-)Alignment

\begin{tabular}{|c|c|c|c|}
\hline Panel A: Industry Life Cycl & $\begin{array}{l}\text {-Wide and Firm-Specif } \\
\text { (1) } \\
\text { Forecasting Equation } \\
\text { Earn }_{\mathrm{t}+1}\end{array}$ & $\begin{array}{l}\text { rnings } \\
\text { (2) } \\
\text { Return Equation } \\
\text { CAR }_{t+1} \\
\end{array}$ & Chi-2 \\
\hline Multiple & & $\begin{array}{c}1.110 * * * \\
(35.38)\end{array}$ & \\
\hline Intercept & $\begin{array}{l}0.010^{* * *} \\
(3.29)\end{array}$ & $\begin{array}{c}0.037 * * * \\
(3.33)\end{array}$ & \\
\hline$I N D L C E A R N_{t}$ & $\begin{array}{c}0.811 * * * \\
(41.02)\end{array}$ & $\begin{array}{c}0.506 * * * \\
(6.68)\end{array}$ & $\begin{array}{c}15.11 \\
(p<0.001)\end{array}$ \\
\hline FirmEARN $_{t}$ & $\begin{array}{c}0.777 * * * \\
(132.72)\end{array}$ & $\begin{array}{c}0.821 * * * \\
(53.78)\end{array}$ & $\begin{array}{c}7.60 \\
(p=0.0058)\end{array}$ \\
\hline $\begin{array}{l}\text { Observations } \\
\text { R-squared }\end{array}$ & $\begin{array}{l}70,137 \\
0.5051\end{array}$ & $\begin{array}{l}70,137 \\
0.0542\end{array}$ & \\
\hline$I N D L C E A R N_{t}=$ FirmEARN $_{t}$ & $\begin{array}{c}2.94 \\
(p=0.0864)\end{array}$ & $\begin{array}{c}16.55 \\
(p<0.001)\end{array}$ & \\
\hline
\end{tabular}

Panel B: (Non-)Alignment with Industry Life Cycle LC - INDLC ALIGN

LC - INDLC NON-ALIGN
(1)
(2)
(3)
(4)

Forecasting Eq.Return Eq. $\quad$ Forecasting Eq.Return Eq.

\begin{tabular}{|c|c|c|c|c|c|c|}
\hline Variables & $\operatorname{Earn}_{t+1}$ & $\mathbf{C A R}_{t+1}$ & Chi-2 & $\operatorname{Earn}_{t+1}$ & $\mathbf{C A R}_{t+1}$ & Chi-2 \\
\hline \multirow[t]{2}{*}{ Multiple } & & $1.176^{* * *}$ & & & $1.091 * * *$ & \\
\hline & & $(26.11)$ & & & $(26.72)$ & \\
\hline \multirow[t]{2}{*}{ Intercept } & $-0.026 * * *$ & 0.032 & & $-0.010 * * *$ & -0.007 & \\
\hline & $(-5.94)$ & $(1.60)$ & & $(-5.10)$ & $(-0.75)$ & \\
\hline \multirow{2}{*}{$L C E A R N_{t}$} & $1.089 * * *$ & $0.579 * * *$ & 14.64 & $0.956^{* * *}$ & $0.785 * * *$ & 5.73 \\
\hline & $(40.11)$ & $(4.49)$ & $(p<0.001)$ & $(59.95)$ & (11.29) & $(p=0.0167)$ \\
\hline \multirow[t]{2}{*}{ FirmEARN $_{t}$} & $0.775 * * *$ & $0.831 * * *$ & 6.34 & $0.744 * * *$ & $0.810 * * *$ & 9.42 \\
\hline & $(89.95)$ & $(38.60)$ & $(p=0.0118)$ & $(93.66)$ & (39.19) & $(p=0.0021)$ \\
\hline Observations & 31,804 & 31,804 & & 38,582 & 38,582 & \\
\hline R-squared & 0.5186 & 0.0585 & & 0.4895 & 0.0537 & \\
\hline \multirow[t]{2}{*}{$L_{C E A R N_{t}}=$ FirmEARN $_{t}$} & 133.18 & 4.06 & & 153.75 & 0.12 & \\
\hline & $(p<0.001)$ & $(p=0.0439)$ & & $(p<0.001)$ & $(p=0.7282)$ & \\
\hline
\end{tabular}

This table reports the results of the market analysis including industry life cycle earnings. The sample includes all firmyear observations with matching data in Compustat and CRSP over the period 1987 to 2016 for firms with shares listed on the NYSE, AMEX, and NASDAQ. Panel A reports the results for the pooled sample, testing the persistence and pricing of industry life cycle-wide and firm-specific earnings. Panel B examines the persistence and pricing of firm life cycle earnings conditional on firm life cycle and industry life cycle being aligned or not aligned. All earnings variables are truncated at the $0.5 \%$ and $99.5 \%$ level. Z-statistics and $p$-values are based on standard errors clustered at firm level. $Z$-statistics are reported in parentheses below the coefficients. ${ }^{* * *}$ indicate statistical significance at the $1 \%$ level (twotailed). Variable definitions can be found in Appendix 4A. 
(columns 3 and 4), the common earnings component is significantly more persistent than the firmspecific deviation (coeff. 0.956 and 0.744 , respectively). Moreover, we find that mispricing occurs in a similar way as in the pooled sample. Specifically, (firm) life cycle-wide earnings are underpriced (chi-2: 5.73, $\mathrm{p}=0.0167$ ) and firm-specific earnings are overpriced (chi-2: 9.42, $\mathrm{p}=0.0021$ ). Based on this, we conclude that our main results are not driven by (non)alignment with the industry life cycle stage. In sum, these results strengthen our earlier finding that firm life cycle drives fundamental performance complementary to industry dynamics and further support the view that firm life cycle is an important determinant of a firm's earnings generating process.

\subsubsection{Analysts Forecasts and Life Cycle Model Predictions}

Our main analyses focus on the average market participant and to what extent life cycle-wide and firm-specific earnings are reflected in stock prices. In this section, we investigate the use of differential persistence levels by more sophisticated market participants such as analysts. It is not clear whether the results that we obtain for the market analysis also hold for analysts. In forming expectations about future firm performance, analysts typically consider a wider range of information and may have access to more information than an average investor, which enables them to make better informed decisions. However, it is ex ante less clear to what extent analysts are aware of the value relevance of life cycle information. A major focus on industry analyses in prior research has given analysts a decent understanding of industry-level information (Hutton et al. 2012), which has resulted in extensive use of industry models in forecasting and valuation. Correspondingly, analysts are now frequently assigned to follow firms in specific industries and as such become industry specialists (e.g., Hutton et al. 2012; Kadan et al. 2012). It has not yet been documented whether analysts are alternatively assigned to groups of firms based on firm life cycle stages and hence, specialize themselves in for example growth or mature firms. Nonetheless, given that they are more thoroughly informed than the average investor it is reasonable to expect that analysts are aware of certain life cycle dynamics and incorporate these in their profitability forecasts. In support of this expectation, Vorst and Yohn (2018) document that analysts partially incorporate the information from modeling mean reversion as a function of firm life cycle in their forecasts.

To examine whether analysts incorporate life cycle information in their expectations about future profitability, we follow prior literature (Fairfield et al. 2009; Vorst and Yohn 2018) and examine the association between analyst profitability forecasts and predicted values obtained from the aggregate earnings model, as well as the life cycle model. If analysts recognize the added value of life cycle information in their analyses, we expect their ROE and ROA forecasts to be more strongly related to life cycle model predictions. We estimate the following regression models:

$$
\begin{aligned}
& \text { FORECAST }_{i, t}=\beta_{0}+\beta_{1} \text { PRED_AGG } i, t+\varepsilon_{i, t} \\
& \text { FORECAST }_{i, t}=\beta_{0}+\beta_{1} \text { PRED_LC }_{i, t}+\varepsilon_{i, t}
\end{aligned}
$$


where FORECAST is either the I/B/E/S first or April consensus (mean) forecast for ROE or ROA, respectively. The first forecast captures the first estimate in $\mathrm{I} / \mathrm{B} / \mathrm{E} / \mathrm{S}$ for year $t$ that is issued after announcing year t-1 earnings. The April forecasts include all consensus forecasts for year $t$ issued in April. We include these as by that time, all earnings from year t-1 will have been announced. PRED_AGG and PRED_LC are the ROE or ROA forecasts obtained from the aggregate earnings model and the life cycle model, respectively. ${ }^{54} \mathrm{ROE}$ is defined as income before extraordinary items available for common stockholders (Compustat IBCOM) scaled by average common equity (Compustat CEQ). ROA is calculated as income before extraordinary items (Compustat IB) scaled by average assets (Compustat AT). To obtain the ROE model forecasts, we estimate the following prediction models per year using a rolling regression window on a holdout sample from the previous 10 years:

$$
\begin{aligned}
& R O E_{i, t}=\beta_{0}+\beta_{1} R O E_{i, t-1}+\varepsilon_{i, t} \\
& R O E_{i, t}=\beta_{0}+\beta_{1} L C R O E_{i, t-1}+\beta_{2} \text { FirmROE }_{i, t-1}+\varepsilon_{i, t}
\end{aligned}
$$

where in model (6b), $R O E_{t-1}$ is decomposed into a value-weighted life cycle-wide ROE component $\left(L C R O E_{t-1}\right)$ and a firm-specific component (FirmROE $\left.E_{t-1}\right)$. We multiply the coefficients from models (6a) and (6b) with the respective lagged earnings variables to finally obtain the current year ROE forecasts (PRED_AGG and PRED_LC), which we associate with analyst forecasts as shown in models (5a) and (5b). To obtain the ROA model forecasts, we follow the same procedure and replace ROE with ROA. Similar as for the market pricing sample, all earnings variables are truncated at the $0.5 \%$ and $99.5 \%$ level. We calculate the above-mentioned model predictions on a sample of 103,228 firm-year observations after applying the following data restrictions: we require non-missing values for firm life cycle, six-digit GICS code, ROE, and ROA. Financial institutions are excluded (sic 6000-6999). We exclude observations where sales revenue or average assets are less than $\$ 10$ million, as well as observations for which the book value of common equity is less than $\$ 1$ million. We further leave out firm-years with an absolute ROE or ROA greater than 1 . Finally, to examine the relative association between the analyst forecasts and our aggregate and life cycle model predictions, we use a Vuong test to compare the R-squares of models (5a) and (5b). Given that we expect analysts to incorporate at least some life cycle information in their forecasts, we expect a significantly larger R-squared for the life cycle model than for the aggregate earnings model.

Results are presented in Table 4.6. Using a sample of 20,325 firm-year observations for the regression with analyst first ROE forecasts as dependent variable, we observe that predicted values from the aggregate and the life cycle (LC) model explain $37.76 \%$ and $38.74 \%$ of the variation in analyst ROE forecasts. The Vuong test analyzes differences in R-squares and shows that the

\footnotetext{
${ }^{54}$ For the analyses involving analyst forecasts, we use ROE and ROA as profitability measures rather than RNOA, as the availability of analyst RNOA forecasts is relatively limited.
} 
explanatory power of the life cycle model is significantly greater than the aggregate earnings model ( $\mathrm{z}=4.3239, \mathrm{p}<0.001)$. We find similar results for the April ROE forecasts, with significantly different R-squares of $40.34 \%$ and $41.56 \%$ for the aggregate and LC model, respectively. For our second profitability measure, ROA, we also find that the LC model explains significantly more of the variation in both first and April analyst ROA forecasts. With a sample size of 14,613 $(11,323)$ firmyears for the first (April) forecasts, we obtain R-squares of $47.45 \%$ (49.83\%) for the aggregate and $48.04 \%(50.60 \%)$ for the LC model. The respective Vuong test statistics equal $\mathrm{z}=2.6751(\mathrm{p}=0.0075)$ for the sample using first $\mathrm{ROA}$ forecasts and $\mathrm{z}=3.1494(\mathrm{p}=0.0016)$ for the sample using April ROA forecasts. Together, these results suggest that analysts do - at least partly - incorporate life cycle information in forming expectations about future firm profitability, as all predicted values from LC models explain a greater part of the variation in analyst ROE and ROA forecasts than predicted values from the aggregate earnings model.

TABLE 4.6

Analyst Forecasts \& Life Cycle Model Predictions

\begin{tabular}{|c|c|c|c|c|}
\hline & Aggregate Model & LC Model & Aggregate Model & LC Model \\
\hline Variables & \multicolumn{2}{|c|}{ First Analyst Forecast } & \multicolumn{2}{|c|}{ April Analyst Forecast } \\
\hline Intercept & $0.0781 * * *$ & $0.0515^{* * *}$ & $0.0774 * * *$ & $0.0487 * * *$ \\
\hline Pred_ROE & $0.9338 * * *$ & $0.9318 * * *$ & $0.9518 * * *$ & $0.9584 * * *$ \\
\hline Observations & 20,325 & 20,325 & 16,895 & 16,895 \\
\hline R-squared & $37.76 \%$ & $38.74 \%$ & $40.34 \%$ & $41.56 \%$ \\
\hline Vuong Test: diff. in $\mathrm{R}^{2}$ & \multicolumn{2}{|c|}{$\mathrm{z}=4.3239$} & \multicolumn{2}{|c|}{$\mathrm{z}=4.9188$} \\
\hline Full/LC model & \multicolumn{2}{|c|}{$\mathrm{p}<0.001$} & \multicolumn{2}{|c|}{$\mathrm{p}<0.001$} \\
\hline Variables & $\begin{array}{c}\text { Aggregate Model } \\
\text { First Analyst }\end{array}$ & $\begin{array}{l}\text { LC Model } \\
\text { recast }\end{array}$ & $\begin{array}{r}\text { Aggregate Model } \\
\text { April Analyst }\end{array}$ & $\begin{array}{l}\text { LC Model } \\
\text { recast }\end{array}$ \\
\hline Intercept & $0.0421 * * *$ & $0.0270 * * *$ & $0.0415 * * *$ & $0.0261 * * *$ \\
\hline Pred_ROA & $1.0557 * * *$ & $1.0450 * * *$ & $1.0640 * * *$ & $1.0580 * * *$ \\
\hline Observations & 14,613 & 14,613 & 11,323 & 11,323 \\
\hline R-squared & $47.45 \%$ & $48.04 \%$ & $49.83 \%$ & $50.60 \%$ \\
\hline Vuong Test: diff. in $\mathrm{R}^{2}$ & \multicolumn{2}{|c|}{$z=2.6751$} & \multicolumn{2}{|c|}{$z=3.1494$} \\
\hline Full/LC model & \multicolumn{2}{|c|}{$\mathrm{p}=0.0075$} & \multicolumn{2}{|c|}{$\mathrm{p}=0.0016$} \\
\hline
\end{tabular}

This table reports the results of our analyst test examining the use of life cycle information in creating expectations about future firm performance. The sample includes all firm-year observations with matching data in Compustat and $\mathrm{I} / \mathrm{B} / \mathrm{E} / \mathrm{S}$. More specifically, the table reports the results of regressions examining the relation between analyst ROE (ROA) forecasts and model ROE (ROA) predictions. First Analyst Forecast and April Analyst Forecast are either the first or April consensus (mean) forecast for ROE or ROA, respectively. The first forecast captures the first estimate in $\mathrm{I} / \mathrm{B} / \mathrm{E} / \mathrm{S}$ for year $\mathrm{t}$ that is issued after announcing year $\mathrm{t}-1$ earnings. The April forecasts include all consensus forecasts for year $\mathrm{t}$ issued in April. Pred_ROE and Pred_ROA are the ROE or ROA forecasts obtained from the aggregate earnings model or the life cycle model, respectively. The coefficients underlying the predicted values are estimated per year using a rolling regression window on a holdout sample from the previous 10 years, and are multiplied with the respective lagged earnings variables to obtain the current year forecasts (Pred_ROE and Pred_ROA). All analyst and model-based variables are truncated at the $0.5 \%$ and $99.5 \%$ level. Standard errors are clustered at firm level. $* * *$ indicate statistical significance at the $1 \%$ level (two-tailed). Variable definitions for ROE and ROA can be found in Appendix 4A. 


\subsubsection{Robustness Tests}

\subsubsection{Sensitivity to Dropping Single Life Cycle Stages}

In our main market analysis, we examine the persistence and pricing of life cycle-wide and firmspecific earnings for the pooled sample including all five life cycle stages. The largest part of this sample consists of growth firms (34\%) and mature firms (44.5\%). To investigate the extent to which our results are driven by a single life cycle stage, we rerun the analysis on subsamples that exclude (one of) these two largest groups. Results are reported in Table 4.7. Columns (1) and (2) present results of the Mishkin test based on a sample excluding growth firms, while columns (3) and (4) exclude mature firms. Columns (5) and (6) exclude both growth and mature firms. For all three subsamples, we find persistence coefficients (columns 1,3, and 5) that are similar to those obtained in the main analysis. Life cycle-wide earnings $\left(L C E A R N_{t}\right)$ are significantly more persistent than firm-specific earnings $\left(\right.$ FirmEARN $\left.N_{t}\right)$ in all subsamples, which shows that our main (persistence) results are not driven by one dominant life cycle stage.

With respect to the return equations (columns 2, 4, and 6), we find that the underpricing of life cycle-wide earnings in Table 4.2 is driven by mature firms. While we continue to find that $L C E A R N_{t}$ is significantly underpriced in the subsample that excludes growth firms (chi-2=16.97, $\mathrm{p}<0.001$ ), we no longer observe a significant difference for $L C E A R N_{t}$ between the persistence coefficient and the assigned market weight in the two subsamples where mature firms are excluded (chi-2 $=0.43, \mathrm{p}=0.5104$; and $\mathrm{chi}=0.17, \mathrm{p}=0.6757$, respectively). In line with the main results in Table 4.2, firm-specific earnings (FirmEARN $N_{t}$ ) remain significantly overpriced by investors.

Collectively, these results suggest that while the persistence of life cycle-wide earnings is not driven by one particular life cycle stage, investors react differently to the common earnings component depending on the life cycle stage of the firm. For 'less stable' firms (i.e., firms in the intro, growth, shake-out, or decline stage), investors seem to attach greater (and accurate) weights to life cycle-wide earnings, while for stable mature firms investors seem to ignore the relevance of life-cycle wide earnings. Although speculative, one explanation could be that investors are better able to incorporate life cycle information when it is more salient that such information is relevant, i.e., for firms that differ substantially from the average stable firm. 


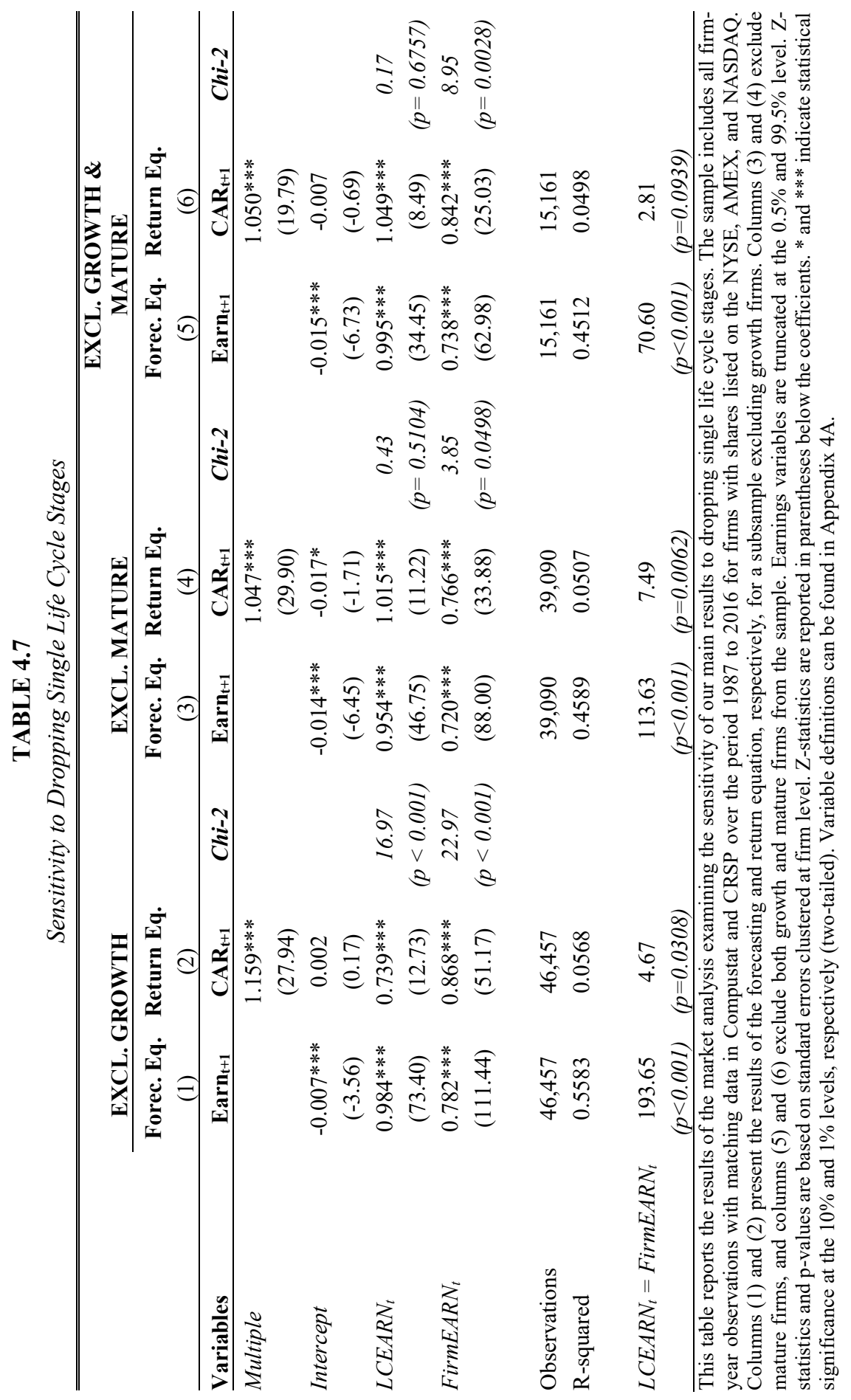




\subsubsection{Life Cycle Tenure}

In the second robustness test, we examine whether our results hold for different lengths of life cycle stage tenure. Prior literature has indicated that firms can pass through life cycle stages in different sequences and stay in one stage for various lengths of time (Miller and Friesen 1984; Quinn and Cameron 1983). This means that firms can move back and forth across the different stages (Dickinson 2011). Generally, we expect the persistence of life cycle-wide earnings to increase with the length of life cycle tenure (i.e., the number of years that a firm stays in the same life cycle stage consecutively). One concern, however, is that the higher informational value of life cycle-wide earnings for future firm profitability is less for firms that stay in one specific stage for only a short period of time. We therefore run our forecasting and pricing regressions (model $3 \mathrm{a}$ and $3 \mathrm{~b}$ ) on partitioned samples, one which is restricted to include firms for which life cycle tenure is limited to one year (33,779 firm-years) and a second sample of firms that have been in the same life cycle stage for at least two years $(34,384$ firm-years).

TABLE 4.8

Life Cycle Tenure

\section{LC TENURE $=1$}

Forec. Eq. Return Eq.

(1)

\begin{tabular}{|c|c|c|c|c|c|c|}
\hline \multirow[b]{2}{*}{ Variables } & (1) & (2) & \multirow[b]{2}{*}{ Chi-2 } & \multicolumn{3}{|c|}{ (4) } \\
\hline & $\operatorname{Earn}_{t+1}$ & $\mathbf{C A R}_{\mathbf{t + 1}}$ & & Earn $_{t+1}$ & CAR $_{t+1}$ & Chi-2 \\
\hline \multirow[t]{2}{*}{ Multiple } & & $1.138 * * *$ & & & $1.081 * * *$ & \\
\hline & & (29.64) & & & (20.73) & \\
\hline \multirow[t]{2}{*}{ Intercept } & -0.004 & $-0.016^{*}$ & & $-0.025^{* * *}$ & 0.023 & \\
\hline & $(-1.46)$ & $(-1.68)$ & & $(-8.75)$ & $(1.57)$ & \\
\hline \multirow[t]{2}{*}{$L C E A R N_{t}$} & $0.907 * * *$ & $0.840 * * *$ & 0.88 & $1.094 * * *$ & $0.635 * * *$ & 19.1 \\
\hline & $(51.79)$ & $(11.84)$ & $(p=0.3492)$ & $(56.80)$ & (6.19) & $(p<0.001)$ \\
\hline \multirow[t]{2}{*}{ FirmEARN $_{t}$} & $0.736^{* * *}$ & $0.833 * * *$ & 19.00 & $0.770 * * *$ & $0.816^{* * *}$ & 3.84 \\
\hline & $(86.23)$ & $(38.44)$ & $(p<0.001)$ & (93.04) & $(35.73)$ & $(p=0.0500)$ \\
\hline Observations & 33,779 & 33,779 & & 34,384 & 34,384 & \\
\hline R-squared & 0.4576 & 0.06 & & 0.5591 & 0.048 & \\
\hline \multirow[t]{2}{*}{$L C E A R N_{t}=$ FirmEARN $_{t}$} & 93.78 & 0.01 & & 237.02 & 3.14 & \\
\hline & $(p<0.001)$ & $(p=0.9271)$ & & $(p<0.001)$ & $(p=0.0763)$ & \\
\hline
\end{tabular}

This table reports the results of the market analysis conditional on firms switching (LC Tenure $=1$ ) or not switching (LC Tenure > 1) life cycle stages from the previous to the current period. The sample includes all firm-year observations with matching data in Compustat and CRSP over the period 1987 to 2016 for firms with shares listed on the NYSE, AMEX, and NASDAQ. All earnings variables are truncated at the $0.5 \%$ and $99.5 \%$ level. Z-statistics and p-values are based on standard errors clustered at firm level. Z-statistics are reported in parentheses below the coefficients. * and *** indicate statistical significance at the $10 \%$ and $1 \%$ levels, respectively (two-tailed). Variable definitions can be found in Appendix 4A. 
Results are reported in Table 4.8. As expected, the persistence of life cycle-wide earnings is higher for firms that are in the same life cycle stage for more than a year. ${ }^{55}$ Yet, even for firms whose presence in a certain stage is limited to one year, life cycle-wide earnings are more persistent than firm-specific earnings. ${ }^{56}$ This suggests that even for firms that are in a life cycle stage for a short period of time, life cycle wide earnings are more persistent than firm-specific earnings, consistent with these firms exhibiting systematic switching patterns across the stages (Dickinson 2011). Columns (2) and (4) show the implicit weights placed on life cycle-wide and firm-specific earnings in share prices. We find that the underpricing of life cycle-wide earnings in Table 4.2 is driven by firms whose life cycle tenure exceeds one year, while firm-specific earnings remain consistently overpriced in both subsamples. To the extent that mature firms are more stable and thus more likely to remain in the same life cycle stage for a longer period of time, these results are consistent with the earlier result that mature firms drive the underpricing of life cycle-wide earnings. However, these results also indicate the absence of a learning effect as the pricing of life cycle-wide earnings does not improve once life cycle tenure increases.

\subsubsection{Positive versus Negative Earnings; and Alternative Life Cycle Specifications}

In our main analyses, we investigate earnings persistence over the pooled sample. In the third robustness test, we look at the sensitivity of earnings persistence to profitable or loss-making firms. Prior literature shows that the earnings of loss-making firms are less persistent and informative about future performance (Hayn 1995). To examine the informational value of life cycle earnings in both cases, we extend our forecasting equation (model $3 \mathrm{a}$ ) and include an interaction variable for lossmaking firms $\left(N E G_{t}\right)$ :

$$
\begin{aligned}
& E A R N_{t+1}=a_{0}+a_{1} L C E A R N_{t}+a_{2} L C E A R N_{t} * N E G_{t}+a_{3} \text { FirmEARN }_{t}+a_{4} \text { FirmEARN }_{t} * \\
& N E G_{t}+a_{5} N E G_{t}+\varepsilon_{t+1}
\end{aligned}
$$

Where $N E G_{t}$ equals one if a firm has negative earnings in year $t$. Results are shown in Table 4.9, Panel A. Even though the persistence of both earnings components is lower when firms are unprofitable, we continue to find that common life cycle earnings are significantly more informative about next year's performance than firm-specific earnings (F-test 51.10, $<<0.001$ ). In sum, results of the first two robustness tests show that incorporating life cycle information in forecasting and valuation is applicable in a multitude of settings, including loss-making firms and firms with a short life cycle tenure.

As a fourth robustness test, we re-estimate our forecasting equation (model 3a) and include life cycle-wide earnings based on two alternative life cycle specifications. Specifically, we continue to use the cash flow based proxy from Dickinson (2011), but now classify firms into one of the five

\footnotetext{
${ }^{55}$ In a separate chi-2 test (untabulated), where we compare the forecasting coefficients of the two subsamples, we find that the difference in persistence of $L C E A R N_{t}$ is significant at the $1 \%$ level.

${ }^{56}$ Persistence results are robust to an alternative split where we compare firms with a life cycle tenure up to two years with firms who are in the same life cycle stage for already more than two years.
} 
stages using the last two and three-year cash flows, respectively. Table 4.9, Panel B, shows that our main result is robust to these two alternative specifications, as we find similar persistence coefficients for both earnings components compared to our main forecasting regression in Table 4.2.

TABLE 4.9

Positive versus Negative Earnings; and Alternative Life Cycle Specifications

\section{Panel A: Positive versus Negative Earnings}

\begin{tabular}{|c|c|c|}
\hline \multirow[b]{2}{*}{ Variables } & \multicolumn{2}{|c|}{ Depvar: Earn $_{t+1}$} \\
\hline & Coeff. & t-stat \\
\hline Intercept & $-0.017 * * *$ & $(-8.61)$ \\
\hline$L C E A R N_{t}$ & $1.024 * * *$ & (74.09) \\
\hline$L C E A R N_{t} * N E G_{t}$ & $-0.101 * * *$ & $(-2.95)$ \\
\hline FirmEARN $_{t}$ & $0.769 * * *$ & $(103.80)$ \\
\hline FirmEARN $_{t} * N E G_{t}$ & $-0.074 * * *$ & $(-3.65)$ \\
\hline$N E G$ & -0.006 & $(-1.19)$ \\
\hline Observations & \multicolumn{2}{|c|}{70,386} \\
\hline Adj. R-squared & \multicolumn{2}{|c|}{0.512} \\
\hline (tot) $L C E A R N_{t}=($ tot $)$ FirmEARN $N_{t}$ & \multicolumn{2}{|c|}{$\begin{array}{c}51.10 \\
(p<0.001)\end{array}$} \\
\hline
\end{tabular}

Panel B: Life Cycle determined over Last 2- and 3-year Cash Flows

\begin{tabular}{lcc} 
Variables & A2_LC & A3_LC \\
Earn $_{\mathbf{t + 1}}$ & $-0.0126^{* * *}$ & $-0.007^{* * *}$ \\
\hline Intercept & $(-6.96)$ & $(-4.01)$ \\
& $0.997^{* * *}$ & $0.976^{* * *}$ \\
LCEARN $_{t}$ & $(77.48)$ & $(74.11)$ \\
& $0.757^{* * *}$ & $0.766^{* * *}$ \\
FirmEARN & $(123.20)$ & $(117.50)$ \\
& & \\
Observations & 68,232 & 61,993 \\
Adj. R-squared & 0.5180 & 0.5190 \\
& & \\
LCEARN $_{t}=$ FirmEARN & & 227.39 \\
& $(p<0.001)$ & $(p<0.001)$ \\
\hline
\end{tabular}

This table reports the results of forecasting regressions examining the persistence of life cycle-wide and firm-specific earnings conditional on profit- or loss-making firms, and based on alternative life cycle specifications. The samples include all firm-year observations with non-missing data in Compustat and CRSP over the period 1987 to 2016 for firms with shares listed on the NYSE, AMEX, and NASDAQ. Panel A examines the impact of loss-making firms on the persistence of life cycle-wide and firm-specific earnings by including an indicator variable for loss-making firms $\left(N E G_{t}\right)$. Panel B examines the persistence of life cycle-wide and firm-specific earnings using a life cycle measure based on the last two and three-year cash flows, respectively. All continuous earnings variables are truncated at the $0.5 \%$ and $99.5 \%$ level. T-statistics and p-values are based on standard errors clustered at firm level. T-statistics are reported in parentheses below or next to the coefficients, respectively. ${ }^{* * *}$ indicate statistical significance at the $1 \%$ level (two-tailed). Variable definitions can be found in Appendix 4A. 


\subsubsection{Other}

Furthermore, for our market tests we use return on net operating assets (RNOA) as underlying profitability measure for $E A R N$. We alternatively define earnings as operating income after depreciation (Compustat OIADP) scaled by average net assets (Compustat AT). We then base life cycle- and firm-specific earnings on this alternative measure, and rerun the forecasting equation. As data on net assets are available in greater numbers than net operating assets, we obtain a larger sample of 90,165 firm-years. Results (untabulated) show that also with the alternative earnings specification, life cycle-wide earnings are significantly more persistent than firm-specific earnings (F-test 464.78, $\mathrm{p}<0.001$ ).

Finally, we also examine the persistence of LCEARN and FirmEARN using earnings variables that are truncated at the $0.5 \%$ and $99.5 \%$ level per fiscal year instead of over the pooled sample. Results (untabulated) show that our results are robust to this alternative specification.

\subsection{Conclusion}

Reported earnings are jointly determined by the accounting system and a firm's fundamental performance. Relatively few studies have examined the effect of firm fundamentals on earnings persistence. Yet, to reasonably evaluate persistence as a measure of earnings quality, more research is required on the relation between fundamental performance and earnings persistence (Dechow et al. 2010). In this paper, we investigate the relative persistence of life cycle-wide and firm-specific earnings, and examine how it is priced by market participants.

Prior literature has shown that firm life cycle is an important driver of the earnings generating process (e.g., Dickinson 2011; Dickinson et al. 2018; Hribar and Yehuda 2015; Vorst and Yohn 2018). Firms in the same life cycle stage share a typical set of internal and external characteristics. To test how within-life cycle commonalities affect earnings persistence, we partition reported earnings into a common earnings component, which captures the average earnings of all firms per life cycle stage and year, and firm-specific deviations from the average.

In line with our expectations, we find that life cycle-wide earnings are significantly more persistent and hence, more informative about next year's performance than firm-specific earnings. Stock prices show similar implicit weights on both components, which indicates that the average investor does not appear to recognize the differential persistence levels. We consequently find that investors underprice life cycle-wide earnings and overprice firm-specific earnings. As we also find a predictable drift in future abnormal returns in the direction of life cycle earnings, we conclude that our main results reflect investor mispricing. Subsequent tests reveal that the effect of firm life cycle is not driven by industry dynamics, showing that life cycle fundamentals are incrementally informative about future firm performance. Furthermore, results are different for more sophisticated market participants such as analysts. We find that analysts at least partly incorporate life cycle information in their forecasts. Finally, we show that life cycle information is relevant beyond the pooled sample and that results are robust to alternative specifications of our life cycle and earnings measure. 
Overall, our study contributes to the literature on earnings persistence as a measure of earnings quality by documenting the importance of firm life cycle as a driver of fundamental firm performance. We show that shared characteristics per firm life cycle stage drive the earnings generating process, such that these dynamics can be captured by a common earnings component and have a predictable effect on earnings persistence. As a result, our findings have implications for forecasting and valuation. A limitation of our study derives from potential noise in the life cycle proxy that we use in this study. As the life cycle stage of a firm cannot be observed directly, prior literature has developed several measures to proxy for firm life cycle. Our choice for the cash flowbased life cycle measure is motivated by Dickinson (2011), who finds that this measure is more consistently aligned with economic theory than the widely used alternative measure by Anthony and Ramesh (1992). Other recent accounting studies have further validated the usefulness of the cash flow-based measure in forecasting and valuation studies (e.g., Cantrell and Dickinson 2019; Dickinson et al. 2018; Vorst and Yohn 2018). Hence, despite the possibility of the measure being noisy, prior studies demonstrate the suitability of the measure in analysis, forecasting and valuation studies. To shed more light on the usefulness of life cycle fundamentals in forecasting and valuation, future research could further examine the extent to which incorporating differential persistence levels based on firm life cycle dynamics is beneficial in different settings or markets, such as the merger market. 


\section{Appendix 4A - Variable Definitions}

\begin{tabular}{|c|c|c|}
\hline Variable & Description & Source \\
\hline \multicolumn{3}{|c|}{ Main Variables - Mishkin Test and Future Abnormal Returns Test } \\
\hline$C A R_{t+1}$ & $\begin{array}{l}\text { Next year's abnormal return: size-adjusted } 12 \text { month buy-and-hold } \\
\text { stock return starting the fourth month after the end of fiscal year } t \text {. }\end{array}$ & CRSP \\
\hline $\operatorname{Earn}_{t+1}$ & $\begin{array}{l}\text { Next year's earnings: operating income after depreciation (OIADP) } \\
\text { scaled by average net operating assets. Net operating assets is equal to } \\
\text { the sum of common stock (CEQ), preferred stock (PSTK), long- and } \\
\text { short-term debt (DLTT and DLC), and minority interest (MIB), minus } \\
\text { cash and short-term investments (CHE). }\end{array}$ & Compustat \\
\hline Earn $_{t}$ & $\begin{array}{l}\text { Current year's earnings: operating income after depreciation (OIADP) } \\
\text { scaled by average net operating assets. Net operating assets is equal to } \\
\text { the sum of common stock (CEQ), preferred stock (PSTK), long- and } \\
\text { short-term debt (DLTT and DLC), and minority interest (MIB), minus } \\
\text { cash and short-term investments (CHE). }\end{array}$ & Compustat \\
\hline$L C E A R N_{t}$ & The average value-weighted earnings per life cycle stage and year. & Compustat \\
\hline FirmEARN $_{t(L C)}$ & $\begin{array}{l}\text { The difference between a firm's reported earnings } E A R N_{t} \text { and life } \\
\text { cycle-wide earnings } L C E A R N_{t} \text {. }\end{array}$ & Compustat \\
\hline \multicolumn{3}{|c|}{ Variables Additional Analyses } \\
\hline $\operatorname{IndEARN}_{t}$ & $\begin{array}{l}\text { The average value-weighted earnings per industry (6-digit GICS) and } \\
\text { year. }\end{array}$ & Compustat \\
\hline FirmEARN $_{t(G I N D)}$ & $\begin{array}{l}\text { The difference between a firm's reported earnings } E A R N_{t} \text { and industry- } \\
\text { wide earnings IndEARN }\end{array}$ & Compustat \\
\hline$I N D L C E A R N_{t}$ & $\begin{array}{l}\text { The average value-weighted earnings per industry life cycle stage and } \\
\text { year. }\end{array}$ & Compustat \\
\hline FirmEARN ${ }_{t(I N D L C)}$ & $\begin{array}{l}\text { The difference between a firm's reported earnings } E A R N_{t} \text { and industry } \\
\text { life cycle-wide earnings INDLCEARN }\end{array}$ & Compustat \\
\hline$I N D L C \_L C a l i g n_{t}$ & $\begin{array}{l}\text { Indicator variable equal to one if the firm- and industry- life cycle } \\
\text { stages are the same, zero otherwise. }\end{array}$ & Compustat \\
\hline$R O E_{t}$ & $\begin{array}{l}\text { A firm's return on equity: income before extraordinary items available } \\
\text { for common stockholders (IBCOM) scaled by average common equity } \\
\text { (CEQ). }\end{array}$ & Compustat \\
\hline$R O A_{t}$ & $\begin{array}{l}\text { A firm's return on assets: income before extraordinary items (IB) } \\
\text { scaled by average assets (AT). }\end{array}$ & Compustat \\
\hline \multicolumn{3}{|c|}{ Variables Robustness Tests } \\
\hline LCtenure $_{t}$ & $\begin{array}{l}\text { The number of consecutive years that a firm is in the same life cycle } \\
\text { stage in year } t \text {. }\end{array}$ & Compustat \\
\hline$N E G_{t}$ & $\begin{array}{l}\text { Indicator variable equal to one if the firm reports an operating loss } \\
(\mathrm{OIADP}<0) \text {, zero otherwise. }\end{array}$ & Compustat \\
\hline \multicolumn{3}{|l|}{ Other Variables } \\
\hline $\begin{array}{l}\text { Intro_stage, } \\
\text { Growth_stage, } \\
\text { Mature_stage, } \\
\text { Shake_stage, } \\
\text { Decline_stage }\end{array}$ & $\begin{array}{l}\text { Indicator variables equal to one if the firm is in the respective life } \\
\text { cycle stage, zero otherwise. To classify firm-year observations into } \\
\text { one of the five life cycle stages, we use the cash-flow based } \\
\text { classification table from Dickinson }(2011, \text { p.1974). }\end{array}$ & Compustat \\
\hline
\end{tabular}






\section{CONCLUSION}

\subsection{Summary}

In this dissertation, I examine the role of industry and life cycle fundamentals in the firm's earnings generating process and their relevance in forecasting and valuation. Earnings information is expected to be useful in decision making for a wide variety of stakeholders. Whereas multiple studies have examined earnings properties by solely focusing on earnings components as defined by the accounting measurement system (i.e., accrual- and cash flow-based disaggregations), we know relatively little about the effect that (knowledge of) fundamental firm characteristics have (has) on the earnings generating process of firms, and thus, on future firm performance. The studies in this dissertation shed more light on how earnings properties are affected by (knowledge of) firm underlying economics, i.e., industry and life cycle fundamentals, and on how these fundamentalsdriven earnings are used by various market participants.

In the first study (chapter two), I examine the relation between auditor industry specialists and accrual informativeness. An important part of the literature on auditor industry specialization has focused on the reliability of its clients' accounting figures, generally providing support that financial statements audited by industry specialists contain more reliable accounting information. In this study, I focus on an alternative quality dimension of accounting information, the relevance of accounting information, which is a critical quality attribute that determines whether the reported financial information is useful to investors. Specifically, I examine how industry specialists' superior knowledge of industry fundamentals affects the informativeness of accruals. Since I can provide arguments in various directions, it is ex ante unclear whether this relation is positive or negative.

Results from a cash flow prediction model show that, on average, accruals of clients audited by an industry specialist auditor are less informative about future cash flows. This holds under various specifications, including a firm-fixed effects analysis and analyses using propensity score matching and entropy balancing. This finding is consistent with industry specialist auditors requiring greater comparability and standardization across clients in the same industry, thereby restricting managers' ability to signal firm-specific private information. Furthermore, results of cross-sectional tests show that this finding is concentrated in industries that are less homogeneous, in firms that are less comparable to industry peers, and in firms that operate in more uncertain environments with more information asymmetry. In more similar industries, superior knowledge of industry fundamentals is particularly useful and relevant, and auditors can easily apply standardized industry procedures. In industries where firms are less similar, however, it is more difficult to transfer knowledge about audit processes and audit risks across clients (Bills et al. 2015). If specialist auditors try to minimize costs and apply standard industry procedures in such industries, this can come at a cost in the form of a loss of accrual relevance. Overall, the results of the first study provide novel evidence on the effects of auditor industry specialization by documenting that auditor industry specialization comes, on average, at the expense of accrual informativeness. 
In the second study (chapter three), I examine the relevance of differences in the persistence of earnings components in target pricing. Research has shown that not all mergers are successful and that mispricing of targets (overpayment) is one reason why mergers can be value-destructive to acquirer shareholders (e.g., Moeller et al. 2005). To lower the investment risk typically associated with significant corporate investments such as mergers and acquisitions, acquirers are incentivized to incorporate all decision-useful information into bid prices. Given that persistence of earnings is often perceived as a positive indicator for earnings relevance or decision-usefulness, it is interesting to examine whether acquirers incorporate within-earnings variation in persistence into their bid prices. Prior literature has concluded that capital market investors fail to incorporate such variation into stock prices, as they fixate on aggregate earnings numbers (e.g., Hui et al. 2016; Sloan 1996). It is not yet clear whether and how these findings transfer to the merger market.

The results show that relative to market pricing, accruals receive significantly greater weights than cash flows in the merger market. This suggests that acquirers perceive (the less persistent) accruals as relatively more informative than (the more persistent) cash flows for estimating future firm performance. Additionally, acquirers 'underreact' to industry-wide cash flows - the most persistent component - and 'overreact' to (the less persistent) firm-specific accruals components. Cross-sectional tests show that the relatively greater weights on accruals are concentrated in various subsets of deals. The perceived superior informativeness of accruals is mainly driven by deals in which the acquirer and the target do not share the same auditor, which is consistent with acquirers obtaining more forward-looking information from accruals when the informational advantage associated with common auditors is absent. Accruals also receive relatively greater weights in subsets of deals with high accounting quality target firms, diversifying transactions, and targets that operate in relatively stable industries as indicated by highly persistent industry earnings. I also observe variation in the overall importance of earnings as a determinant of bid prices. Except for diversifying transactions, earnings have a higher overall importance in deals with non-common auditors, high accounting quality targets, and targets benefiting from a high industry earnings persistence. Collectively, the cross-sectional results show that the importance of earnings components in M\&A pricing varies with information asymmetry. With respect to the hypothesis, the results suggest that acquirers are aware of certain persistence differences in earnings, but do not price all (fundamentals-driven) earnings components according to their persistence levels. More specifically, the significantly greater weights placed on accruals in comparison to cash flows suggest that the components' perceived informativeness about future firm value is not in line with their general persistence levels. While acquiring firms at least partially consider the impact of industry fundamentals on earnings persistence, as shown in the cross-sectional test on industry earnings persistence, they nonetheless seem to perceive less persistent (both industry-wide and firm-specific) accruals as relatively more informative. I therefore conclude that while acquirers are aware of fundamentals-driven variation in persistence, persistence differences in disaggregate earnings components do not play a relevant role in target pricing. 
In the third study (chapter four), I investigate the existence and informational value of life cycle-wide and firm-specific earnings, and examine the extent to which these components are reflected in share prices. Recent studies have shown that life cycle stage commonalities affect earnings dynamics (Dickinson 2011; Vorst and Yohn 2018) and their findings suggest that a common, life cycle-wide earnings component exists. Given the relatively sticky nature of the fundamentals underlying these life cycle-wide earnings, I expect this component to be more persistent than firm-specific deviations from the life cycle-wide average. Furthermore, I expect investors to misprice these components, as prior literature has documented that they fail to incorporate persistence differences into stock prices (e.g., Hui et al. 2016; Sloan 1996).

Consistent with my expectations, I find that life cycle-wide earnings are significantly more persistent than firm-specific earnings and thus enjoy a higher informational value. Implicit weights impounded in stock prices show that capital market investors underreact to the common component and overreact to the firm-specific component. By showing that life cycle-wide earnings significantly predict future abnormal stock returns, I confirm that my results are reflective of investor mispricing. Additionally, I test whether life cycle-wide earnings add incremental value over industry-wide earnings, as industry and firm life cycle may share some underlying fundamentals such as a firm's competitive environment. Results reveal that the effect of firm life cycle on the earnings generating process is not driven by industry dynamics, indicating that life cycle fundamentals are incrementally informative about future firm performance. Furthermore, results are different for more sophisticated market participants such as analysts. I find that analysts, at least partially, incorporate life cycle information in their earnings forecasts and as such perform better than the average market participant. Finally, I show that life cycle information remains relevant in various subsets of firms and that results are robust to alternative specifications of my life cycle and earnings measure. Overall, this study adds to the understanding of a firm's earnings generating process and provides additional evidence on the relevance of life cycle information in forecasting and valuation.

\subsection{Contributions and Future Research}

With this dissertation, I provide several important contributions to the understanding of the role of industry and life cycle fundamentals in the firm's earnings generating process and its relevance in forecasting and valuation. The results of the first study contribute to the literature on auditor industry specialization by considering another fundamental quality attribute of accounting information. Previous studies have mainly concentrated on examining the association between industry specialist auditors and the reliability of accounting information. I focus on the informativeness of accounting information, which is consistent with the two fundamental quality attributes of the FASB's conceptual framework, namely relevance and faithful representation. The take-away that auditor industry specialists are not always associated with higher earnings quality should therefore be of interest to standard-setters, but also to audit firms, as they attach great importance to investing in industry-specific expertise. As I also provide insights into the role of fundamentals in the earnings generating process, my findings should additionally be of interest to investors who wish to rely on 
accounting numbers to infer the future cash-generating ability of firms. In the second study, I contribute to a growing body of literature on the role of publicly available accounting information in M\&A pricing. While previous studies have mainly focused on the role of aggregate accounting fundamentals in target pricing, I exploit the variation in persistence within accounting fundamentals and analyze to what extent this differential persistence is considered in target pricing. The findings in this study should be of interest to accountants in academia and practice, as it broadens our understanding of the relevance of disaggregate accounting components in target valuation. Results of the third study contribute to the literature on earnings persistence as a measure of earnings quality by documenting the importance of firm life cycle as a driver of a firm's fundamental performance. Specifically, I show that shared characteristics in a life cycle stage are captured by a common earnings component and have a predictable effect on earnings persistence. While capital market investors misprice life cycle-wide and firm-specific earnings, analysts do incorporate life cycle information in their forecasts. Overall, this study adds to the understanding of a firm's earnings generating process and provides additional evidence on the relevance of life cycle information in forecasting and valuation.

There are several possible avenues for future research to extend the studies presented in this dissertation. The first study focuses on the predictive value of accounting information to examine accrual informativeness. This disregards the confirmatory role that accounting information plays. Future research could investigate whether industry specialist auditors also affect the confirmatory role of accounting information. Additionally, future research could investigate whether the presence of industry specialist auditors is associated with more comparable accounting information among their clients, where comparability reflects the extent to which variation in economic outcomes explained by accounting figures is the same for two firms. A limitation of the second study is the inability of the current set of analyses to identify the extent to which merger pricing is affected by the strategic considerations of the deals. Future research could examine the effect of expected synergies and strategic intent on the valuation roles of disaggregate earnings components. In addition, the second study shows that the earnings components' perceived informativeness about future firm value is not in line with their general persistence levels. Persistence as a measure of earnings quality is often perceived to be positively related to relevance or decision-usefulness. Yet, it is unknown whether acquirers' focus on less persistent accrual components can be interpreted as mispricing, as the second study does not link merger pricing to deal outcomes. Future studies could, for example, examine post-deal performance to shed light on the economic consequences related to variation in acquirers' weighting of financial accounting information. Furthermore, future research could examine the role of other fundamentals-driven earnings components in M\&A pricing. Finally, the third study extends prior research on the role of life cycle fundamentals in forecasting and valuation. Future studies could further examine the extent to which incorporating life cycle-driven earnings components is beneficial in different setting or markets, such as the merger market. As analysts do incorporate life cycle information in their work, future research could investigate 
whether analysts are grouped to specialize themselves in certain life cycle stages and examine potential benefits of such specialization efforts. 



\section{REFERENCES}

Allen, E. J., C. R. Larson, and R. G. Sloan. 2013. Accrual Reversals, Earnings and Stock Returns. Journal of Accounting and Economics 56: 113-129.

Andrade, G., M. L. Mitchell, and E. Stafford. 2001. New Evidence and Perspectives on Mergers. Journal of Economic Perspectives 15 (2): 103-120.

Anthony, J. H., and K. Ramesh. 1992. Association Between Accounting Performance Measures and Stock Prices: A Test of the Life Cycle Hypothesis. Journal of Accounting and Economics 15 (2-3): 203-227.

Arikan, A. M., and R. M. Stulz. 2016. Corporate Acquisitions, Diversification, and the Firm's Life Cycle. The Journal of Finance 71 (1): 139-194.

Armstrong, C. S., W. R. Guay, and J. P. Weber. 2010. The Role of Information and Financial Reporting in Corporate Governance and Debt Contracting. Journal of Accounting and Economics 50: 179-234.

Audousset-Coulier, S., A. Jeny, and L. Jiang. 2016. The Validity of Auditor Industry Specialization Measures. Auditing: A Journal of Practice \& Theory 35 (1): 139-161.

Ayers, B., and R. Freeman. 1997. Market Assessment of Industry and Firm Earnings Information. Journal of Accounting and Economics 24: 205-218.

Badertscher, B. A., D. W. Collins, and T. Z. Lys. 2012. Discretionary Accounting Choices and the Predictive Ability of Accruals with Respect to Future Cash Flows. Journal of Accounting and Economics 53 (1-2): 330-352.

Bae, G. S., S. U. Choi, D. S. Dhaliwal, and P. T. Lamoreaux. 2017. Auditors and Client Investment Efficiency. The Accounting Review 92 (2): 19-40.

Ball, R., and P. Brown. 1968. An Empirical Evaluation of Accounting Income Numbers. Journal of Accounting Research 6 (2): 159-178.

Ball, R., S. Jayaraman, and L. Shivakumar. 2012. Audited Financial Reporting and Voluntary Disclosure as Complements: A Test of the Confirmation Hypothesis. Journal of Accounting and Economics 53 (1-2): 136-166.

Balsam, S., J. Krishnan, and J. S. Yang. 2003. Auditor Industry Specialization and Earnings Quality. Auditing: A Journal of Practice \& Theory 22 (2): 71-97.

Barth, M. E., D. P. Cram, and K. K. Nelson. 2001. Accruals and the Prediction of Future Cash Flows. The Accounting Review 76 (1): 27-58.

Barth, M. E., K. Li, and C. G. McClure. 2018. Evolution in Value Relevance of Accounting Information. Working Paper Stanford University and University of Chicago.

Bédard, J. 1989. Expertise in Auditing: Myth or Reality? Accounting, Organizations and Society 14 (1-2): 113-131.

Berger, P. G., and E. Ofek. 1995. Diversification's Effect on Firm Value. Journal of Financial Economics 37 (1): 39-65.

Bills, K. L., D. C. Jeter, and S. E. Stein. 2015. Auditor Industry Specialization and Evidence of Cost Efficiencies in Homogenous Industries. The Accounting Review 90 (5): 1721-1754.

Black, B. S. 1989. Bidder Overpayment in Takeovers. Stanford Law Review 41 (3): 597-660.

Bradshaw, M. T., M. S. Drake, J. N. Myers, and L. A. Myers. 2012. A Re-Examination of Analysts' Superiority over Time-Series Forecasts of Annual Earnings. Review of Accounting Studies 17 (4): 944-968.

Brown, P., and R. Ball. 1967. Some Preliminary Findings on the Association between the Earnings of a Firm, its Industry, and the Economy. Journal of Accounting Research 5: 55-77. 
Burgstahler, D. C., and I. D. Dichev. 1997. Earnings, Adaptation, and Equity Value. The Accounting Review 72 (2): 187-215.

Bushman, R. M., A. J. Smith, and F. Zhang. 2011. Investment Cash Flow Sensitivities Really Reflect Related Investment Decisions. Working Paper University of North Carolina, University of Chicago, and Yale School of Management.

Cahan, S. F., J. M. Godfrey, J. Hamilton, and D. C. Jeter. 2008. Auditor Specialization, Auditor Dominance, and Audit Fees: The Role of Investment Opportunities. The Accounting Review 83 (6): 1393-1423.

Cahan, S. F., D. C. Jeter, and V. Naiker. 2011. Are All Industry Specialist Auditors the Same? Auditing: A Journal of Practice \& Theory 30 (4): 191-222.

Cai, Y., Y. Kim, J. C. Park, and H. D. White. 2016. Common Auditors in M\&A Transactions. Journal of Accounting and Economics 61: 77-99.

Cai, Y., and M. Sevilir. 2012. Board Connections and M\&A Transactions. Journal of Financial Economics 103: 327-349.

Cairney, T. D., and G. R. Young. 2006. Homogenous Industries and Auditor Specialization: An Indication of Production Economies. Auditing: A Journal of Practice \& Theory 25 (1): 4967.

Call, A. C., M. Hewitt, T. Shevlin, and T. L. Yohn. 2016. Firm-Specific Estimates of Differential Persistence and their Incremental Usefulness for Forecasting and Valuation. The Accounting Review, 91 (3): 811-833.

Campa, D., and A. Hajbaba. 2016. Do Targets grab the Cash in Takeovers: The Role of Earnings Management. International Review of Financial Analysis 44: 56-64.

Cantrell, B.W., and V. Dickinson. 2019. Conditional Life Cycle: An Examination of Operating and Market Performance for Leaders and Laggards. Management Science Forthcoming.

Chen, W., P. Hribar, and S. Melessa. 2018. Incorrect Inferences When Using Residuals as Dependent Variables. Journal of Accounting Research 56 (3): 751-796.

Chi, H.-Y., and C.-L. Chin. 2011. Firm versus Partner Measures of Auditor Industry Expertise and Effects on Auditor Quality. Auditing: A Journal of Practice \& Theory 30 (2): 201-229.

Collins, D. W., M. Pincus, and H. Xie. 1999. Equity Valuation and Negative Earnings: The Role of Book Value of Equity. The Accounting Review 74 (1): 29-61.

Danos, P., J. W. Eichenseher, and D. L. Holt. 1989. Specialized Knowledge and Its Communication in Auditing. Contemporary Accounting Research 6 (1): 91-109.

DeAngelo, H., L. DeAngelo, and R. M. Stulz. 2006. Dividend Policy and the Earned/Contributed Capital Mix: A Test of the Life-Cycle Theory. Journal of Financial Economics 81 (2): 227254.

Dechow, P. M., W. Ge, and C. Schrand. 2010. Understanding Earnings Quality: A Review of the Proxies, their Determinants and their Consequences. Journal of Accounting and Economics 50: 344-401.

Dechow, P. M., S. P. Kothari, and R. L. Watts. 1998. The Relation Between Earnings and Cash Flows. Journal of Accounting and Economics 25 (2): 133-168.

Dechow, P. M., S. A. Richardson, and R. G. Sloan. 2008. The Persistence and Pricing of the Cash Component of Earnings. Journal of Accounting Research 46 (3): 537-566.

Dechow, P. M., R. G. Sloan, and A. P. Sweeney. 1995. Detecting Earnings Management. The Accounting Review 70 (2): 193-225.

DeFond, M., C. S. Lennox, and J. Zhang. 2018. The Primacy of Fair Presentation: Evidence from PCAOB Standards, Federal Legislation, and the Courts. Accounting Horizons 32 (3): 91-100. 
DeFond, M., and J. Zhang. 2014. A Review of Archival Auditing Research. Journal of Accounting and Economics 58 (2-3): 275-326.

Dhaliwal, D. S., P. T. Lamoreaux, C. S. Lennox, and L. M. Mauler. 2015. Management Influence on Auditor Selection and Subsequent Impairments of Auditor Independence during the PostSox Period. Contemporary Accounting Research 32 (2): 576-607.

Dhaliwal, D. S., P. T. Lamoreaux, L. P. Litov, and J. B. Neyland. 2016. Shared Auditors in Mergers and Acquisitions. Journal of Accounting and Economics 61: 49-76.

Dichev, I. D., and V. W. Tang. 2009. Earnings Volatility and Earnings Predictability. Journal of Accounting and Economics 47: 160-181.

Dickinson, V. 2011. Cash Flow Patterns as a Proxy for Firm Life Cycle. The Accounting Review 86 (6): 1969-1994.

Dickinson, V., H. Kassa, and P. D. Schaberl. 2018. What Information Matters to Investors at Different Stages of a Firm's Life Cycle? Advances in Accounting 42: 22-33.

Dopuch, N., R. Mashruwala, C. Seethamraju, and T. Zach. 2012. The Impact of a Heterogeneous Accrual-Generating Process on Empirical Accrual Models. Journal of Accounting, Auditing \& Finance 27 (3): 386-411.

Drake, M. S., P. T. Lamoreaux, P. J. Quinn. and J. R. Thornock. 2019. Auditor Benchmarking of Client Disclosures. Review of Accounting Studies 24 (2): 393-425.

Drake, K. D., and M. Martin. 2018. Implementing Relative Performance Evaluation: The Role of Life Cycle Peers. Working Paper University of Arizona and University of Illinois at Chicago

Dunn, K. A., and B. W. Mayhew. 2004. Audit Firm Industry Specialization and Client Disclosure Quality. Review of Accounting Studies 9 (1): 35-58.

Dye, R. A., and S. S. Sridhar. 1995. Industry-Wide Disclosure Dynamics. Journal of Accounting Research 33 (1): 157-174.

Easton, P. D., T. S. Harris, and J. A. Ohlson. 1992. Aggregate Accounting Earnings Can Explain Most of Security Returns: The Case of Long Event Windows. Journal of Accounting and Economics 15: 119-142.

Fairfield, P. M., S. Ramnath, and T. L. Yohn. 2009. Do Industry-Level Analyses Improve Forecasts of Financial Performance? Journal of Accounting Research 47 (1): 147-178.

Fairfield, P. M., R. J. Sweeney, and T. L. Yohn. 1996. Accounting Classification and the Predictive Content of Earnings. The Accounting Review 71 (3): 337-355.

Fairfield, P., and T. Yohn. 2001. Using Asset Turnover and Profit Margin to Forecast Changes in Profitability. Review of Accounting Studies 6: 371-385.

Ferracuti, E., and S. R. Stubben. 2019. The Role of Financial Reporting in Resolving Uncertainty about Corporate Investment Opportunities. Journal of Accounting and Economics Forthcoming.

Financial Accounting Standards Board (FASB). 2010. Statement of Financial Accounting Concepts No. 8 - Conceptual Framework for Financial Reporting.

Foster, G. 1981. Intra-Industry Information Transfers Associated with Earnings Releases. Journal of Accounting and Economics 3 (3): 201-232.

Francis, J. R. and P. N. Michas. 2013. The Contagion Effect of Low-Quality Audits. The Accounting Review 88 (2): 521-552.

Francis, J. R., M. L. Pinnuck, and O. Watanabe. 2014. Auditor Style and Financial Statement Comparability. The Accounting Review 89 (2): 605-633.

Gaver J. J., and S. Utke. 2019. Audit Quality and Specialist Tenure. The Accounting Review 94 (3): 113-147. 
Gort, M., and S. Klepper. 1982. Time Paths in the Diffusion of Product Innovations. The Economic Journal 92 (367): 630-653.

Grullon, G., R. Michaely, and B. Swaminathan. 2002. Are Dividend Changes a Sign of Firm Maturity? The Journal of Business 75 (3): 387-424.

Guay, W., D. Taylor, and J. Xiao. 2015. Adapt or Perish: Evidence of CEO Adaptability to Industry Shocks. Working Paper University of Pennsylvania.

Gupta, D., and Y. Gerchak. 2002. Quantifying Operational Synergies in a Merger/Acquisition. Management Science 48 (4): 517-533.

Hainmueller, J. 2012. Entropy Balancing for Causal Effects: A Multivariate Reweighting to Produce Balanced Samples in Observational Studies. Political Analysis 20 (1): 25-46.

Han, K. C., D. Y. Suk, and H. M. Sung. 1998. The Evidence of Bidders' Overpayment in Takeovers: The Valuation Ratios Approach. The Financial Review, 33: 55-68.

Hanlon, M., E. L. Maydew, and T. Shevlin. 2008. An Unintended Consequence of Book-Tax Conformity: A Loss of Earnings Informativeness. Journal of Accounting and Economics 46 (2-3): 294-311.

Hayn, C. 1995. The Information Content of Losses. Journal of Accounting and Economics 20 (2): 125-153.

Hite, J. M., and W. S. Hesterly. 2001. The Evolution of Firm Networks: From Emergence to Early Growth of the Firm. Strategic Management Journal 22 (3): 275-286.

Hribar, P., and D. W. Collins. 2002. Errors in estimating Accruals: Implications for Empirical Research. Journal of Accounting Research 40 (1): 105-134.

Hribar, P., and N. Yehuda. 2015. The Mispricing of Cash Flows and Accruals at Different LifeCycle Stages. Contemporary Accounting Research 32 (3): 1053-1072.

Hui, K. W., K. K. Nelson, and P. E. Yeung. 2016. On the Persistence and Pricing of Industry Wide and Firm-Specific Earnings, Cash Flows, and Accruals. Journal of Accounting and Economics 61 (1): 185-202.

Hui, K. W., and P. E. Yeung. 2013. Underreaction to Industry-Wide Earnings and the Post-Forecast Revision Drift. Journal of Accounting Research 51: 701-737.

Hutton, A., L. Lee, and S. Shu. 2012. Do Managers Always Know Better? The Relative Accuracy of Management and Analyst Forecasts. Journal of Accounting Research 50 (5): 1217-1244.

International Accounting Standards Board (IASB). 2018. Conceptual Framework for Financial Reporting.

Jawahar, I. M., and G. L. McLaughlin. 2001. Toward a Descriptive Stakeholder Theory: An Organizational Life Cycle Approach. Academy of Management Review 26 (3): 397-414.

Jeter, D. C. 2014. Auditor Industry Specialization, In: The Routledge Companion to Auditing, edited by Hay, D., Knechel, W.R. and M. Willekens, London, Routledge, p.191-199.

Johnston, J., and J. Zhang. 2018. Auditor Style and Financial Reporting Similarity. Working Paper Illinois State University.

Joos, P., and G. A. Plesko. 2005. Valuing Loss Firms. The Accounting Review, 80 (3): 847-870.

Kadan, O., L. Madureira, R. Wang, and T. Zach. 2012. Analysts' Industry Expertise. Journal of Accounting and Economics 54 (2-3): 95-120.

Kallunki, J. P., and H. Silvola. 2008. The Effect of Organizational Life Cycle Stage on the Use of Activity-Based Costing. Management Accounting Research 19 (1): 62-79.

Kim, J-B., J. J.Lee, and J. C. Park. 2015. Audit Quality and the Market Value of Cash Holdings: The Case of Office-Level Auditor Industry Specialization. Auditing: A Journal of Practice \& Theory 34 (2): 27-57. 
Klepper, S. 1996. Entry, Exit, Growth, and Innovation over the Product Life Cycle. The American Economic Review 86 (3): 562-583.

Knechel, W. R., A. Vanstraelen, and M. Zerni 2015. Does the Identity of Engagement Partners Matter? An Analysis of Audit Partner Reporting Decisions. Contemporary Accounting Research 32 (4): 1443-1478.

Koberg, C. S., N. Uhlenbruck, and Y. Sarason. 1996. Facilitators of Organizational Innovation: The Role of Life-Cycle Stage. Journal of Business Venturing 11 (2): 133-149.

Konstantinidi, T., A. Kraft, and P. F. Pope. 2016. Asymmetric Persistence and the Market Pricing of Accruals and Cash Flows. Abacus 52 (1): 140-165.

Kothari, S. P. 2001. Capital Markets Research in Accounting. Journal of Accounting and Economics 31: 105-231.

Kothari, S. P., and C. Wasley. 2019. Commemorating the Fifty-Year Anniversary of Ball and Brown (1968): The Evolution of Capital Market Research over the Past Fifty Years. Journal of Accounting Research Forthcoming.

Krishnan, G. V. 2003. Does Big 6 Auditor Industry Expertise Constrain Earnings Management? Accounting Horizons Supplement: 1-16.

Krishnan, J., C. Li, and Q. Wang. 2013. Auditor Industry Expertise and Cost of Equity. Accounting Horizons 27 (4): 667-691.

Kwon, S. Y., J. Park, and J. Yu. 2018. The Effect of Industry-Specialist Auditors on SEO Underpricing Before and After the Global Financial Crisis. Auditing: A Journal of Practice \& Theory 37 (1): 89-113.

Lambert, R. A. 2001. Contracting Theory and Accounting. Journal of Accounting and Economics 32: 3-87.

Lajoux, A., and C. Elson. 2000. The Art of M\&A Due Diligence. New York: McGraw-Hill.

Lev, B. 1969. Industry Averages as Targets for Financial Ratios. Journal of Accounting Research 7 (2): 290-299.

Lev, B. 1983. Some Economic Determinants of Time-Series Properties of Earnings. Journal of Accounting and Economics 5: 31-48.

Lev, B. and P. Zarowin. 1999. The Boundaries of Financial Reporting and How to Extend Them. Journal of Accounting Research 37 (2): 353-385.

Lim, C-Y., and H-T. Tan. 2010. Does Audit Tenure Improve Audit Quality? Moderating Effects of Industry Specialization and Fee Dependence. Contemporary Accounting Research 27 (3): 923-957.

Lipe, R. 1990. The Relation Between Stock Returns and Accounting Earnings Given Alternative Information. The Accounting Review 65 (1): 49-71.

Lynall, M. D., B. R. Golden, and A. J. Hillman. 2003. Board Composition from Adolescence to Maturity: A Multitheoretic View. Academy of Management Review 28 (3): 416-431.

Magee, R. P. 1974. Industry-Wide Commonalities in Earnings. Journal of Accounting Research 12 (2): $270-287$.

Marquardt, C., and E. Zur. 2015. The Role of Accounting Quality in the M\&A Market. Management Science 61 (3): 604-623.

Maletta, M., and A. Wright. 1996. Audit Evidence Planning: An Examination of Industry Error Characteristics. Auditing: A Journal of Practice \& Theory 15 (1): 71-86.

Martin, X., and R. Shalev. 2017. Target Firm-Specific Information and Acquisition Efficiency. Management Science 63 (3): 672-690.

McMullin, J. L., and D. Schonberger. 2018. Entropy-Balanced Discretionary Accruals. Working Paper Indiana University and University of Rochester. 
McNichols, M., and S. R. Stubben. 2015. The Effect of Target-Firm Accounting Quality on Valuation in Acquisitions. Review of Accounting Studies 20: 110-140.

Miller, D., and P. H. Friesen. 1984. A Longitudinal Study of the Corporate Life Cycle. Management Science 30 (10): 1161-1183.

Milliman, J., M. A. Von Glinow, and M. Nathan. 1991. Organizational Life Cycles and Strategic International Human Resource Management in Multinational Companies: Implications for Congruence Theory. Academy of Management Review 16 (2): 318-339.

Minutti-Meza, M. 2013. Does Auditor Industry Specialization Improve Audit Quality? Journal of Accounting Research 51 (4): 779-817.

Mishkin, F. 1983. A Rational Expectations Approach to Macroeconometrics: Testing Policy Effectiveness and Efficient Markets Models. Chicago, IL: University of Chicago Press for the National Bureau of Economic Research.

Moeller, S. B., F. P. Schlingemann, and R. M. Stulz. 2005. Wealth Destruction on a Massive Scale? A Study of Acquiring-Firm Returns in the Recent Merger Wave. Journal of Finance 60 (2): 757-782.

Moores, K., and S. Yuen. 2001. Management Accounting Systems and Organizational Configuration: A Life-Cycle Perspective. Accounting, Organizations and Society 26 (4-5): 351-389.

Mueller, D. C. 1977. The Persistence of Profits Above the Norm. Economica 44 (176): 369-380.

Nissim, D., and S. Penman. 2001. Ratio Analysis and Equity Valuation: From Research to Practice. Review of Accounting Studies 6: 109-154.

Ohlson, J. A. 1995. Earnings, Book Values, and Dividends in Equity Valuation. Contemporary Accounting Research 11 (2): 661-687.

Owen, S., and A. Yawson. 2010. Corporate Life Cycle and M\&A Activity. Journal of Banking \& Finance 34 (2): 427-440.

Owens, E. L., J. S. Wu, and J. Zimmerman. 2017. Idiosyncratic Shocks to Firm Underlying Economics and Abnormal Accruals. The Accounting Review 92 (2):183-219.

Quinn, R. E., and K. Cameron. 1983. Organizational Life Cycles and Shifting Criteria of Effectiveness: Some Preliminary Evidence. Management science 29 (1): 33-51.

Palmrose, Z.-V., and W. R. Kinney Jr. 2018. Auditor and FASB Responsibilities for Representing Underlying Economics - What U.S. Standards Actually Say. Accounting Horizons 32 (3): 83-90.

Power, M. 1996. Making Things Auditable. Accounting, Organizations and Society 21 (2-3): 289315.

Public Company Accounting Oversight Board (PCAOB) 2015. Communications with Audit Committees. AS 1301. Washington, DC: PCAOB.

Rabier, M. R. 2018. Value is in the Eye of the Beholder: The Relative Valuation Roles of Earnings and Book Value in Merger Pricing. The Accounting Review 93 (1): 335-362.

Raman, K., L. Shivakumar, and A. Tamayo. 2013. Target's Earnings Quality and Bidders' Takeover Decisions. Review of Accounting Studies 18: 1050-1087.

Reichelt, K., and D. Wang. 2010. National and Office-Specific Measures of Auditor Industry Expertise and Effects on Audit Quality. Journal of Accounting Research 48 (3): 647-686.

Rhodes-Kropf, M., D. T. Robinson, and S. Viswanathan. 2005. Valuation Waves and Merger Activity: The Empirical Evidence. Journal of Financial Economics 77: 561-603.

Richardson, S., R. Sloan, M. Soliman, and I. Tuna. 2005. Accrual Reliability, Earnings Persistence and Stock Prices. Journal of Accounting and Economics 39: 437-485. 
Robin, A. J., and H. Zhang. 2015. Do Industry-Specialist Auditors Influence Stock Price Crash Risk? Auditing: A Journal of Practice \& Theory 34 (3): 47-79.

Schwert, G. W. 1996. Markup Pricing in Mergers and Acquisitions. Journal of Financial Economics 41: 153-192.

Shipman, J. E., Q. T. Swanquist, and R. L. Whited. 2016. Propensity Score Matching in Accounting Research. The Accounting Review 92 (1): 213-244.

Shivakumar, L. 2013. The Role of Financial Reporting in Debt Contracting and in Stewardship. Accounting and Business Research 43 (4): 362-383.

Skaife, H. A., and D. D. Wangerin. 2013. Target Financial Reporting Quality and M\&A Deals that go Bust. Contemporary Accounting Research 30 (2): 719-749.

Sloan, R. G. 1996. Do Stock Prices Fully Reflect Information in Accruals and Cash Flows about Future Earnings? The Accounting Review 71 (3): 289-315.

Soliman, M. 2008. The Use of DuPont Analysis by Market Participants. The Accounting Review 83: 823-853.

Srivastava, A. 2014. Why Have Measures of Earnings Quality Changed Over Time? Journal of Accounting and Economics 57: 196-217.

Subramanyam, K. 1996. The Pricing of Discretionary Accruals. Journal of Accounting and Economics 22 (1-3): 249-281.

The Economist. 2019. Breaking the Wave. (July 6). Available at: https://www.economist.com/business/2019/07/06/investors-and-regulators-fall-out-of-lovewith-colossal-deals

Vorst, P., and T. L. Yohn. 2018. Life Cycle Models and Forecasting Growth and Profitability. The Accounting Review 93 (6): 357-381.

Vorst, P., and T. L. Yohn. 2019. Intra-Life Cycle Information Transfers. Working Paper Maastricht University and Indiana University.

Waring, G. F. 1996. Industry Differences in the Persistence of Firm-Specific Returns. The American Economic Review 86 (5): 1253-1265.

Yohn, T. L. 2018. Research on the Use of Financial Statement Information for Forecasting Profitability. Accounting \& Finance Forthcoming: 1-19.

Zimmerman, J. L. 2015. The Role of Accounting in the Twenty-First Century Firm. Accounting and Business Research 45 (4): 485-509. 



\section{VALORIZATION}

Accounting information is used for various purposes and by various stakeholders. Where accounting was originally designed to hold a stewardship role to manage conflicts of interest in firms, its primary role has gradually shifted to being used in firm valuation. Capital market participants use accounting information to form expectations about a firm's future performance and motivate subsequent investment decisions. The focus on this valuation role is also reflected in the objective of accounting standard setters, who require accounting information to accurately reflect firms' underlying economics such that the information is relevant and has the ability to make a difference in users' decisions. Yet, as outlined in Chapter 1, accounting information - and aggregate earnings in particular - is said to have decreased in relevance over time. At the same time, certain specific accounting figures seem to have gained in relevance to investors. Hence, given the purpose of reported earnings information as defined by accounting standard setters, and the limitations of aggregate earnings as single performance input for valuation purposes, it is important to more extensively examine the (quality of the) earnings generating process of firms. Specifically, there is need for a more detailed understanding of what determines future firm performance, and how current earnings information, including disaggregations of earnings, can be used to improve profitability forecasts and firm value estimates, as well as to identify potential market inefficiencies.

The social and economic relevance of this dissertation are reflected in its investigation of the role of industry and life cycle fundamentals in the firm's earnings generating process, and their relevance in forecasting and valuation. The findings from this dissertation can inform, amongst others, auditors in forming their professional judgement, capital market participants in their valuations and investment decisions, and accounting standard setters in their standard setting process.

Specifically, the findings in Chapter 2 suggest that auditor industry specialization comes, on average, at the expense of accrual informativeness. This is consistent with industry specialist auditors requiring greater comparability and standardization across clients in the same industry, thereby restricting managers' ability to signal firm-specific private information. This finding should be of interest to auditors, standard-setters, and capital market participants. First, auditors often organize themselves along industry lines by creating and applying industry-specific audit programs. The results in this study shed light on potential negative side effects of such industry-focused standardizations, by documenting the potential bias included in specialists' judgements. This implication should also be of interest to standard-setters, as accounting standards require reported information to accurately reflect firms' underlying economics. The results show that this may be less the case when firms are audited by industry specialists, especially in less homogeneous industries. These results also imply that auditor industry specialization may not always be associated with higher earnings quality. Consequently, the findings should be of interest to investors who wish to rely on accounting numbers to infer the future cash-generating ability of firms. When investing in firms operating in more uniform industries, investors may more heavily rely on accounting 
information that is audited by industry specialists than when investing in firms that operate in less homogenous and less persistent industries.

The findings in Chapter 3, which examines the relevance of differential persistence of earnings components in the pricing of mergers and acquisitions, suggest that while acquirers are aware of fundamentals-driven variation in persistence, these persistence differences do not play a relevant role in target pricing. Acquirers seem to (rationally) make alternative valuation choices based on the components' perceived informativeness and not general persistence levels. The findings should be of interest to accountants in academia and practice, as it broadens our understanding of the relevance of disaggregate accounting fundamentals in target valuation. The knowledge obtained from Chapter 3 can serve as a basis for further research on the economic consequences (e.g., post-deal performance) of acquirers' focus on perceived informativeness instead of general persistence levels.

The findings in Chapter 4 show that commonalities shared by firms in the same life cycle stage are captured by a common earnings component that affects earnings persistence in a predictable way. These results are of interest to parties actively involved in forecasting and valuation. Specifically, the results inform investors, analysts, and other capital market participants about the persistence coefficients of life cycle-wide and firm-specific earnings components, which may serve as inputs in their valuation models. To the extent that a higher persistence improves the accuracy of valuation outcomes, incorporating life cycle information may improve capital market participants' valuations and investment decisions. Yet, it should be stressed that incorporating life cycle information can only partly reduce the information asymmetry inherent in valuation tasks. The findings of Chapter 4 should be of particular interest to investors, as they show that investors currently misprice the disaggregated earnings components. While analysts already incorporate life cycle information, at least partially, the findings of this study may help them to further improve their forecasts of future firm performance.

Overall, the findings of this dissertation provide insights in the role of industry and life cycle fundamentals in the firm's earnings generating process. More specifically, this dissertation enhances our understanding of how (specialist knowledge of) fundamental firm characteristics affect a firm's (future) earnings, and how these earnings are currently used by various capital market participants including investors, analysts, and acquirers. Hence, this dissertation discusses and provides ways to increase the relevance of current earnings in forecasting and firm valuations, and as such adds to the ongoing debate about the value relevance of accounting information, and earnings information in particular, for capital market participants. 


\section{CURRICULUM VITAE}

Britt Smeets was born on March 10, 1989 in Wessem, the Netherlands. In 2010, she graduated with a BSc. Economics and Business Economics from Maastricht University, having spent a semester abroad at Université de Lausanne in Switzerland. After completion of her bachelor studies, Britt lived in Innsbruck, Austria, for a traineeship at General Electric. Returning to Maastricht for her master's degree, Britt graduated cum laude in 2012, with a MSc. in International Business, specializing in accounting.

Subsequently she joined the Department of Accounting and Information Management at Maastricht University as a PhD student. Her research and teaching activities have focused on auditing and financial accounting, as well as financial statement analysis and valuation. She presented her research at workshops at KU Leuven and Maastricht University, and several international conferences, such as the midyear meeting of the Auditing Section of the American Accounting Association (AAA), the International Symposium on Audit Research (ISAR), the Audit Quality Workshop, the European Accounting Association (EAA) Doctoral Colloquium and conferences, and the Hawaii Accounting Research Conference (HARC).

At the time of publication, Britt holds a post-doc position - funded by the Foundation for Auditing Research (FAR) - at the Department of Accounting and Information Management at Maastricht University. 
